\title{
Determining the modelling input parameters for Heating, Ventilation, and Air Conditioning systems in New Zealand commercial buildings
}

Anthony Gates

\author{
A thesis submitted to the \\ School of Architecture, Victoria University of Wellington \\ in fulfilment of the requirements for the degree of \\ Master of Building Science
}

Victoria University of Wellington

February 2013 



\section{Author}

\section{Anthony Gates}

School of Architecture

Victoria University of Wellington

Email: a.gates1988@gmail.com

Mobile: +64-21-065-2434

\section{Supervisor}

\section{Michael Donn}

\section{Director of Centre for Building Performance Research}

School of Architecture

Victoria University of Wellington

Email: michael.donn@vuw.ac.nz

Office: +64-4-463-6221

Mobile: +64-21-611-280 



\section{Abstract}

Template energy calculation models that have been produced by the Building Energy End-use Study (BEES) team are used to quickly and reliably model commercial buildings and calculate their energy performance. The template models contain standardised equipment, lighting, and occupancy loads; cooling and heating requirements are calculated using an ideal loads air system. Using seven buildings, Cory et al. 2011a have demonstrated that the template models have the potential to closely match the monthly energy performance of detailed (individually purpose built) models and the real buildings. Three of these models were within the $\pm 5 \%$ acceptable tolerance to be considered calibrated.

The four template models that were not within the acceptable tolerance have been identified to have complex Heating, Ventilation, and Air Conditioning (HVAC) systems that the ideal loads air systems could not replicate. Because HVAC systems consume one of the largest proportions of energy in commercial buildings, this has a significant impact on the reliability of the template models. To address this issue, a set of detailed HVAC systems were needed to replace the ideal loads air systems. Due to HVAC system parameters not being collected by the BEES team and the lack of published modelling input parameters available, it is unknown what values are reasonable to use in the models.

This study used a Delphi survey to collect real building information of the commonly installed HVAC systems in New Zealand commercial buildings. The survey formed a consensus between HVAC engineers that determined what the most commonly installed systems are and their associated performance values. The outcome of the survey was a documented set of system types and modelling input parameters that are representative of New Zealand HVAC systems.

The responses of the survey were used to produce a set of HVAC system templates that replace the ideal loads air systems. The HVAC template models updated the software default parameter values with values that are representative of commonly installed systems in New Zealand. The importance of the updated input values was illustrated through a comparison of the calculated monthly energy consumption. The resulting difference in energy consumption using the updated parameter values is typically $<5 \%$ monthly; at worst it is $75 \%$ for Variable Air Volume (VAV) system in the Wellington climate during June. 


\section{Acknowledgements}

I would like to thank and acknowledge everyone that has assisted, contributed, and helped in any way towards the completion of this study.

Firstly, my supervisor Mike, your knowledge and guidance over the years have kept me interested and motivated in building science. It has been a pleasure to have had you as my supervisor.

The Building Research Association of New Zealand (BRANZ) and the Building Energy End-use Study (BEES) for the financial support that was provided as well as helping to form a topic idea.

Thank you to the participants of the survey who offered their time and expertise to undertake the survey. Without your input, this would not have been possible.

Rob Bishop, Dru Crawley, Phil Haves, Jon Hand, and others that I have corresponded with; your feedback and assistance has been appreciated throughout various stages of this study.

Lastly, thanks to family and friends who have also provided support during this time of study. 


\section{Contents}

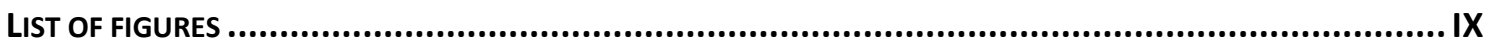

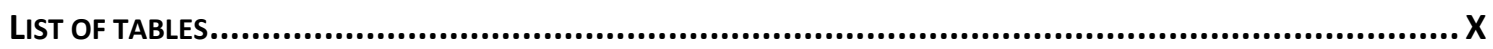

ABBREVIATIONS \& DEFINITIONS X XI

ORGANISATIONS

ENERGY AND MECHANICAL RELATED EQUIPMENT ......................................................................... XII

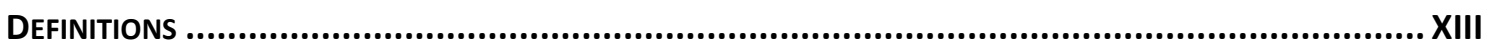

THESIS OUTLINE XX XV

OVERVIEW OF THIS STUDY 1

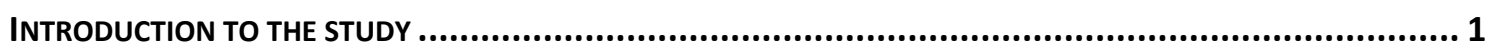

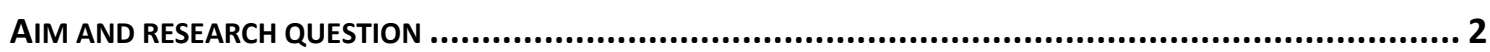

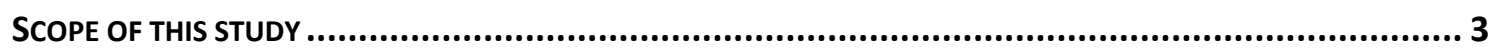

$\begin{array}{ll}\text { BUILDING TYPE, SIZE, AND AGE } & 3\end{array}$

BUILDING ENERGY END-USE STUDY (BEES) 5

$\begin{array}{ll}\text { USING ENERGYPLUS AS THE ENERGY CALCULATION PROGRAM } & 6\end{array}$

Version of EnergyPlus used in this study 6

$\begin{array}{ll}\text { TESTING AND VALIDATION } & 6\end{array}$

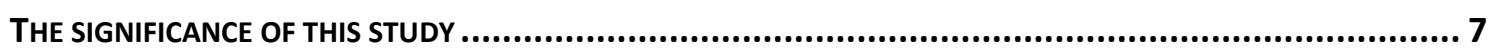

BUILT FORMS AND GEOMETRY TEMPLATE MODELS $\quad 8$

$\begin{array}{ll}\text { WHY THE HVAC TEMPLATES WERE NEEDED } & 9\end{array}$

IMPORTANCE OF HVAC SYSTEMS IN AN ENERGY CALCULATION MODEL

HOW MUCH ENERGY DOES HVAC EQUIPMENT USE IN COMMERCIAL BUILDINGS? ............................ 11

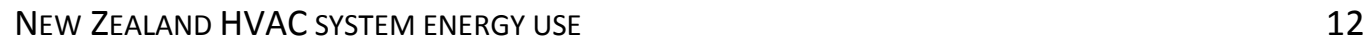


INTERNATIONAL COMPARISON OF HVAC SYSTEM ENERGY USE

UK - Energy consumption guide 19

US - California commercial end-use survey 16

Japan - Energy consumption measurement survey for commercial buildings in Japan 17

$\begin{array}{ll}\text { SUMMARY OF THE COMPARED STUDIES } & 18\end{array}$

SIGNIFICANCE OF MODELLING THE CORRECT HVAC SYSTEM .................................................. 19

\begin{tabular}{lr} 
DESIGN OF THE STUDY & 21 \\
\hline
\end{tabular}

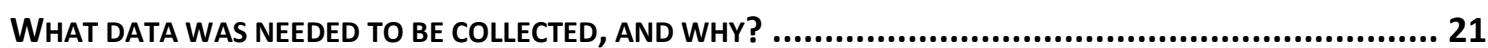

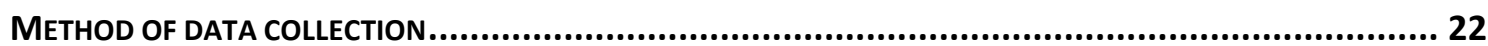

ENSURING A CONSENSUS OPINION COULD BE FORMED 23

WhY THE DELPHI METHOD WAS SELECTED TO COLLECT DATA 23

$\begin{array}{ll}\text { OVERVIEW OF THE DELPHI METHOD } & 24\end{array}$

$\begin{array}{ll}\text { OVERCOMING LIMITATIONS OF THE DELPHI METHOD } & 26\end{array}$

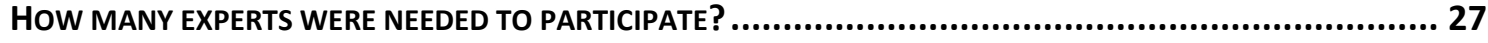

$\begin{array}{ll}\text { GETTING EXPERTS INVOLVED } & 28\end{array}$

WhY AN ONLINE SURVEY WAS SELECTED TO COLLECT THE DATA............................................ 29

$\begin{array}{ll}\text { DISTRIBUTING AN ONLINE SURVEY } & 30\end{array}$

$\begin{array}{ll}\text { USING THE ONLINE SURVEY TOOL QUALTRICS } & 31\end{array}$

WOULD THE COLLECTED DATA BE APPLICABLE INTERNATIONALLY?

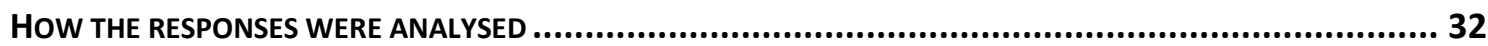

DETERMINING THE TYPES OF EXPERTS

IDENTIFYING AND FORMING A CONSENSUS ON THE MOST COMMON HVAC SYSTEMS 33

IDENTIFYING AND FORMING A CONSENSUS ON THE MODELLING PARAMETER VALUES

CONFIRMING RESPONSES WITH MANUFACTURES' DATA

USING RESPONDENTS FEEDBACK AS QUALITY CONTROL FOR THE QUESTIONS

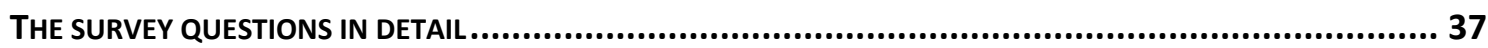

$\begin{array}{ll}\text { CONSTRUCTION AND HIERARCHY OF THE SURVEY QUESTIONS } & 37\end{array}$

$\begin{array}{ll}\text { THE QUESTIONS } & 39\end{array}$

Round one $\quad 39$

$\begin{array}{ll}\text { Round two } & 40\end{array}$

Round three $\quad 40$

\begin{tabular}{ll} 
SURVEY RESPONSES & 41 \\
\hline
\end{tabular}

THE EXPERTS THAT PARTICIPATED IN THIS SURVEY .......................................................... 41

NUMBER OF EXPERTS IN THE SURVEY

YEARS OF EXPERIENCE THE EXPERTS HAVE 
THE PROCESS OF FORMING A CONSENSUS

THE LIKELY INSTALLED HVAC SYSTEMS $\quad 44$

THE MODELLING PARAMETER VALUES FOR THE IDENTIFIED HVAC SYSTEMS 46

SUMMARY OF THE CONSENSUS FOR THE HVAC SYSTEMS IN THE POOR ENERGY EFFICIENCY AND COMMON

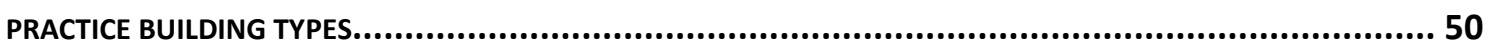

$\begin{array}{lr}\text { THE LIKELY INSTALLED HVAC SYSTEMS } & 50\end{array}$

Summary of the installed HVAC systems 52

THE VALUES OF THE MODELLING INPUT PARAMETERS

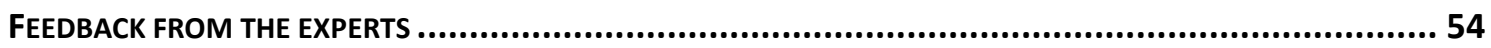

ADDRESSING LIMITATIONS AND ISSUES $\quad 54$

Round one feedback 55

Round two feedback 55

Round three feedback 56

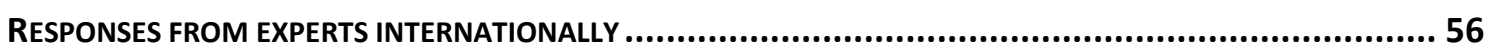

PRODUCING AND TESTING THE HVAC TEMPLATE MODELS $\quad 59$

Producing THE HVAC TEMPLATE MOdELS................................................................ 59

USING THE SURVEY RESPONSES TO PRODUCE ENERGYPLUS HVAC TEMPLATE MODELS

The HVAC modelling values collected in the survey 60

$\begin{array}{ll}\text { Other modelling input parameters } & 60\end{array}$

HOW THE HVAC TEMPLATE FILES ARE INTENDED TO BE USED

Using a template model $\quad 62$

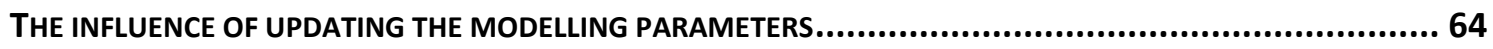

COMPARING THE RESULTS OF SOFTWARE DEFAULT VALUES AND THE HVAC TEMPLATE VALUES 64

Annual and Monthly Energy Performance Difference $\quad 65$

How different NZ climates influence the change in performance 67

\begin{tabular}{lr} 
CONCLUSIONS & 69 \\
\hline
\end{tabular}

SUCCESS OF THE SURVEY - WHAT INFORMATION WAS ABLE TO BE COLLECTED? ..................................69

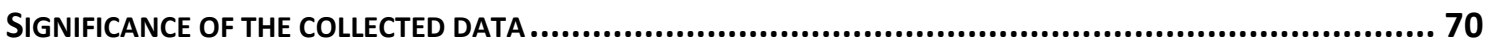

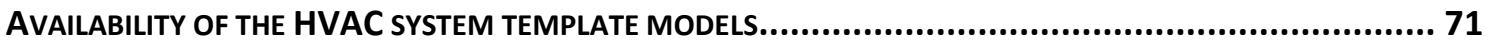

\begin{tabular}{ll} 
FUTURE WORK & 73 \\
\hline
\end{tabular}

\begin{tabular}{lr} 
BIBLIOGRAPHY & 75 \\
\hline
\end{tabular}

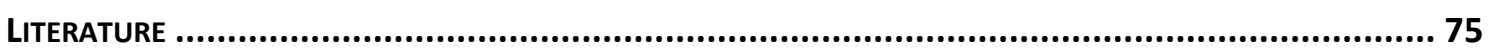

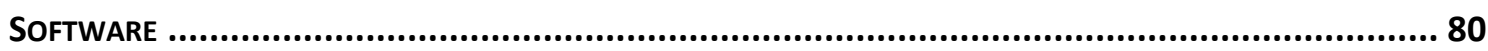




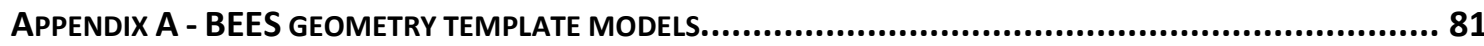

APPENDIX B - TEMPLATE MODELS: ASSIGNED MATERIALS AND CONSTRUCTION................................... 83

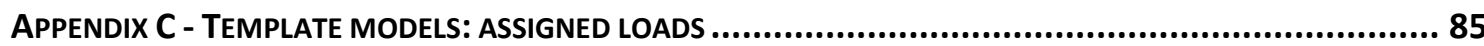

APPENDIX D - TEMPLATE MODELS: ASSIGNED OPERATIONAL SCHEDULES .......................................... 87

APPENDIX E - HOW THE MARGIN OF ERROR RELATES TO THE SAMPLE SIZE ....................................... 89

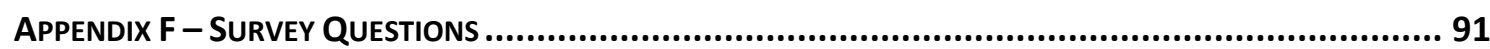

F1: ROUND ONE SURVEY QUESTIONS $\quad 91$

F2: ROUND TWO SURVEY QUESTIONS - SIMULATORS 96

F3: ROUND TWO SURVEY QUESTIONS - NON-SIMULATORS 129

F4: ROUND THREE SURVEY QUESTIONS 133

APPENDIX G - ENERGYPLUS OBJECTS USED FOR MODELLING HVAC SYSTEMS .................................145

G1: GOOD ENERGY EFFICIENCY BUILDING

G2: COMMON PRACTICE BUILDING 146

G3: POOR ENERGY EFFICIENCY BUILDING 146

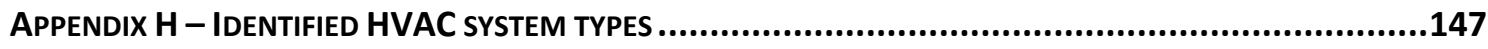

H1: ROUND ONE - IDENTIFYING LIKELY INSTALLED HVAC SYSTEMS 147

H2: ROUND TWO - FORMING A CONSENSUS 149

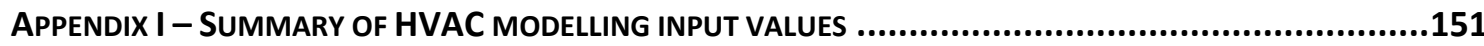

I1: GOOD ENERGY EFFICIENCY BUILDING TYPE 151

12: COMMON PRACTICE BUILDING TYPE 153

I3: POOR ENERGY EFFICIENCY BUILDING TYPE 155

APPENDIX J - COMPARISON OF ENERGY CONSUMPTION: DEFAULT VALUES VS TEMPLATE VALUES .............157

J1: Cellular Strip 157

J2: ROW OF SINGLE ROOMS 159

J3: SINGLE ROOM 159

J4: SMALL OPEN PLAN 161

J5: LARGE OPEN PLAN 161

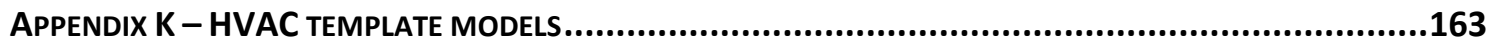




\section{List of figures $\&$ tables}

\section{List of figures}

FIGURE 1. EXAMPLE OF A BUILT FORM GEOMETRY TEMPLATE MODEL.

FIGURE 2. CALCULATED ANNUAL ENERGY CONSUMPTION BY BUILDING SECTOR.............................................. 12

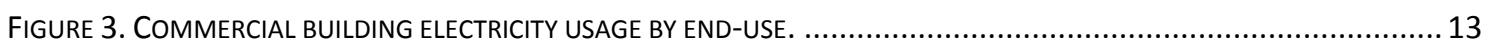

FIGURE 4. CALIFORNIAN COMMERCIAL BUILDING ENERGY END-USES: ELECTRICITY AND GAS COMBINED. ........................ 17

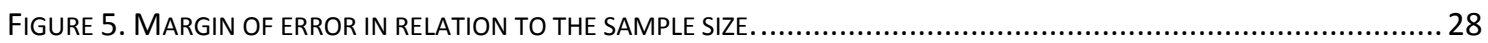

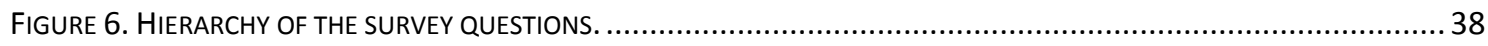

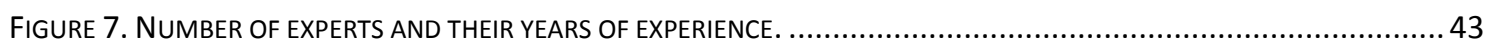

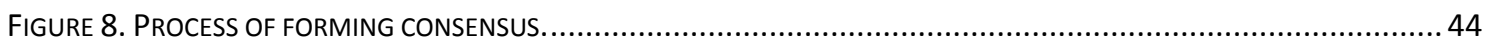

FIGURE 9. HVAC SYSTEM TYPES IDENTIFIED FOR A GOOD ENERGY EFFICIENCY BUILDING. ....................................... 45

FIGURE 10. CONSENSUS RESPONSE ON THE TYPES OF HVAC SYSTEMS FOR A GOOD ENERGY EFFICIENCY BUILDING..............46

FIGURE 11. HVAC SYSTEM TYPES IDENTIFIED FOR A POOR ENERGY EFFICIENCY BUILDING.......................................51

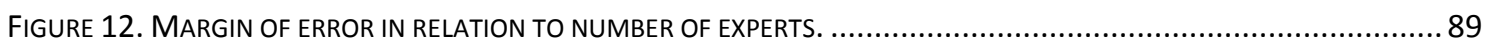

FIGURE 13. HVAC SYSTEM TYPES IDENTIFIED FOR A GOOD ENERGY EFFICIENCY BUILDING.................................... 147

FIGURE 14. HVAC SYSTEM TYPES IDENTIFIED FOR A COMMON PRACTICE BUILDING....................................... 148

FIGURE 15. HVAC SYSTEM TYPES IDENTIFIED FOR A POOR ENERGY EFFICIENCY BUILDING.................................. 148

FIGURE 16. CONSENSUS RESPONSE ON THE TYPES OF HVAC SYSTEMS FOR A GOOD ENERGY EFFICIENCY BUILDING............149

FIGURE 17. CONSENSUS RESPONSE ON THE TYPES OF HVAC SYSTEMS FOR A COMMON PRACTICE BUILDING.................. 150

FIGURE 18. CONSENSUS RESPONSE ON THE TYPES OF HVAC SYSTEMS FOR A POOR ENERGY EFFICIENCY BUILDING...........150 


\section{List of tables}

TABLE 1. BEES BUILDING STRATA DIVISION

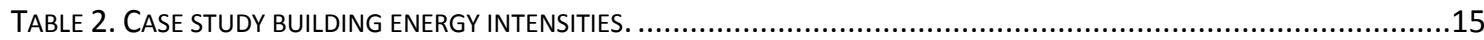

TABLE 3. SUMMARY OF HVAC ENERGY CONSUMPTION IN COMMERCIAL BUILDINGS. ............................................18

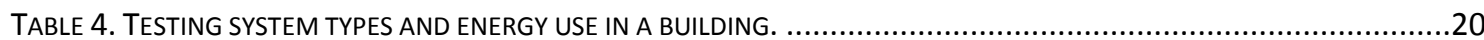

TABLE 5. BREAKDOWN OF THE NUMBER OF EXPERTS IN EACH ROUND OF QUESTIONS..............................................42

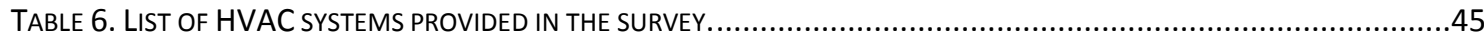

TABLE 7. ModelLING INPUT PARAMETER VALUES: CHILled BEAMS, GOOD ENERGY EFFICIENCY BUILDING.........................48

TABLE 8. MODELLING INPUT PARAMETER VALUES: VAV, GOOD ENERGY EFFICIENCY BUILDING.....................................49

TABLE 9. SUMMARY OF THE HVAC SYSTEMS TYPES THE CONSENSUS FORMED. ...................................................53

TABLE 10. ANNUAL ENERGY CONSUMPTION DIFFERENCE FOR OP5 BUILT FORM IN WELLINGTON.................................65

TABLE 11. MONTHLY HVAC ENERGY DIfFERENCE FOR OP5 BUILT FORM IN WELLINGTON. ........................................66

TABLE 12. HOW CLIMATE AND BUILT FORM INFLUENCES THE PERFORMANCE OF THE TEMPLATE MODELS........................67

TABLE 13. ASSIGNED MATERIALS AND CONSTRUCTIONS IN THE TEMPLATE MODELS. ................................................83

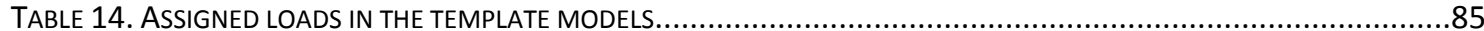

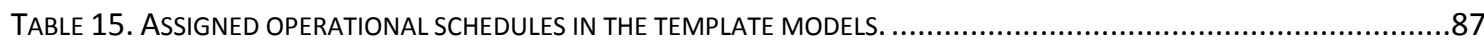

TABle 16. Modelling InPUt PARAMETER VALUES: ChILled BEAMS, GOOD ENERgy EFFICIENCY BUILDING.................... 151

TABLE 17. MODELLING INPUT PARAMETER VALUES: VAV, GOOD ENERGY EFFICIENCY BUILDING................................ 152

TABLE 18. MODELLING INPUT PARAMETER VALUES: VAV, COMMON PRACTICE BUILDING................................... 153

TABLE 19. ModelLING INPUT PARAMETER VALUES: FAN COIL UNIT, COMMON PRACTICE BUILDING. .......................... 154

TABLE 20. MODELLING INPUT PARAMETER VALUES: SPLIT SYSTEM HEAT PUMP, POOR ENERGY EFFICIENCY BUILDING........ 155

TABLE 21. Modelling INPUt PARAMETER VALUES: PACKAGEd AHU, POOR ENERGY EFFICIENCY BUILDING................... 155

TABLE 22. MODELLING INPUT PARAMETER VALUES: FAN COIL UNIT, POOR ENERGY EFFICIENCY BUILDING..................... 156

TABLE 23. DifFERENCE IN ENERGy CONSUMPTION: CS BUILT FORM - AUCKLAND, WELLINGTON, AND CHRISTCHURCH. ... 157

TABLE 24. DifFERENCE IN ENERGY CONSUMPTION: RSR BUILT FORM - AUCKLAND, WELLINGTON, AND CHRISTCHURCH. . 159

TABLE 25. DifferenCE IN ENERgy CONSUMPtION: SR BUILT FORM - AUCKLAND, WeLLINGTON, AND CHRISTCHURCH. .... 159

TABLE 26. DifferenCE IN ENERGy CONSUMPTION: OP1 BUILT FORM - AUCKLAND, WELLINGTON, AND CHRISTCHURCH.. 161

TABLE 27. DifFERENCE IN ENERGY CONSUMPTION: OP5 BUILT FORM - AUCKLAND, WELLINGTON, AND CHRISTCHURCH.. 161 


\section{Abbreviations \& Definitions}

\section{Organisations}

ASHRAE American Society of Heating, Refrigeration, and Air conditioning Engineers

BEES Building Energy End-use Study

BRANZ Building Research Association of New Zealand

BRECSU Building Research Energy Conservation Support Unit

CIBSE Charted Institute of Building Services Engineers

ECNZ Energy Commission of New Zealand

EMANZ Energy Management Association of New Zealand

IRHACE Institute of Refrigeration, Heating, Air Conditioning Engineers

NREL National Renewable Energy Laboratory

RAND Research ANd Development corporation

US DOE United States, Department of Energy 


\section{Energy and mechanical related equipment}

AHU Air Handling Unit

BMS Building Management System

$\mathrm{CO}_{2}$ Carbon Dioxide

COP Coefficient Of Performance

DX Direct expansion

expidf Expanded Input Data File (used in the computer program EnergyPlus)

FCU Fan Coil Unit

GWh GigaWatt hour

HVAC Heating, Ventilation, and Air Conditioning

idf Input Data File (used in the computer program EnergyPlus)

kWh kiloWatt hour

VAV Variable Air Volume

VRF Variable Refrigerant Flow 


\section{Definitions}

Auto-size A function in EnergyPlus where the software is used to calculate the required cooling and heating capacity of equipment or the required air/water flow to achieve the setpoint temperatures.

Delphi method Surveying method that uses multiple rounds of questions to form a consensus opinion between a group of experts.

DOE-2 Computer software program to calculate building energy consumption. Not used in this study, but is provided as an example of an available program.

EnergyPlus Computer software program to calculate building energy consumption. It has been used in this study to develop the set of HVAC system template models.

Enthalpy heat recovery Recovers both sensible and latent heat within a space.

IES Integrated Environmental Solutions - Computer software program to calculate building energy consumption. Not used in this study, but is provided as an example of an available program.

Model, Detailed Detailed models are individually built models that match the built form, loads, and schedules of an actual building.

Model, Template Template models are simplified models that use standardised input parameters and values to allow for quick and reliable modelling of a building.

Qualtrics The online tool used for creating, distributing, and collecting the survey. 


\section{Thesis Outline}

This section provides an overview of the content within the seven chapters of this thesis.

\section{Chapter 1: Overview of this study}

This chapter introduces this thesis. It explains the research question and aim while addressing the scope of the study. The chapter also explains the significance of this study.

\section{Chapter 2: Importance of having HVAC systems in an energy calculation model}

A review of relevant literature identified the importance of using HVAC systems within an energy calculation model. This was achieved by identifying how much energy HVAC systems contribute to the total energy consumption of a commercial building. Both New Zealand and international studies were reviewed.

\section{Chapter 3: Design of the study}

To collect the modelling input parameters that are relevant for New Zealand, a Delphi method survey was conducted. This chapter explains why a survey was selected to collect the data and summarises the design of the survey. The explanation of the survey reviews the surveying method used, identifies what information was intended to be collected, determines the target audience to participate, explains how the data was planned to be analysed and used, and covers the distribution and collection of the survey.

\section{Chapter 4: Survey responses}

A consensus of survey responses identified the most commonly installed HVAC systems and the associated modelling parameters for New Zealand. This chapter documents the responses from the experts who participated in the survey and explains how a consensus was formed.

\section{Chapter 5: Producing and testing the HVAC system template models}

This chapter explains the process of making the HVAC system template models based on the input parameter values that have been collected using a Delphi method survey. A summary of the values used within the template models is provided, as well as an explanation of how the models are intended to be used. Concluding the chapter are the results after using the models to calculate monthly energy consumption. The results identify the influence the new input values have in comparison to the EnergyPlus default values. This chapter highlights the significance of this study and the collected modelling parameter values. 


\section{Chapter 6: Conclusions}

The conclusions sum up and determine two main aspects within this thesis: firstly, the success of the survey, and secondly the significance of the collected modelling input values. The success of the survey was measured through how well the survey was suited for collecting the required set of modelling values. The significance of the collected modelling input values was concluded through the comparison of the results produced when calculating the energy consumption using the software default values and the values collected in this study.

\section{Chapter 7: Future work}

The final chapter explains the future work that can continue from the outcomes of this study.

Primarily this consists of further development and testing of the HVAC system template models. 


\section{Overview of this study}

This chapter introduces this study and provides background information that explains the significance and importance of this research. The aim and scope presents the focus and addresses limitations of the study.

\section{Introduction to the study}

Heating, Ventilation, and Air Conditioning (HVAC) systems consume one of the largest proportions of energy within commercial buildings (Perez-Lombard et al., 2011). In New Zealand it has been identified that this can be up to $80 \%$ of a building's total energy consumption (Isaacs et al., 2010). Commercial building studies reviewed from Japan, the United Kingdom, and the United States also identify that HVAC systems contribute to a large proportion of the total energy consumed.

With the increase of available software packages that allow for a building's energy consumption to be calculated, rational and alternative choices of building shapes and types of HVAC systems can be tested during early stages of design (Lebrun, 1994). Through modelling an HVAC system, an optimal type of system and the associated equipment can be determined for the building. In order to produce reliable results, the modelling input parameter values that are used need to be representative of real system performance. To improve reliability of modelling input values, the Building Energy End-use Study (BEES) is currently collecting real building performance data throughout New Zealand.

The Building Energy End-use Study (BEES) is monitoring commercial buildings throughout New Zealand to determine aspects of energy and water performance which will provide representative data of various sized buildings (Isaacs, 2009). One method the BEES team have used to present and make the collected data available is through producing a set of building energy calculation template models with standardised equipment, lighting, and occupancy loads; cooling and heating requirements are calculated using an ideal loads air system. The template models are used to quickly and reliably model commercial buildings and calculate their energy performance.

Testing with seven buildings, the template models have shown that they can closely match detailed (individually purpose built) models and the real building's energy consumption. Three of these buildings were within an acceptable calibration tolerance of $\pm 5 \%$ (Cory et al., 2011a). The buildings not within the acceptable tolerance were determined to have complex HVAC 
systems that could not be replicated by the ideal loads air system. To address this issue, a set of detailed HVAC systems were needed to replace the ideal loads air systems. Because HVAC aspects are not being collected by the BEES team and there is a lack of published modelling input parameter values available, it is unknown what values are reasonable to use when modelling HVAC systems in New Zealand. To collect the information on HVAC systems, a Delphi survey of HVAC engineers was conducted.

A Delphi survey method uses multiple rounds of questions to form a consensus between a group of experts (Gordon, 1994). In this study, the Delphi survey determined two aspects with regards to HVAC systems in New Zealand. The first aspect identified the most commonly installed HVAC systems in commercial buildings. To get a representative sample of the types of systems that are commonly installed, three building types based on a division of performance were used: good energy efficiency, common practice, and poor energy efficiency. The second aspect determined what the modelling input parameters for the HVAC systems are. An outcome of the survey was a set of data that determines the most commonly installed HVAC systems and the input parameter values that are reasonable to use when modelling the systems. These values were used to produce a set of HVAC system templates that are incorporated into the BEES template models.

This study documents the process of constructing the survey to form a consensus between the HVAC engineers when collecting the modelling information; this includes how the responses were analysed. In addition to the survey, a set of HVAC system template models were produced. The template models are a way of simplifying and standardising the modelling of HVAC systems with energy calculation software. The templates use the consensus responses to update and replace the software default values in order to make the energy calculations more representative of New Zealand HVAC systems.

\section{Aim and research question}

The aim of this study was to collect detailed information on Heating, Ventilation, and Air Conditioning (HVAC) systems that are commonly installed within New Zealand commercial buildings. The information that was collected needed to be representative of the most commonly installed systems. By using the representative systems, the outcomes are able to be standardised for any location. To be able to address the whole country, a survey was considered to be the most appropriate method of data collection. 
The intention of the collected information was to produce a set of HVAC system template models using a computer based building energy calculation software program. The information collected in this study had to provide enough detail to produce a set of HVAC system template models, while remaining generalised so that they are representative for all of New Zealand.

The overall research question that developed from the aim of the study was;

Can real building information of Heating, Ventilation, and Air Conditioning (HVAC) systems be collected using a survey and be used to produce a set of template models within building energy calculation software?

The outcomes of this study addresses the aim and answers the research question by collecting detailed information about the most commonly installed HVAC systems and the associated performance values. These values were then used to produce a set of HVAC template models that are representative for New Zealand commercial buildings.

\section{Scope of this study}

The scope identifies the types of buildings that the study focuses on, describes the connection to the Building Energy End-use Study (BEES), determines the computer software that was used, and explains how the produced template models are tested.

As the aim and research question state, the main boundary of this study was to focus on New Zealand Heating, Ventilation, and Air Conditioning (HVAC) systems within commercial buildings. With the intention of using a survey, standardised information about the HVAC systems and their modelling input parameters was collected to produce a set of template models. Because of the standardised information collected, it was not specific for a geographic location or area within the country. This means that the completed template models are representative of any building modelled in New Zealand. The type, size, and age of the buildings that this study focuses on provides the scope of what buildings the HVAC systems represent.

\section{Building type, size, and age}

This study developed a survey to collect real building information about HVAC systems from HVAC engineers. To limit the amount and type of information that could be collected, the scope of the building type, size, and age was defined.

The building type that the scope of this study focused on was commercial buildings with central HVAC plant equipment; these are typically the larger commercial buildings because 
they warrant the need for complex systems. Commercial buildings were selected to focus on because this allowed for this study to be within the scope of the Building Energy End-use Study (BEES).

Commercial buildings have many end uses and can be interpreted in numerous ways. For clarity this study defines commercial buildings in the same way the BEES team have, using the New Zealand Building Code definition of commercial and communal non-residential buildings (Department of Building and Housing, 2009). To further refine the types of buildings that are represented by commercial and communal non-residential buildings, the BEES team excluded industrial, all ancillary, outbuildings, and communal non-residential; the building types that are left "in broad terms, are office and retail uses" (Isaacs et al., 2009. pgii).

Because of the large number of commercial buildings and their variation in floor area, it can be expected that the buildings perform differently. For this reason, the BEES team have categorised the building sizes into five strata groups based on a minimum floor area. A breakdown of the floor area in relation to the number of buildings throughout New Zealand is illustrated in Table 1. The total floor area of each building stratum represents $20 \%$ of the total floor area for all commercial buildings.

\begin{tabular}{|r|c|c|c|c|c|c|} 
& \multicolumn{7}{c|}{ Building Strata } \\
\cline { 2 - 8 } & 1 & 2 & 3 & 4 & 5 & Total \\
\hline Minimum floor area $\left(\mathrm{m}^{2}\right)$ & 5 & 650 & 1,500 & 3,500 & 9,000 & \\
\hline Approx. number of buildings & 33,781 & 10,081 & 4,288 & 1,825 & 564 & 50,539 \\
\hline \% of buildings & $67 \%$ & $20 \%$ & $8 \%$ & $4 \%$ & $1 \%$ & $100 \%$ \\
\hline Total floor area (million $\mathbf{m}^{2}$ ) & 9.9 & 9.6 & 9.5 & 9.6 & 9.8 & 48.4 \\
\hline \% of total floor area & $20 \%$ & $20 \%$ & $20 \%$ & $20 \%$ & $20 \%$ & $100 \%$ \\
\hline
\end{tabular}

Table 1. BEES building strata division.

Recreated from (BRANZ, 2011)

The buildings selected in this study are those that have a minimum floor area of $3,500 \mathrm{~m}^{2}$; this is represented by strata four and five buildings. This minimum floor area was selected because these building are most likely to have centralised HVAC systems that service the buildings.

To ensure that the experts that participated in the survey provide information that is relevant for recently constructed and newly constructed buildings, the building age was limited to buildings that have been built or designed within the last 10 years. The scope does not address buildings that have been retrofitted within the last ten years, unless the HVAC system has been completely replaced with a new system. 


\section{Building Energy End-use Study (BEES)}

An explanation of the Building Energy End-use Study (BEES) is included in the scope because it provides direction and limitations that are used in this study. To summarise BEES, it is a "6-year long project monitoring and analysing the energy and water consumption of non-residential buildings around New Zealand" (BRANZ, 2011). The purpose of BEES is to increase knowledge on energy use patterns of buildings and the equipment used (Isaacs et al., 2009).

To achieve the goals of the BEES programme, three forms of data collection have been used: web search, phone surveys, and on-site monitoring.

- Web search - Approximately 3,500 buildings were randomly selected from the total buildings on record in the Quotable Value (QV) database. Using Google Earth (Google, 2010a) and Google StreetView (Google, 2011), building information was collected: this included building floor plate area, building height and inter-storey height, glazing percentage on visible façades, and estimated building construction types (Isaacs et al., 2010).

- Phone Surveys - This aspect interviewed the businesses that occupy the selected buildings to collect information on the number of occupants, energy and water consumption, and operational hours. Out of the 1,647 buildings selected for the phone survey, 268 completed it (Isaacs et al., 2010).

$\checkmark$ On-site Monitoring - About 50 buildings that had completed the phone survey were selected, at random, to have on-site monitoring of the indoor environments and energy use. Over a two week period, the selected buildings had the electricity, water, and gas consumption monitored with data loggers. The building's environment was also monitored to assess the air temperature, humidity levels, lighting levels, and $\mathrm{CO}_{2}$ concentrations (Isaacs et al., 2010).

The data that was collected from the buildings using these methods are processed into a format that is then available to use and refer to in a number of ways. One method of making the information available was to construct computer based energy models of the buildings involved in the study. However, "it was determined that to make an individual model of each building would be time-consuming and would not serve the long-term BEES goals" (Isaacs et al., 2010. pg62); therefore standardised template models were developed. The templates models have been constructed in the software EnergyPlus. 


\section{Using EnergyPlus as the energy calculation program}

The software program selected to model the HVAC systems and produce the set of template models was EnergyPlus. There are many building energy calculation programs available such as DOE-2 and IES; this study used EnergyPlus. EnergyPlus was selected for use in this study for two main reasons: firstly because it is a widely documented, tested, and validated program. Validation testing can be found in work by (Witte et al., 2001), (Henninger et al., 2003), and (Henninger et al., 2004). Secondly, it is the program with which the BEES research team is most familiar. The BEES team already have models constructed using EnergyPlus and the work from this study expands on the existing models. An advantage of selecting a single program to collect data and produce the template models is because of the consistency between the modelling parameters that are used to model, and the questions that are asked in the survey to collect the input values. This minimises any errors or variations between values collected with the survey and the values used in the template models.

EnergyPlus (Lawrence Berkeley National Laboratory, 2010) is an "energy analysis and thermal load simulation program" (U.S Department of Energy, 2011) that is used for modelling buildings and the associated loads: including HVAC, lighting, equipment, and occupancy. Further details of the capabilities of EnergyPlus are explained in the 2001 and 2008 work by (Crawley et al., $2001 \&$ 2008). It is a program engine that is continually being developed and improved. An example of this is the Graphical User Interface development being done by Lawrence Berkeley National Laboratory (Haves, 2010).

\section{Version of EnergyPlus used in this study}

EnergyPlus version 6.0 was used in this study to identify the required input parameter values needed and also to produce the HVAC system template models. During this study, EnergyPlus version 7.0 was released but due to timing of the release, November 2011, the data collection using a survey of HVAC engineers was already in progress. To maintain consistency between the data collection and the modelling of the HVAC systems, the latest version was not used.

\section{Testing and validation}

One of the outcomes of this study was a set of HVAC system template models that have been produced using EnergyPlus. EnergyPlus is a whole building energy calculation program that has been validated. Included within the validation of the program is further, more detailed validation of the individual components such as the HVAC system objects.

The HVAC objects that are within EnergyPlus have been validated using the HVAC BESTEST method (Neymark et al., 2001). Documentation about the BESTEST validation method and how 
it has been used with the HVAC system objects within EnergyPlus are explained in Neymark's and Henninger's HVAC BESTEST publications (Neymark et al., 2001), (Neymark and Judkoff, 2002), and (Henninger et al., 2003).

Testing the produced HVAC template models against the energy performance of real buildings was not a part of the scope of this study because the program and modelling components themselves are already validated. It is therefore assumed that the results produced when calculating energy consumption using the template models can be trusted. Although the developed HVAC template models are not tested against real building data in this study, the models have been tested to ensure that they run and no modelling errors occur after running the models. Future work will compare the calculated and real building energy consumption.

\section{The significance of this study}

The National Renewable Energy Laboratory (NREL) in the United States (US) with collaboration from other national laboratories, private industry, and universities have produced a set of commercial building energy models that represent typical energy performances for 15 various commercial building classifications (Torcellini et al., 2008). The building classifications include small to large offices, retail, education, health, and restaurants. Each building classification model contains the performance values, such as the equipment energy intensity that is likely to be within that classification of building. Because the models have been developed in the US, there are also variations in the modelling parameters for the different climate zones that the models represent. The template models produced in New Zealand by the Building Energy End-use Study have used information from these benchmarks wherever New Zealand specific data was unavailable because the origins of the data are comprehensively documented.

With respect to the HVAC systems that are included within the US benchmark models, the default equipment and the associated performance values provided in the models are based on the minimum requirements stated in ASHRAE Standard 90.1-2004 (Torcellini et al., 2008). It can therefore be sensibly assumed that the values are reasonable for use within the United States; however it is unknown if the values are reasonable for the equipment types and performance values used in New Zealand. This is due to the differences in the commonly used HVAC systems and the equipment types. Not knowing if the values are reasonable for a New Zealand context emphasises the significance of this study.

An outcome of the New Zealand Building Energy End-use Study (BEES) is that a set of template models have been created to represent commercial building energy performance. These 
template models are continually being developed as additional real building performance data is collected. This study focuses on the development of the HVAC systems that are included within the template models.

In the smaller scope, the HVAC templates that have been produced in this study are used within the geometry template models that have already been developed by the BEES team. To explain why the HVAC templates were needed to be included within the geometry template models, it must first be explained what the built forms are and how the geometry template models have been developed.

\section{Built forms and geometry template models}

The template models developed by Cory et al. 2009 contain a set of standardised input parameters. These consist of: common built form geometries and assigned materials; equipment, lighting, and occupancy intensity loads (energy loads per floor area); occupancy and operational schedules; and ideal loads air systems for calculating the cooling and heating loads. Development and use of the template models is similar to the National Renewable Energy Laboratory (NREL) commercial building benchmark models (Torcellini et al., 2008). The intention of the template models was that there is a "standardised method for modelling every BEES surveyed building, accurately and quickly" (Cory et al., 2009).

The geometry is based on the built forms described in A classification of built forms by (Steadman et al., 2000). Initially there were 10 built forms and associated models as described in Cory et al., 2009; but further work on the web search investigation by the BEES team has identified that only five of these built forms are common throughout New Zealand.

An example of the built form and how it has been transferred to an energy model template can be seen in Figure 1. An index of all five of the built forms and the corresponding models can be seen in Appendix A.

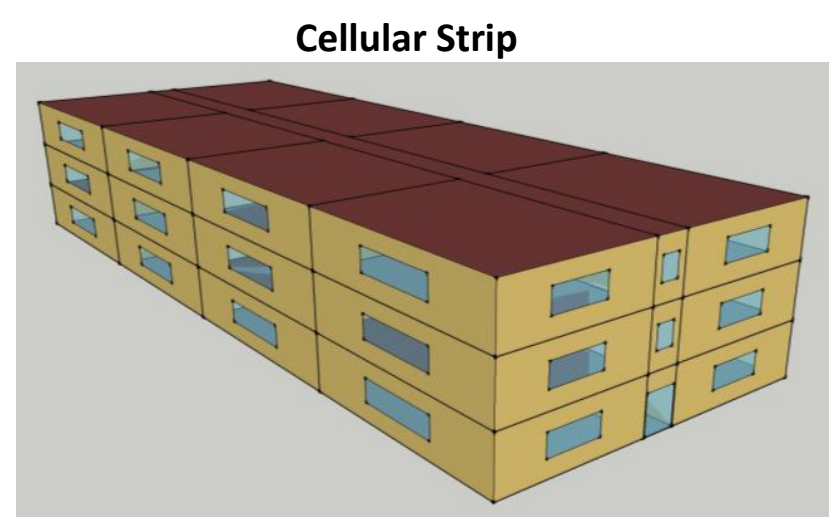

Figure 1. Example of a built form geometry template model. Image sourced from (Cory et al., 2011a).
(CS): The day lit cellular strip template represents a multi-storied building with cellular zones. An example of this would be a multi premised office building with internal communal transition space. 
The materials and construction sets used within the template models are standardised for commercial buildings. This consists primarily of a concrete construction. A breakdown of each building element and assigned construction can be seen in Appendix B.

Equipment, lighting, and occupancy intensities within the geometry templates are based on the recommended loads stated in the New Zealand Standard NZS4243: Energy efficiency Large buildings, part one and part two. NZS4243: part one provides the equipment and occupancy intensities while NZS4243: Part Two provides the lighting loads. The intensities are tabulated and explained in Appendix C. These loads are assigned to each zone within the models. NZS4243 is also used to provide the recommended operational schedule times and load/occupancy percentages that are used within the models. The schedules are based on common office hours of operation. The operation of the equipment, lighting, and occupancy is therefore primarily between the hours of 0800 and 1800, Monday to Friday. Full documentation of the schedules can be seen in Appendix $D$.

The ideal loads air systems used within the geometry template models maintain the temperature setpoints of $18-25^{\circ} \mathrm{C}$ within each zone of the models. The ideal loads air system is a modelling component that "supplies cooling or heating air to a zone in sufficient quantity to meet the zone load" (EnergyPlus, 2011. pg866), no central plant equipment is associated to this component. This aspect of the template models has been identified as being a problematic aspect due to the difficulty of matching a building's performance with a complex HVAC system. This was highlighted in the paper by Cory et al., 2011a.

\section{Why the HVAC templates were needed}

When using the template models to estimate the energy consumption of a building, the results have shown potential to closely match the monthly energy performance of a detailed (individually purpose built) model and the real building (Cory et al., 2011a). Seven case study buildings were modelled and tested in the paper to compare the energy consumption; each building was modelled individually in detail and using the templates. The outcome of the calculated monthly energy consumption for the template models showed that three of the models were within $5 \%$ of the real building's energy consumption. For an energy model to be considered calibrated to an acceptable tolerance, the model must match the real building's energy consumption within $\pm 5 \%$ for monthly data or $\pm 10 \%$ for hourly data (ASHRAE Standard, 2002).

The four buildings that had a calculated energy consumption outside of the acceptable tolerance were identified to have complex HVAC systems with centralised plant equipment. This determined that the ideal loads air systems within the template models could not match 
the performance of a complex HVAC system; therefore the ideal loads air systems are an aspect that reduces the reliability of the template models.

This study expands from the work done by Cory et al., 2011a by addressing the limitation of the ideal loads air systems within the template models. The limitation is addressed in this study by producing a set of HVAC system templates that replace the ideal loads air systems. Because it was unknown if the EnergyPlus default modelling parameter values were reasonable to use for New Zealand HVAC systems, a survey consulting HVAC engineers was conducted to collect the modelling parameter values. 


\section{Importance of HVAC systems in an energy calculation model}

The importance of having Heating, Ventilation, and Air Conditioning (HVAC) systems within an energy calculation model is to accurately replicate the energy and thermal performance of a building.

Two common uses for energy simulations of models containing HVAC systems are to: calculate the required sizing loads (e.g. cooling and heating capacities or air/water flow rates) that are needed within the building to maintain a specified temperature; and to calculate the energy consumption of the equipment installed. A breakdown of the calculated energy consumption can determine what the end-uses for the energy are, for example, determining how much energy is used by a chiller or boiler.

Three important aspects of modelling HVAC systems are used to highlight why they should be included within a building model:

- Firstly, the energy that is consumed by HVAC systems is one of the largest proportions in commercial buildings (Perez-Lombard et al., 2011);

- Secondly, the performance of different types of systems can significantly change the calculated energy consumed;

- Thirdly, the modelling parameter values should match actual system values to produce reliable outcomes.

This chapter expands on these three aspects and further explains the importance of including HVAC systems within an energy calculation model.

\section{How much energy does HVAC equipment use in commercial buildings?}

To identify how much energy is consumed by HVAC systems in commercial buildings, independent studies were reviewed. The studies that were reviewed are New Zealand and internationally based. The United Kingdom, United States, and Japan were used to put the energy consumed in New Zealand buildings into context. 


\section{New Zealand HVAC system energy use}

In the 2007 study, New Zealand electric energy efficiency potential, the Electricity Commission of New Zealand (ECNZ) partnered with the energy consultancy company KEMA to better understand the market demand for energy efficiency. The study also estimated the potential savings that could be made throughout New Zealand (KEMA and ECNZ, 2007). The scope of the study was to calculate the consumed energy and predict the potential energy savings within existing residential, commercial, and industrial buildings using commercially available and viable methods. To do this, a sample selection of buildings were monitored to record their energy consumption. The greatest limitation of this study is that it only focused on the electricity use within the buildings, therefore gas or other fuel based equipment are not taken into account. Although only electricity is assessed within the study, it still provides an understanding of how much energy is used in commercial buildings.

In 2006, the annual electricity use for New Zealand was approximately 38,000 GWh (GigaWatt hours) (KEMA and ECNZ, 2007). Out of the total, the commercial building sector accounted for $23 \%(8,740 \mathrm{GWh})$; this represents the smallest energy usage for the building sector. Figure 2 illustrates the breakdown of energy consumption for the three building sectors that was calculated.

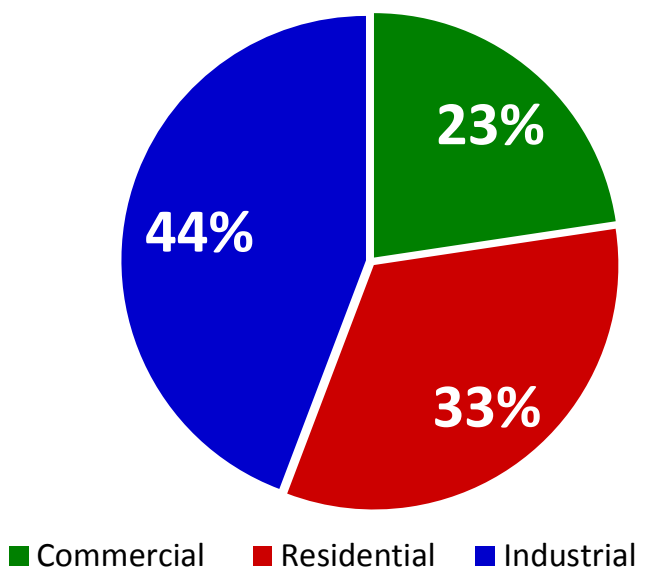

Figure 2. Calculated annual energy consumption by building sector. Recreated from (KEMA and ECNZ, 2007).

With a focus on the commercial buildings, the KEMA and ECNZ report illustrate the annually consumed energy for all commercial buildings as a break down for each of the end-uses. This can be seen in Figure 3.

As Figure 3 illustrates, interior lighting consumes the highest proportion of energy used at 32\% of the total; this accounts for $\sim 2,800 \mathrm{GWh}$ annually. HVAC equipment represents the second 
highest proportion, consuming approximately 2,400 GWh of energy annually. The HVAC equipment represents $28 \%$ of the energy consumed by commercial buildings. The remaining $40 \%$ of energy consumed in commercial buildings is used by a range of different end-uses such as domestic water heating, plug load equipment, and other miscellaneous loads.

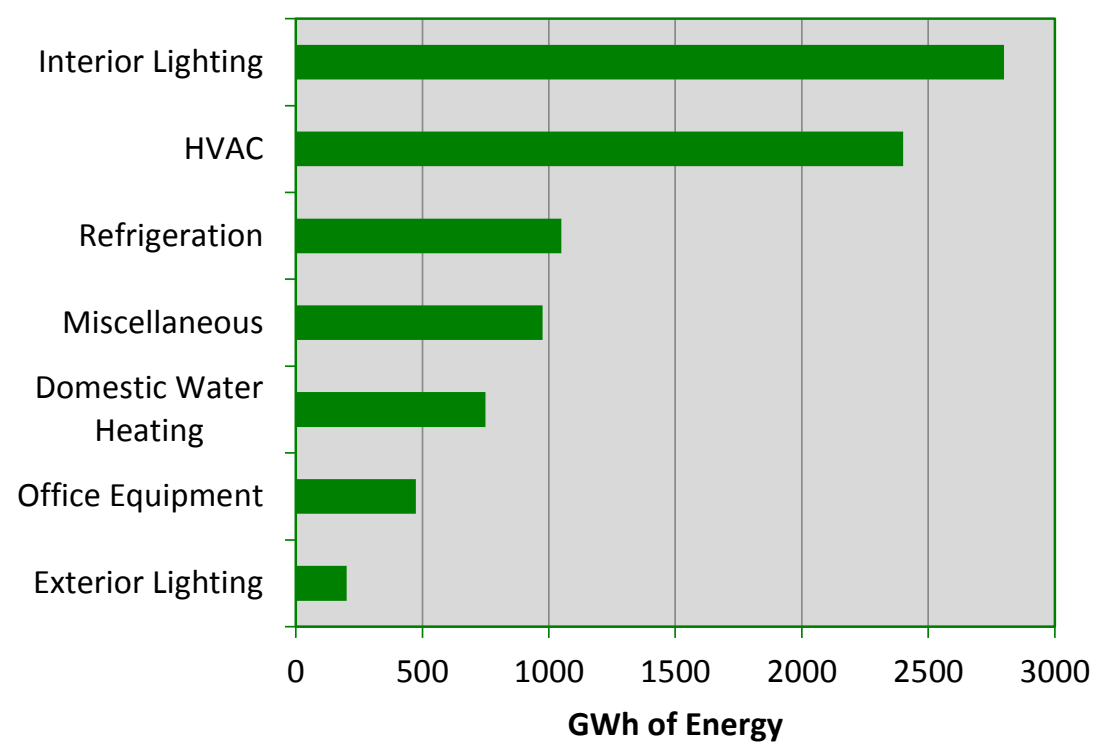

Figure 3. Commercial building electricity usage by end-use. Recreated from (KEMA and ECNZ, 2007).

Although the KEMA and ECNZ report has identified HVAC equipment to consume $2,400 \mathrm{GWh}$ of energy annually, this only represents the electricity that is used. To address this limitation of the report and have a comprehensive understanding of the total energy consumed in New Zealand commercial buildings, including gas, the preliminary results of the Building Energy End-use Study were reviewed.

The energy consumption figures for HVAC systems vary between the 2007 KEMA and ECNZ report and the more recent study, the Building Energy End-use Study (BEES). Because the BEES data that is currently published is still specific to individual buildings, an average for the overall building stock has not been determined yet. As a result, the data that is reported upon in the BEES year three report presents a range of different values. The range of values presented identify that the HVAC energy proportion of $28 \%$ in the KEMA report is too low. The BEES report identifies that $40-80 \%$ can be expected. Gas energy use is also monitored in the BEES which explains why there is a higher proportion of energy consumed by HVAC equipment in comparison to the KEMA report. Because the collected data also contains the gas energy use, it provides a more reliable representation of the total energy consumption and end-uses within commercial buildings. 
With current energy monitoring data that has been collected and presented in the BEES year three report, the energy use for HVAC systems is highly variable, "ranging from $1 \%$ to $58 \%$ of total electricity consumption" (Isaacs et al., 2010). The year three report by Isaacs et al. states that this is a result of monitored data, at the time of analysis, not representing a full year and only in a small sample of monitored buildings. As the study progresses these values may change and become more defined. Because the generalised information currently available is not able to provide representative data, the case study buildings presented are used as a means to determine the total HVAC equipment energy that can be expected in the commercial building stock.

Because the main case study building that is provided in the year three report has a floor area of $\sim 3,000 \mathrm{~m}^{2}$, it is not within the classification of strata four or five buildings that are focused on in this study. It is therefore not an appropriate example to use when demonstrating the significance that HVAC systems have on the energy performance of buildings in relation to this study. The floor areas of the other case study buildings presented in Table 2 were not provided, however it can be sensibly assumed that the tower block office building would have a floor area greater than $3,500 \mathrm{~m}^{2}$ and therefore be representative of the size of buildings focused on in this study.

The breakdown of the annual energy load intensities demonstrate the amount of energy (Watts) that are used per floor area, $\mathrm{W} / \mathrm{m}^{2}$. Table 2 shows that the tower block office building uses $39 \mathrm{~W} / \mathrm{m}^{2}$ for the HVAC system, while equipment uses $15 \mathrm{~W} / \mathrm{m}^{2}$, and lighting $16 \mathrm{~W} / \mathrm{m}^{2}$. In relation to the overall building energy consumption, the HVAC system represents the highest proportion of energy consumed, $56 \%$.

Although the tower block office building uses the least amount of energy per floor area in comparison to the other case study buildings, the same trend of the HVAC system accounting for the highest proportion of energy is illustrated. Ranging from approximately $40 \mathrm{~W} / \mathrm{m}^{2}$ to $80 \mathrm{~W} / \mathrm{m}^{2}$, the HVAC systems have the highest energy intensity per floor area of the buildings. This corresponds to $40-80 \%$ of the building's total energy consumption of various sized commercial buildings. Based on the results from monitored case study buildings, it can be concluded that HVAC systems consume the greatest energy within commercial buildings. 


\begin{tabular}{|c|c|c|c|c|c|c|c|c|}
\hline \multicolumn{1}{|c|}{} & \multicolumn{2}{c|}{ Lighting } & \multicolumn{2}{c|}{ Plug loads } & \multicolumn{2}{c|}{ HVAC } & TOTAL \\
\cline { 2 - 9 } & $\mathrm{W} / \mathrm{m}^{2}$ & $\%$ & $\mathrm{~W} / \mathrm{m}^{2}$ & $\%$ & $\mathrm{~W} / \mathrm{m}^{2}$ & $\%$ & $\mathrm{~W} / \mathrm{m}^{2}$ \\
\hline $\begin{array}{c}\text { Case study } \\
\text { building }\end{array}$ & 47 & $27 \%$ & 54 & $31 \%$ & 75 & $43 \%$ & 176 \\
\hline $\begin{array}{c}\text { Single storey } \\
\text { office }\end{array}$ & 14 & $17 \%$ & 2 & $2 \%$ & 68 & $81 \%$ & 84 \\
\hline $\begin{array}{c}\text { Tower block } \\
\text { office }\end{array}$ & 16 & $23 \%$ & 15 & $21 \%$ & 39 & $56 \%$ & 70 \\
\hline $\begin{array}{c}\text { Mixed use } \\
\text { office }\end{array}$ & 13 & $10 \%$ & 30 & $24 \%$ & 81 & $65 \%$ & 124 \\
\hline
\end{tabular}

Table 2. Case study building energy intensities.

Recreated from (Isaacs et al., 2010).

To put the New Zealand commercial building energy consumption into context, international studies were reviewed. These studies are from the United Kingdom, United States, and Japan as they provide a range of different climate locations, construction methods, and energy efficiency requirements.

\section{International comparison of HVAC system energy use}

The international studies in this section identify how much energy a commercial building uses to provide a detailed understanding of the energy used by HVAC systems. Three studies were reviewed:

- Energy consumption guide 19, UK;

- California commercial end-use survey, USA;

$\checkmark$ and the energy consumption measurement survey for commercial buildings, Japan.

\section{UK - Energy consumption guide 19}

The United Kingdom energy consumption guide 19, published in the year 2000 by the Building Research Energy Conservation Support Unit (BRECSU), provides a detailed overview of the energy consumed within office buildings; electricity, gas, and oil were assessed in the study. The study shows that office buildings typically consume between $200 \mathrm{kWh} / \mathrm{m}^{2}$ and $560 \mathrm{kWh} / \mathrm{m}^{2}$ of energy; however with good energy conservation measures in place, this can be reduced to $110-350 \mathrm{kWh} / \mathrm{m}^{2}$ (BRECSU, 2000). With the cooler climate of the UK, the majority of the energy used for the HVAC systems is for providing heating. The study has a breakdown of energy use which identifies that the HVAC systems use from $15 \%$ to $50 \%$ of a building's total energy consumption (BRECSU, 2000).

Comparing the HVAC energy consumption between commercial buildings in the UK and New Zealand, the differences identify that New Zealand buildings have a higher proportion of 
total energy being consumed by HVAC equipment. In contrast to the cooler climate of the UK, a Californian study was reviewed to identify how the warmer climate influences the HVAC system energy consumption.

\section{US - California commercial end-use survey}

The California Energy Commission hired Itron, Inc. to prepare a report on the energy performance of commercial buildings throughout the state of California in the year 2006. The report is called the California commercial end-use survey (Itron inc, 2006). One of the main outcomes from the report is a state-wide average for the electricity and gas consumption in commercial buildings.

A limitation of this report is that it includes more than just office buildings in the data collection; other uses included are restaurants, healthcare, and educational buildings. Because of the additional building types presented in the report, end-uses such as cooking and refrigeration have greater energy consumption than what could be expected in typical office buildings.

To address the limitation of the different building types, the annual energy intensities $\left(\mathrm{kWh} / \mathrm{m}^{2} /\right.$ year) are reviewed for each end-use. This addresses the limitation because it is an absolute value that can be comparable between different buildings. By using the energy intensity values of the end-uses to make comparisons with other studies, the same energy load values are compared.

Energy consumed by buildings in California is shown to have a similar energy intensity to typical UK commercial buildings. Itron inc., identifies the average energy intensity to be $448 \mathrm{kWh} / \mathrm{m}^{2} /$ year; this includes both electricity and gas. Out of the total, HVAC systems contribute to $143 \mathrm{kWh} / \mathrm{m}^{2} /$ year. This calculates to be $32 \%$ of the total energy consumed which is the highest end-use proportion. A percentage breakdown of the energy intensities for each end-use are shown in Figure 4. 


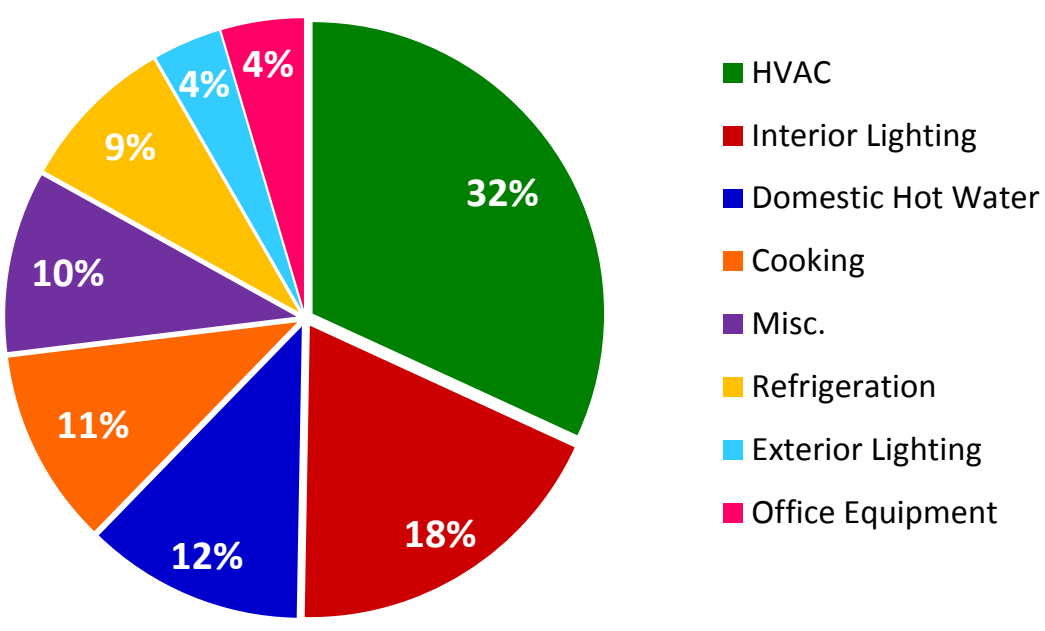

Figure 4. Californian commercial building energy end-uses: electricity and gas combined. Recreated from (Itron inc, 2006).

The breakdown of the energy end-uses show that the majority of the energy in Californian commercial buildings is consumed by the Heating, Ventilation, and Air Conditioning systems; $32 \%$ of the total energy consumed. A further breakdown identifies that the electricity and gas used by the HVAC systems account for $92 \%$ and $8 \%$ respectively (Itron inc, 2006). Little gas is used due to the heating not being a high demand for the climate.

Although being in a predominantly warm climate and therefore having a higher demand for cooling loads, the overall HVAC energy consumption is similar to the usage identified in the UK study which ranged from $15 \%$ to $50 \%$.The significance of the results from the California commercial end-use survey is that it confirms the preliminary outcomes of the New Zealand Building Energy End-use Study (BEES) and the UK energy consumption guide 19; the HVAC systems in commercial buildings consume the highest proportion of energy.

\section{Japan - Energy consumption measurement survey for commercial buildings in Japan}

In a similar method to the Building Energy End-use Study and the California commercial end-use survey, the 2001 Japanese study; energy consumption measurement survey for commercial buildings in Japan (Murakami et al., 2009), reports the results that have been collected from a number of building surveys. The buildings surveyed have identified the energy that is consumed by commercial buildings and what end-uses contribute to the overall energy consumption.

Buildings consume $28 \%$ of the overall energy consumed within Japan (Murakami et al., 2009); the remaining energy is used by transportation, industry, agriculture, and other small miscellaneous sectors. Within the building sector, commercial buildings use 13.2\% (Murakami 
et al., 2009). In relation to European countries such as the UK, Germany, and France; the total annual energy consumption per capita is very similar, however it is approximately half the usage in comparison to the United States (The institute in energy economics of Japan, 2006).

A breakdown of the energy end-uses in the commercial buildings identifies that " $50 \%$ is for air conditioning, 30\% for lighting and office equipment, and $20 \%$ for elevators, hot water, and other uses" (Murakami et al., 2009. pg183). A detailed analysis of three buildings by Nakagomi shows a similar energy breakdown with HVAC accounting for $42 \%$ to $45 \%$ of the overall energy consumption (Nakagomi et al., 2001).

\section{Summary of the compared studies}

Table 3 shows the summary of how much energy is consumed by HVAC systems in the three countries reviewed, as well as New Zealand. The percentage proportion of energy consumed and the absolute value of energy intensities are presented.

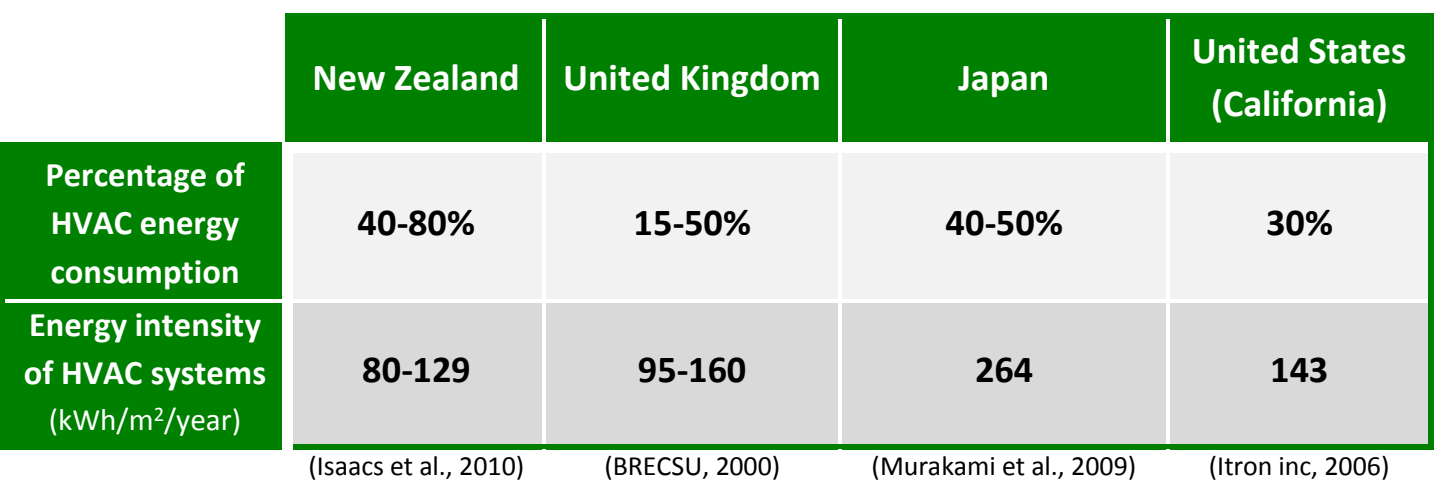

Table 3. Summary of HVAC energy consumption in commercial buildings.

For the studies that were reviewed, it was identified that HVAC systems in New Zealand commercial buildings contribute to the highest percentage of a building's energy consumption; ranging from $40 \%$ to $80 \%$ of the total energy use. Although New Zealand commercial buildings appear to have the highest percentage of energy used for the HVAC systems, these values can be misleading due to the way each study classifies commercial buildings. To eliminate this uncertainty, the energy intensity of the HVAC systems was reviewed.

As the energy intensity provides an absolute energy consumption, it is directly comparable between the four studies. The outcome of this identifies that HVAC systems in New Zealand commercial buildings consume a similar amount of energy per square metre of floor area annually as the good performing buildings in the UK - the low energy consuming buildings. In contrast to this, the Japanese commercial buildings typically consume the greatest amount of 
energy; approximately twice as much energy per square metre of floor area in comparison to New Zealand.

This wide range between countries of absolute energy intensities and proportion of total energy consumption used by HVAC highlights the importance of establishing reliable New Zealand data. International examples cannot provide reliable information. This highlights the importance of including HVAC systems within an energy calculation model, especially within New Zealand buildings as it has a significant influence on the overall building performance.

\section{Significance of modelling the correct HVAC system}

Available simulation software today allows for rational and alternative choices to be made on the type of HVAC system to be installed in a building during early design stages (Lebrun, 1994). It has been identified that HVAC systems account for one of the highest proportions of energy consumption in commercial buildings; this is up to $80 \%$ in some cases (Isaacs et al., 2010). Because of the high energy consumption of HVAC systems, it is necessary to include them when modelling a building as it has a "direct impact on the operational cost of the building" (Barbosa and Mendes, 2008. pg276).

In terms of modelling the systems, there are many publications that provide methods to assist with modelling HVAC systems. One example is by Trčka and Hensen who provide an overview of modelling approaches that can be used to model various systems and the associated controls within different software packages (Trčka and Hensen, 2010). In addition to simply having a system modelled, the importance of having a matching system and correct values for the parameters modelled should be emphasised. This is because it has a significant impact on the calculated results.

With the way various HVAC systems operate, the energy consumption calculated largely differs depending on the system modelled. A review of different studies was done to compare the energy use of different systems within the same building model. These studies highlight the importance of matching a system when modelling an existing building and testing to find the optimal performance systems for a proposed building.

The work by Bojic et al, 2010 compares the resulting energy difference of using various heating and cooling systems within a commercial building. The three systems and the resulting energy consumption that were compared in the study are shown in Table 4. 


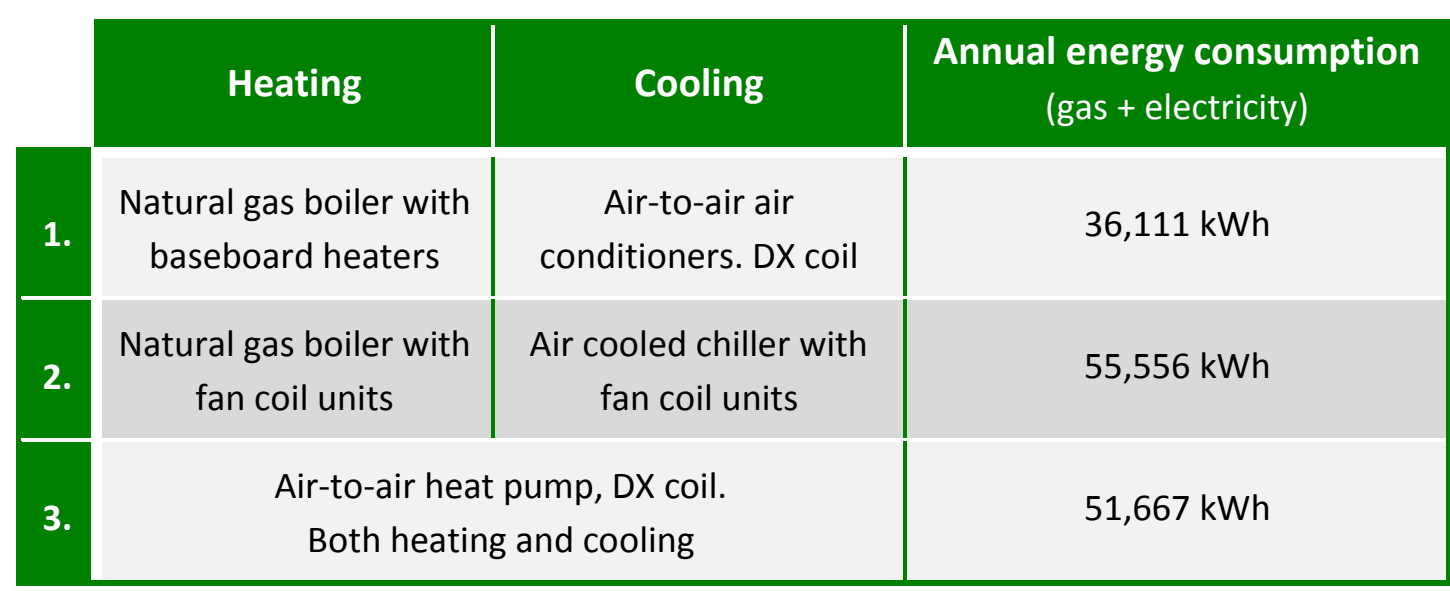

Table 4. Testing system types and energy use in a building.

Created with data from (Bojic et al., 2010).

The results of calculating the total energy consumption for these three systems using the same building highlights the impact that the type of system can have on the overall energy performance. In summary of the study, the least energy consuming system (system 1) uses $35 \%$ less energy than system 2 which consumes the most energy.

As well as having the correct system modelled, one issue that is recommended to be considered when modelling an existing building is the degradation of the equipment that arises through general operation. To truly match a building's performance, faults and other performance issues needs to be addressed (Basarkar et al., 2011). This is a difficult aspect to model due to most building simulation tools and software having a limited ability to model faults (Basarkar et al., 2011). The 2011 work by Basarkar et al. identifies some of the common faults found with existing HVAC systems and addresses them using EnergyPlus. The outcomes are that "common HVAC faults such as clogged piping, leaking air dampers, and deviating thermostat sensor readings can influence the HVAC energy use by up to 22\%" (Basarkar et al., 2011. pg2902).

Although the work by Basarkar raises an important issue of accurate modelling for existing HVAC systems, these issues are not addressed within the scope of this study. This is because the issues are specific to a single situation. As the aim of this study was to collect data that is representative for any building, data on specific faults could not be collected or incorporated into the HVAC system template models. The scope of this study addresses this issue by minimising any uncertainty in the performance of the systems by collecting HVAC information for buildings built or designed in the last 10 years. 


\section{Design of the study}

The design of the study makes the connection between identifying what data is, selecting a method for collecting the data, and ultimately the creation of the survey that was used to collect the data.

\section{What data was needed to be collected, and why?}

To identify what information was needed, the final application that the data was used for was explored in relation to the research question of this study.

The research question is;

Can real building information of Heating, Ventilation, and Air Conditioning (HVAC) systems be collected using a survey and be used to produce a set of template models within building energy calculation software?

The final application of the data was to produce a set of HVAC system template models for New Zealand commercial buildings. To do this, the template models needed to represent the most commonly installed HVAC systems. This was the first set of data that was needed to be collected. After identifying the most commonly installed systems, the second set of data that was needed to be collected and determined was the modelling parameter values.

As there are potentially a large number of HVAC system types that could have been identified as being commonly installed, the building types were limited to manage this issue. The scope of the study was set to address existing commercial buildings that were built or designed within the last 10 years and have a floor area which is $3,500 \mathrm{~m}^{2}$ or greater (defined within the BEES project as being within stratum four and five). Buildings this size are likely to use centralised plant equipment. To further define the buildings, they were divided into three divisions of performance in terms of energy efficiency: good energy efficiency, common practice, and low energy efficiency. It was expected that the divisions of performance for the buildings would dictate the type of HVAC system installed and therefore identify a different type of system for each building type.

The outcome of the data collection was to be able to produce a set of HVAC system template models representative of the most commonly installed systems. To achieve this aim, it was necessary to collect two sets of data: firstly identify the most commonly installed systems; and 
secondly determine the modelling input parameter values. Constructing the template models required the EnergyPlus default values to be replaced by the collected modelling values.

Because the templates were to be incorporated within the existing built form geometry template models, some modelling parameters were not collected; this is because they are building or zone specific parameters. Building and zone specific parameters change based on the zone volume so cannot be used within a template model that is intended to be stretched to the size of the building being modelled. An example of a building or zone specific parameter is the cooling capacity load of a chiller. For the modelling parameters such as this, EnergyPlus is able to auto-size and calculate the required capacity load of the equipment based on the dimensions of the model (EnergyPlus, 2010).

\section{Method of data collection}

Selecting the most appropriate data collection method was an important aspect to consider as it can influence what is collected and how it can be used. The overall outcome of the collected data was used to identify the HVAC systems that are representative of the most commonly installed systems throughout New Zealand and know the input parameter values that are used when modelling the systems. These aspects were then used to produce a set of standardised computer based HVAC template models. Data collection methods such as using case study buildings was considered, however this would not have provided nation-wide representative data. It was therefore decided that a survey of HVAC engineers would be the most efficient method to collect the type of data needed.

A survey is an efficient method of data collection for a number of reasons; mainly because of the ease and speed with which it can be administered (Fox et al., 2003) as well as the large audience that it can reach simultaneously (Bethlehem, 2010). Using a survey also allowed for a specific target audience to be used as participants. These aspects of a survey meant that it would be able to be easily distributed throughout New Zealand in order to collect representative data from a nation-wide audience.

The target audience for the survey was experienced HVAC system engineers and simulators that are involved with either the design or installation of HVAC systems in commercial buildings. They were the target audience because of the specialised data that was collected is only known by experienced practitioners. One issue with having experienced engineers participate in the survey was that there was potential for them to provide different responses based on their individual knowledge. An outcome of this would be that conclusions would not 
have been able to be formed. To address this potential issue before it happened, an appropriate surveying method had to be selected so that a consensus of opinions could be formed between the engineers.

\section{Ensuring a consensus opinion could be formed}

When asking a group of engineers to answer questions and provide opinions within a survey, there is a chance that the responses received are different for each participant. In this study, it would mean that each type of HVAC system could get an equal number of responses stating that it is the most commonly installed system for the building type. To ensure that this does not happen and the issue is addressed, a traditional surveying method could not be used. Therefore to collect the data from the engineers, the survey was administered using the Delphi method.

A Delphi method survey uses multiple rounds of questions to ask a group of experts for their opinion. Based on their responses a consensus can be formed. This surveying method is able to form a consensus because the participating experts are presented with all of the responses and opinions given by the other experts' and are provided an opportunity to agree or disagree. The result of this is that; "more often than not, groups of experts move towards consensus" (Gordon, 1994. pg4). The Delphi surveying method was selected to ensure that a consensus could be formed between the experts that participated.

\section{Why the Delphi method was selected to collect data}

Okoli and Pawlowski provide a comparison between a traditional survey and the Delphi method survey. They list the positive and negative aspects of both methods of data collection in relation to evaluation criteria such as the sample size required, reliability, and anonymity (Okoli and Pawlowski, 2004). Using the evaluation criteria and the data that was to be collected in this study, the Delphi method was determined as being the most suitable method of data collection.

The Delphi method was selected to collect data in this study because it could easily and reliably form a consensus opinion between the engineers consulted. This allowed for the specialised data to be standardised throughout New Zealand but remain representative of what is commonly used. Because the data collected is specialised, only knowledge and opinions from experts was able to be used; this ensured that the end results were reliable and could be used to produce the HVAC template models.

To put the Delphi method into context, if a traditional survey consisting of one stage of questions was used or non-experts were consulted, the end result of the collected data would 
not be reliable due to generalised results being based on the averages of individuals without the experience or knowledge to justify their opinions. The Delphi method eliminates any uncertainty that is caused through using statistical averages of data that is commonly done with other data collection methods. As Okoli and Pawlowski identify, the average of individual responses is inferior to the averages produced by a group of experts and their decision processes used (Okoli and Pawlowski, 2004).

Other than the reliability of the collected data, additional reasons why the Delphi method was selected to collect the data is because of the logistics of getting responses from experts throughout the country. Ideally, having a group of HVAC system engineers and simulators together in the same room in the form of a discussion panel would provide an opportunity to achieve a consensus opinion. However due to the experts being in various locations throughout the country, this was not an option. Another reason not to use a discussion panel was because factors can often arise in a face-to-face situation, "that have little to do with the issue at hand" (Gordon, 1994. pg1). Due to the survey being administered through correspondence online, any off-topic issues and conflicts between the experts were eliminated.

Correspondence with the experts provided other advantages to the data collection. One of the advantages was that the experts involved were anonymous to each other. Because of the anonymity, the experts were more likely to change or abandon their opinions when presented with the results from previous rounds of questions; this happens because there are no personality clashes (Okoli and Pawlowski, 2004). In relation to personality clashes, using a survey means that the experts have no direct communication with each other which eliminates the behaviour often found in a discussion panel, agreeing with the loudest voice rather than the soundest argument (Gordon, 1994).

\section{Overview of the Delphi method}

The surveying method used in this study is based on the Delphi method which easily forms a consensus opinion between the experts who participated. The Delphi method was "developed in the 1950s by the RAND (Research ANd Development) Corporation" (Cuhls, 2004. pg94). Cuhls goes on to say that through a series of studies, the Delphi method is a means of conducting surveys which obtain reliable consensus opinions from a group of experts. The Delphi method was "developed in response to problems associated with conventional group assessment techniques, which can create problems of response bias due to the dominance of powerful opinion leaders" (EVALSED, 2009). It is "primarily used to facilitate the formation of a 
group judgment" (EVALSED, 2009) to agree on a reasonable answer when forecasting unknown issues.

Due to the quantitative type of data that the Delphi method is used to collect, it is primarily found in the fields of science, technology, and education (Cuhls, 2004). The outcomes of the responses are results of using expert opinions which cannot be formed through using other surveying methods or by using the statistical analysis of non-experts such as the general population (Okoli and Pawlowski, 2004).

Through years of development, the surveying method has become a tool that can be used in a wide variety of problem solving situations when consulting experts for their opinions (Okoli and Pawlowski, 2004). The method has been documented in many studies identifying the circumstances in which it can be used and methodologies stating how it can be applied. Typically, "Delphi studies are processes that include the preparation of a survey, the survey itself in two or more rounds, and some analyses and implementation when the survey is finished" (Cuhls, 2004. pg93). This methodology is adapted for the purpose of this study.

This study uses three rounds of questions to survey a group of experts and form a consensus opinion about the most commonly installed HVAC systems in commercial buildings, and the modelling parameter values used to model the systems. After analysis of the responses, the outcomes are implemented through the creation of a set of HVAC system template models.

A Delphi method survey works by using multiple rounds of questions. At each round the answers to the previous one are provided to the experts so that they are able to change their minds based on the answers of others. "In a sense, the Delphi method is a controlled debate" (Gordon, 1994. pg4) where a panel of experts have been selected and are willing to participate in the study to provide their own opinions on the questions asked. The outcome is a consensus on the most reasonable idea or response for each question.

An important aspect of the Delphi method is the number of experts required in order to form valid conclusions. Unlike other surveys, a Delphi method survey does not identify average values or statistically valid values. Because statistical calculations are not applied to the responses, the uncertainty is minimised for the value that is considered to be the most reasonable; this in turn increases the reliability of the outcome from the responses. To further increase the reliability of the responses, only experts are consulted to answer the questions. An advantage of not applying statistical calculations to the responses and only consulting experts is that the number of experts required to participate can be less than a typical survey requires. For a Delhi method survey, only 10-18 people are required to participate; other 
surveying methods typically require a larger sample group in order to provide statistically significant results (Okoli and Pawlowski, 2004). "Because the number of respondents is usually small, Delphis do not (and are not intended to) produce statistically significant results; in other words, the results provided by any panel do not predict the response of a larger population or even a different Delphi panel" (Gordon, 1994. pg4).

\section{Overcoming limitations of the Delphi method}

The number of positive attributes explained in the overview is why the Delphi method was selected as the method for collecting the data in this study. However, the disadvantages must also be identified as they result in some limitations when collecting data when using this method.

Because the Delphi method uses multiple rounds of questions in order to form consensus opinions, the time required to conduct the survey can be a limiting factor. A single round can require three weeks, and therefore a three round survey such as this one can be expected to take three months to prepare, collect, and analyse all of the data (Gordon, 1994). The reason for the extensive time taken with the survey is because the responses from each round have to be analysed and are used to form the questions of the following rounds. To reduce the time that is needed to form the questions for each round in this survey, the questions were initially outlined which allowed all rounds of questions to be drafted. The drafted questions were updated once the results from the experts were received and analysed.

Gordon (1994) argues that the Delphi method does not provide 'true' opinions from the experts because generalised outcomes are formed through applying pressure on those with extreme opinions, making them work harder to defend their opinions (Gordon, 1994). However, in this case the target audience are experts in a specific field which reduces the possibility of having extremely opposing opinions.

Other people argue that the Delphi method is in no way better than any other data collection method; "Delphi is in no way superior to other (simpler, faster, and cheaper) judgement methods" (Woudenberg, 1991. pg147). Woudenberg argues this based on the findings from comparing the outcomes of questions using different surveying methods to evaluate the same issue. Through comparing the outcomes, the study showed that the accuracy of the results using the Delphi method had only a slight increase in comparison to other methods, even when specialised issues were assessed. The small increase in accuracy using the Delphi method is documented as being a result of the repetition of judgement and partly from having pressure to form a consensus opinion (Woudenberg, 1991). Because of this, Woudenberg 
justifies that the Delphi method is a collection method that is in no way better than other methods. Woudenberg reviews several studies and he concludes that "No evidence was found to support the view that Delphi is more accurate than other judgement methods" (Woudenberg, 1991. pg131).

\section{How many experts were needed to participate?}

The number of experts in a group participating in a Delphi method survey is not based on the statistical power of more is better, but formed on the basis of the knowledge of the experts. Often the number of experts required depends on the number of topics, fields, and the expected response rate (Cuhls, 2004). As this study is specialised on one topic, the sample size of experts required to participate was able to be reduced. Although having a small sample group can be identified as a limitation, when experts are consulted on a specialised topic it is not a limitation. This is because answers that experts provide are more reliable than responses from a large number of the general population. Due to experts being consulted, typically there are 10-18 experts on a Delphi panel and they are usually able to form a consensus opinion on the given topic (Okoli and Pawlowski, 2004).

Data that was collected in this study is defined as being nominal quantitative data as it can be assigned to a category and allows for statistical analysis (Denscombe, 2007). For quantitative data collection methods, there are many studies that support the idea that only a small number of experts are required to form a consensus opinion. Nielsen (2006) has done studies that focus on collecting user feedback and forming a consensus opinion between the users. Although the work by Nielsen focuses on the usability of web pages and computer program interfaces, the outcomes of the studies can still be applied to this study because Nielsen collects quantitative data that is used to form a consensus opinion.

In summary of Nielsen's studies, the comparison of the margin of error against the sample size (Figure 5) concludes that 20 experts is the recommended number to have in a quantitative study. This is concluded because the margin of error does not significantly reduce when more than 20 experts are involved; but the margin of error increases if fewer than 20 experts are involved, and radically increases when less than 10 expects are involved. This conclusion is based on the collected data having $90 \%$ reliability, meaning that it has a high level of accuracy. Figure 5 illustrates how the margin of error is likely to be greater as the need for the collected data is to be more reliable, through increasing the reliability of the collected data, more experts are needed to participate in order to reduce the margin of error. A detailed 
explanation of Figure 5 and how the number of experts relates to the margin of error is discussed in Appendix E.

\section{How the margin of error relates to the number of experts}

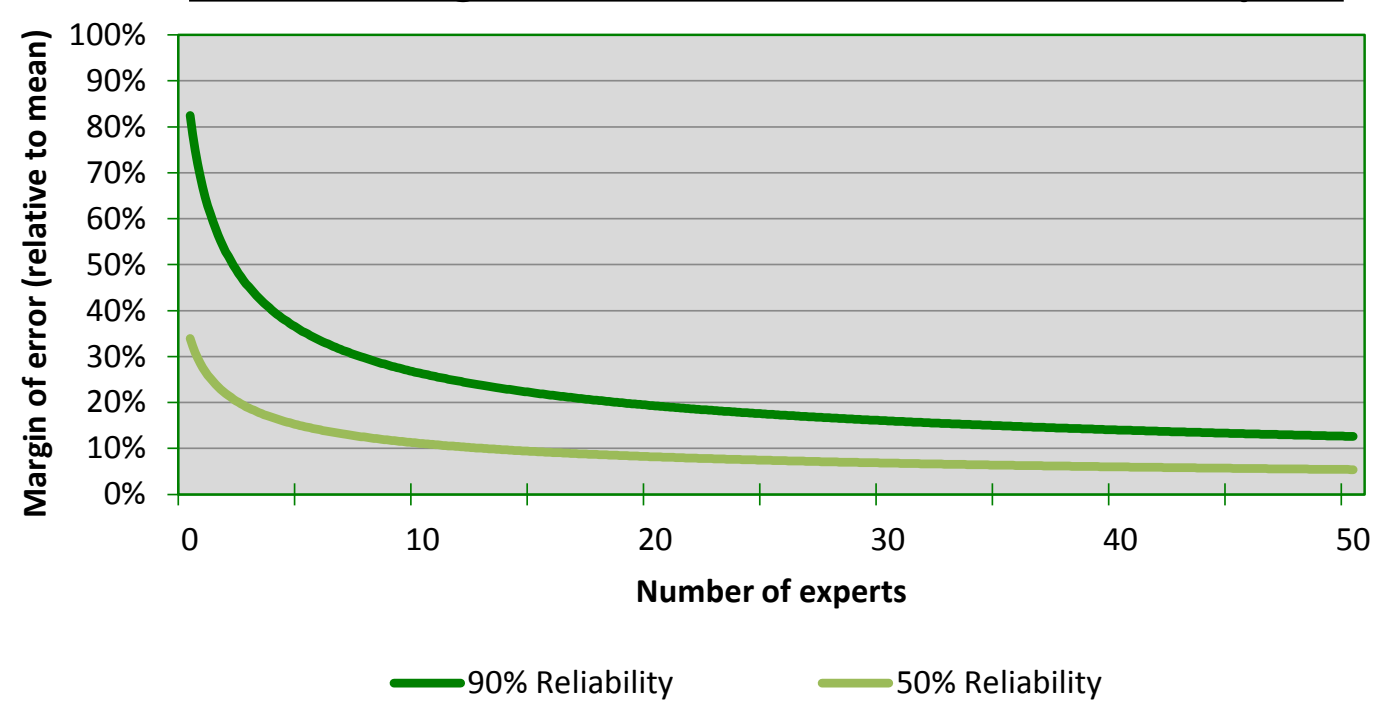

Figure 5. Margin of error in relation to the sample size.

Recreated from (Nielsen, 2006)

\section{Getting experts involved}

The Delphi method makes use of "non-representative, knowledgeable persons" (Gordon, 1994. pg7), whom are classed as being experts in their field of work. The term expert is defined as being "a person who is very knowledgeable about or skilful in a particular area" (Oxford Dictionary, 2011). It was identified that 20 experts is the ideal number of participants to be involved with a Delphi method survey. To ensure that the target audience that participated in the survey were experts in relation to HVAC systems, the survey was only distributed to qualified engineers.

To distribute the survey to engineers, the organisations IRHACE (Institute of Refrigeration, Heating \& Air Conditioning Engineers) and EMANZ (Energy Management Association of New Zealand) were contacted and asked to make the survey available to their members. The members of these organisations are all qualified engineers in relation to HVAC systems (IRHACE, 2012). The organisations published a summary of this study and a link to the survey in their emailed newsletters. The link to the survey allowed for the experts to directly participate in the survey. Contact details were also provided for any expert wanting further information or explanation. 
In addition to the newsletters from organisations, individual companies were approached to ask if they were willing to participate. This was done nation-wide by phoning engineering companies. To remove any bias, when approaching and contacting companies, all engineering companies within the IRHACE and EMANZ membership directory were contacted. This allowed for the experts within the company to determine if they are willing to participate. For the experts that were willing to participate, contact details were collected and a follow-up email was sent that contained a summary of the study and a link to the survey. Overall, this method of contacting the experts provided a better response rate than the newsletters from the organisations.

When getting experts to participate, a review of literature identified that a common issue is the sampling coverage errors that can arise from the selection of the participants; this is noted by (Bethlehem, 2010), (Couper, 2000), and (Wang and Doong, 2007). To address this issue, the survey was only made available to the target audience and contact was made with all directory listed engineering companies. This resulted in the participants being self-selected, meaning that they chose to participate.

Regarding the sampling coverage errors, "if the selection process was repeated, a slightly different set of sample persons would be obtained" (Couper, 2000. pg467). A similar disadvantage was identified within the literature of the Delphi method; "the results provided by any panel do not predict the response of a larger population or even a different Delphi panel" (Gordon, 1994. pg4). Although this is not an issue with the methodology of doing the survey, it must still be noted as the same results cannot be guaranteed to be produced if the study is repeated.

\section{Why an online survey was selected to collect the data}

An online survey was selected as the medium for conducting the survey for a number of reasons; the principal reason was because of the ease and speed with which online surveys can be administrated when distributing the questions and collecting the data (Fox et al., 2003). Other reasons that justified using an online survey include the ability to provide a high level of anonymity between the experts (Coomber, 1997) and being a "simple means of getting access to a large group of potential respondents" (Bethlehem, 2010. pg161). These advantages identified why an online survey was the most appropriate method in comparison to other methods, such as traditional paper and pencil, face-to-face, mail, or telephone surveys (Bethlehem, 2008). 
The advantages of using an online survey to collect the data justified the reason to select it as a means to conduct the survey. However a review of literature identified one main issue with using an online survey to collect data; an online survey can only be taken by those that have access to the internet (Bethlehem, 2010). Although this is a valid issue, it is not applicable in this case; Bethlehem's study used the general population as the target audience which is more likely to have people that do not have internet access. As this study had a target audience of experts that are employed within a company, and contact was made via email, it was obvious that internet access was not an issue.

Wang and Doong identify other issues with sampling errors that arise due to the method of distribution of an online survey. This issue was addressed through the method in which the survey was distributed. The survey was not made available to the general public and was only made accessible through an invite to participate. By doing this, only experts with relevant knowledge were able to participate; in turn this reduced uncertainty in the collected data and increased the reliability.

\section{Distributing an online survey}

With online surveys, there are a number of methods which can be used to distribute it. Various methods and their advantages are highlighted by Wang and Doong, 2007. Determining the method of distribution depends on the type of survey being used. For online surveys, Wang and Doong identify that there are three types of distribution methods commonly used (Wang and Doong, 2007. pg2).

1. Type I is part of a website and is 'open' to any visitor, there is no control over who visits and who can participate.

2. Type II is 'closed', and respondents are invited to visit the site to complete the questionnaire, which may be password protected or use other means to restrict access.

3. Type III is 'hidden', and the questionnaire appears to a visitor when triggered by a mechanism such as on a certain date or after reaching a defined number of visitors to the site. This type includes the pop-up survey.

The selection of which survey delivery method to use is based on the type of survey and who the target audience is. The survey type used in this study is type two, a closed survey. This is because the survey was only intended for the target audience who are experts in the field of HVAC design in commercial buildings. To ensure that the survey was only accessible to these 
experts, invites for experts to participate were sent via two relevant professional associations in New Zealand: IRHACE (Institute of Refrigeration, Heating \& Air Conditioning Engineers) and EMANZ (Energy Management Association of New Zealand). This invite method allowed for the survey link to be forwarded onto other professional colleagues but does not make it available to the general public. This method of distributing the survey was able to maintain the reliability of the results through knowing that only experts are able to participate.

Through distributing the survey in this way, it characterised as a self-selection survey as defined by Bethlehem, 2008. A self-selection survey is when experts are made aware of the survey and decide whether or not they want to participate (Bethlehem, 2008). By using a self-selection survey, the selection process was not biased in any way as it allowed for the experts to participate on a voluntary basis.

\section{Using the online survey tool Qualtrics}

An online survey was determined to be the best method for creating the survey due to the ease of distributing it. To create the survey and distribute it available to the experts, the online tool Qualtrics was used (Qualtrics Inc., 2011). Qualtrics was selected as it provides a simple user interface to create surveys, distribute them, and collect the responses. As the experts complete the survey, their responses are automatically updated and recorded within Qualtrics. All functions of Qualtrics are available online, meaning that no additional software is required to be installed to run it.

The university recommends the use of Qualtrics because of the available features and support. Because it is a recommended tool to use, there is an existing background image for the surveys to use which has the logo of the university. This background was used in the survey for this study to confirm that the study in being done in connection with Victoria University of Wellington.

By creating the survey through Qualtrics, the logistics of distributing, monitoring, and collecting the surveys are simplified. The process of this is done by emailing the experts a link directly to the survey accompanied with a cover letter explaining the survey. The emailed link takes each expert directly to the survey for them to answer and provide responses. At the completion of the survey, the responses are automatically recorded and become available within the results section of Qualtrics.

Simple statistical analysis of the results is automatically done and formed into a basic report to provide a brief overview of the responses. These results are easily exported into a format that is readable within a spreadsheet for further analysis. 


\section{Would the collected data be applicable internationally?}

In addition to the New Zealand experts that participated in the survey, an international audience was also consulted. The people consulted internationally did not participate in the survey but were provided a summary of the results once the survey had been concluded.

The reason for consulting an international audience was to identify if the commonly installed HVAC system types and the associated modelling parameters used in New Zealand are similar or different in comparison to other countries and climates. Through doing this comparison, it could be determined if the modelled HVAC templates could be used in an international context.

To ensure that a range of countries and climates are covered with the international comparison, participants of the IEA-task 40 (International Energy Agency, 2012) and other energy and HVAC modelling professionals were consulted.

\section{How the responses were analysed}

For a Delphi method survey, the responses for each round of questions are analysed before the following round of questions are created. This is because each round of questions presents the experts with the responses from the previous round of questions in order to form a consensus opinion on the given topic. In this study, three rounds of questions were used to form a consensus opinion on the types of HVAC systems that are commonly used in New Zealand commercial buildings and the modelling input values that best represent the systems.

The online tool Qualtrics, which was used to create the survey, was also used to analyse the responses of each round of questions. Qualtrics automatically records the responses of the questions as they were completed and provides a tally of the results. The results were tallied for all experts but can be broken down into individual responses when needed.

The analysis of the survey is broken down into five aspects:

1. Determining who the experts are and how many years of experience they have;

2. Identifying and forming a consensus on the commonly installed HVAC systems;

3. Identifying and forming a consensus on the modelling input parameter values for the commonly installed HVAC systems;

4. Confirming the modelling values through an independent review of manufacturers' data; 
5. Using the feedback provided as a means of quality control for the questions.

\section{Determining the types of experts}

The experts that were eligible to participate in the survey of this study were anyone that is involved with the design or installation of HVAC systems in commercial buildings. Because of the difference between the experts that design HVAC systems and the experts that install the systems, the responses that they are able to provide differ. The experts that are involved with the design of HVAC systems know the most commonly used systems in commercial buildings and the parameter values that are used when modelling the systems. In comparison, the experts that are involved in the installation of the systems are only familiar with the types of systems that are commonly installed in the buildings as they are not involved with the modelling of the systems.

To determine what questions of the survey each expert is able to answer, in round one they are asked if they are involved with energy computer simulations using programs such as EnergyPlus, DOE-2, and IES; the answer options are either yes or no. Depending on the answer to this question, the experts were provided with one of two different sets of questions in round two of the survey. One set of questions were for the experts that are involved with modelling; this round of questions asked the experts for the parameter values that are used when modelling the systems while forming a consensus on the likely installed HVAC systems. The other set of questions were for the experts that are not involved with simulations or modelling of the systems; these questions only formed a consensus opinion on the types of systems that are commonly installed.

The analysis of the question which identified the two types of experts was done by matching the answer that they provided to their email. This ensured that the correct second set of questions was sent to the correct set of expert.

Identifying and forming a consensus on the most common HVAC systems

In the round one questions, the experts were asked to identify the most commonly installed HVAC systems in New Zealand commercial buildings. Based on the responses of this, the second round of questions form a consensus between the experts which confirms the types of systems. The questions were split into the three building types that are a division of a building's performance: good energy efficiency, common practice, and poor energy efficiency.

For each of the three building types, the questions provide a matrix table of the HVAC systems that are common and able to be modelled in EnergyPlus. The experts were asked to rank the 
systems in order of most likely installed to the least likely installed. They were also provided a space to include any other type of system if applicable. The responses to this question were analysed by identifying the systems that were ranked the highest by all experts. This identified two or three systems for each of the building types. The systems that were ranked the highest became the basis of the questions in round two when forming a consensus.

The round two questions presented the highest ranked systems for the three building types and asked the experts if they agreed or not that they are likely to be the most commonly installed system for the building type. The same questions were presented to both types of experts that are involved with the survey. To analyse the responses of the second round of questions that formed the consensus, the totals for the agreed and disagreed responses were tallied up. A consensus between the experts is formed when the majority of the experts agree that the HVAC systems are the most commonly installed in New Zealand commercial buildings.

\section{Identifying and forming a consensus on the modelling parameter values}

The round two questions that identify the modelling parameter values were only answered by the experts that are involved with the modelling of HVAC systems. The questions were broken down into three sections to simplify and therefore provide clarity to the questions for the experts. In turn, this also allowed for the analysis to be performed more quickly and reduced errors in the collected data. The sections that the questions are broken down into are a general overview of the HVAC system and how it relates to the building; the second section defines the HVAC equipment types that are installed; and the third section identifies the system efficiency and performance values. This is done for all of the HVAC systems that the consensus confirmed are commonly installed in New Zealand commercial buildings.

\section{Systems overview}

The overview of the HVAC systems section asks questions that put the systems into context of the building types that they are servicing. These questions identify the percentage of the building that is conditioned, the controls that are used to operate the systems, and the outdoor air supply rate that is used by the system. These aspects are important to know for modelling purposes as they have an influence on how the building operates. Because the questions relating to the systems overview are generic, these questions were asked for all HVAC system types that the consensus confirmed are likely in New Zealand commercial buildings. 
To analyse the percentage of the area that the system is conditioning in the building type, the question provides four options: $<25 \%, 26-50 \%, 51-74 \%$, and $>75 \%$. To answer, the experts select one of the options provided. The analysis of this question identifies the likely option to be associated to the HVAC system by being the one that was selected the most by the experts. The option selected the most is presented in the round three questions when forming a consensus opinion.

The control(s) that are used with the system and building type were identified by presenting commonly used automated controls to the experts; a space was also provided to input additional controls if needed. The experts could select multiple controls if needed. To analyse this question, any of the controls that over half of the experts selected was considered to be likely installed for the system and building type. These controls were used in the round three questions when forming the consensus.

Outdoor air flow rates are collected in the measurement of litres per second per person in the conditioned space (L/s/person). The default EnergyPlus value is presented to the experts to either agree or disagree with; if the default value is not reasonable then the expert is asked to provide a value that is more reasonable to use. To analyse the responses, the value that was provided by the majority of the experts is considered to be the most reasonable and is presented when forming a consensus between the experts.

\section{System equipment types}

The system equipment types that were identified relate to the types of components and their operation that are used within the HVAC system. For example, heating coils could be electric, hot water, or a DX (Direct eXpansion) coil. The equipment types were needed to be identified because of the significant influence that different equipment has on the overall energy performance of a system.

Because of the various types of equipment that can be assigned to the systems that were identified to be installed in New Zealand commercial buildings, the questions asked in round two of the survey were specific to each system. The questions presented all options of equipment types applicable to the system and asked the experts to select the one that is most likely used for the HVAC system and building type it is installed in. To analyse the responses provided, the equipment type that was selected the greatest number of times was used as the parameter that is agreeable by the experts. The selected parameters were presented in the round three questions when forming a consensus opinion. 


\section{System efficiencies}

The systems efficiency values such as the Coefficient of Performance (COP), coil temperature set points, and fan motor efficiencies were also needed to be collected in order to develop the HVAC system template models. As with the systems overview and the equipment types, the efficiency values are collected in Round two and a consensus formed in Round three.

In round two of the survey, the questions asked the experts if the default values that are provided within EnergyPlus are reasonable or not. The default values that were provided in the questions related to the equipment type that was selected in the same round of questions. To identify if the value was reasonable or not, two tick boxes were provided which were used to agree or disagree with the presented value. The experts selected the box that they believed was true. If they disagreed, then a space was provided to input an alternative value that they believed was more reasonable. This was done for all of the input values relating to the efficiency values required to model the HVAC system for each of the three building types.

To analyse the responses to these questions, the responses were tallied up after all of the experts had completed answering the questions. The value with the greatest number of responses, either agreeing with the default value or providing an alternative value, was the value identified as being most likely associated with the HVAC system type and building type. The identified value was presented in the round three questions when forming a consensus between the experts.

When there is not a large difference between the responses for the default values and the provided alternative values, an independent review of manufacturers' data was done.

\section{Confirming responses with manufactures' data}

Manufacturer data was reviewed to confirm the values that were provided by the experts who disagreed with the default values as being reasonable values to use in the models. The review was also done when experts responded saying that the default value was not reasonable but they were unsure of an alternative value. This process was done at the completion of the second round of questions and the outcomes were used to support the questions in round three. The review usually confirmed that the alternative values provided are reasonable as they matched the manufacturers' data.

To avoid any bias from performance values of a single manufacturer, the review used multiple manufacturers and their available catalogues and data sets. The review was able to identify and confirm the alternative values that the experts provided in round two. The review also provided a means of quality control due to the values being confirmed as being reasonable. 
Another means of quality control was asking the experts for feedback at the end of each round of questions.

\section{Using respondents feedback as quality control for the questions}

Although each round of questions in the survey was tested to check that the questions are displayed correctly and can be answered, the last question within each part of the survey allows for the experts to comment on any issues that they may have had when completing it. This provided the experts an opportunity to note anything that needed to be addressed after they had just completed it. To ensure that any issues were addressed as quickly as possible, the responses were checked daily to review the responses for this question.

Any issues noted were analysed in two ways; firstly, it was determined if the issues have affected the answering of the questions. For example, the terminology used may have led to the questions being interpreted differently by the experts and this would have led to the responses being significantly different. Other issues affecting the answering could have been due to the questions not loading correctly online. Secondly, the analysis determined how common the issues were. If the issues were common for the majority of the experts, it indicated a problem with the questions or the survey in general.

If any issue was identified to have significantly affected the answers that had been submitted, individual responses or potentially whole questions would have needed to be ignored from the final analysis due to providing invalid responses.

\section{The survey questions in detail}

The multiple rounds of this Delphi survey formed a consensus opinion between the experts that participated. The consensus determined two aspects: what the most commonly installed HVAC systems are in New Zealand commercial buildings and what the typical modelling parameter values of the systems are.

This section of the chapter explains the order of the survey questions and how they were constructed, and also describes the questions that were asked in each round.

\section{Construction and hierarchy of the survey questions}

The survey consisted of three rounds of questions which were all constructed, distributed, and collected online using the tool Qualtrics. The multiple rounds of the Delphi survey was used to form consensus for the types of likely installed HVAC systems and their input parameter values used to model the systems. Consensus between the experts was formed during the second 
and third rounds of questions by using the responses of the previous rounds to construct the second and third rounds of questions. The hierarchy of the question structure and the outcomes of each round of questions are illustrated in Figure 6.

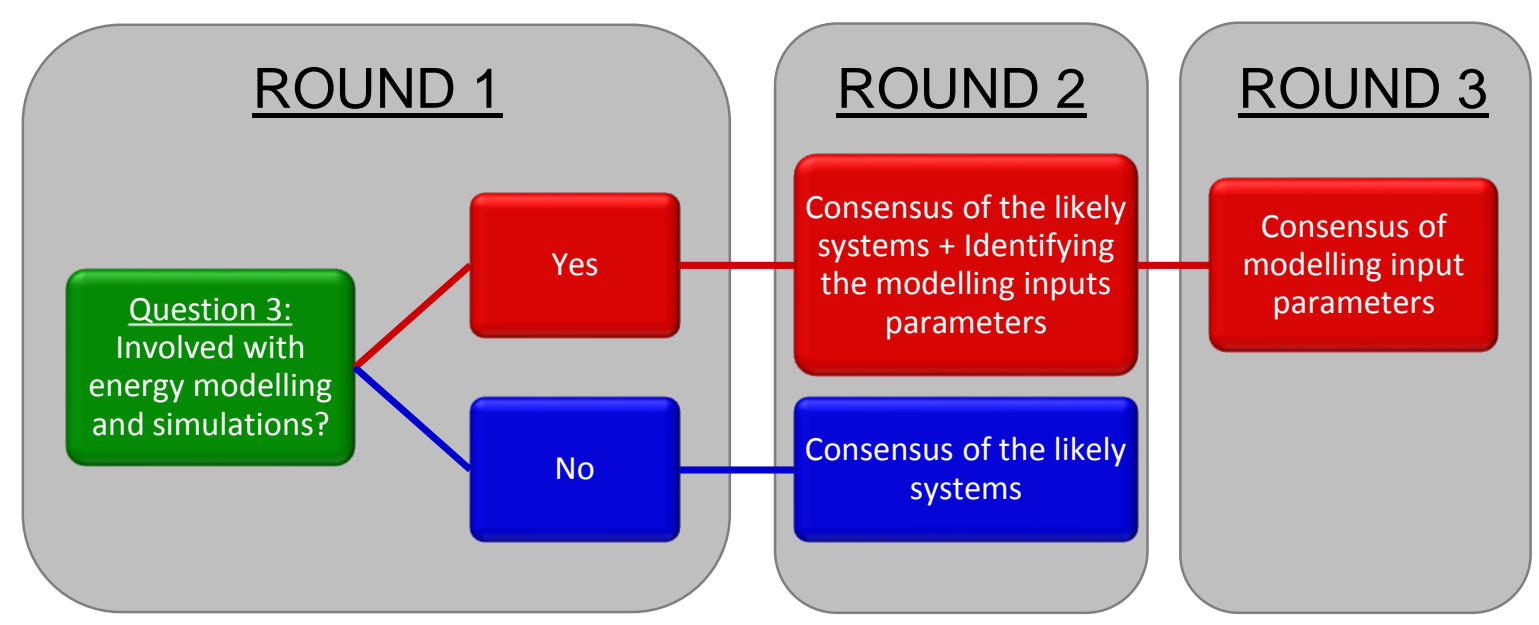

Figure 6. Hierarchy of the survey questions.

As Figure 6 illustrates, the construction of the survey allowed for the experts to be classified into two groups during the first round. The two groups are: those that are involved with simulation, and those that are not. The two groups had to be identified as they were asked very different questions in the following rounds. The experts that were grouped as being the non-simulators only needed to help form consensus on the types of systems installed while the simulators group of experts were asked additional questions regarding the parameter values used to model the HVAC systems.

To construct the survey in a clear and direct way so that the responses could be used to produce a set of HVAC system template models, the questions were based on the parameters that are required by EnergyPlus to model the HVAC systems. The EnergyPlus operation manual (EnergyPlus, 2010) and the IDF editor (GARD Analytics, 2010) were used to identify the input parameters required. To identify equipment types, the questions present the available options that can be used within EnergyPlus and asks the experts to identify which of the equipment types is most likely to be used when modelling the system. When identifying the performance values, the default EnergyPlus value was presented and the experts were asked if it was reasonable or would they suggest an alternative value.

Equipment and performance values that were not included within the survey questions are the parameters that are building dependent. For example, these are the values that determine the capacity size for cooling and heating of the modelled systems. EnergyPlus is able to auto-size 
these parameters based on the calculated cooling and heating loads required for the volume of the conditioned zones.

Before finalising the questions, an independent expert that did not participate in the survey was consulted to check that the terminology used and the questions asked would be understandable by the target audience. This check was done to make sure that the questions would be interpreted as they were intended and therefore maintain the reliability of the responses. Fox et at, 2003. highlight that it is "important that respondents interpret questions in the manner in which the researcher intended" (Fox et al., 2003. pg169); aspects of interpretation become more important when the questions are not administered in person. Some minor terminology and layout issues were addressed after being noted as potential issues.

The final step before distributing the survey to the experts was to submit it to the human ethics committee to gain approval ${ }^{1}$.

\section{The questions}

This section provides a breakdown of the questions used in each round of the survey and explains the objective of the questions. Appendix F displays a copy of the questions used in each round of the survey.

\section{Round one}

The main focus of round one was to determine what HVAC systems are the most commonly installed within New Zealand commercial buildings. Round one also identified the years of experieince the experts have and whether or not they are involved with computer modelling of HVAC systems, this determined which set of questions were used in round two.

Reliability of the responses from the experts was based on the years of experience that they have. The question asked was not used to weigh or put emphaisis on the responses from experts with more years of experience, but was a quality control for the experts that provided responses that were largely different from the majority of the group. If an expert had a response that is largely different, their years of experience would be reviewed to determine if their responses provided are reliable or not. The assumption made was that the greater the number of years experience, the more reliable their responses are.

\footnotetext{
${ }^{1}$ Human Ethics Committee approval was granted by Victoria University of Wellington on $26^{\text {th }}$ September 2011. Approval number 18800.
} 
To determine the most commonly installed HVAC systems, a list of various systems was provided in the question and the experts were asked to rank the systems in order of the most likely installed to the least likely installed. A space was also provided to allow for additional systems to be included. This was done for the three building types. The systems that were ranked the highest in the responses from all of the experts were used to produce the questions in round two.

\section{Round two}

There are two question sets in round two: one for the experts that are involved with modelling and simulations of HVAC systems, and the other question set for the experts that are not involved with the modelling of systems. Both sets of questions have the objective of forming a consensus on the most likley installed HVAC systems. In addition to forming the consensus on the types of HVAC systems, the experts involved with modelling are asked to identify what the modelling parameter values of the systems are.

To form a consensus on the most commonly installed HVAC systems, the experts are presented with the responses that the majority of the particpants selected in the round one questions. They are asked if they agree with the HVAC systems that were identified as being likely installed in the three building types. The objective of this was to form a consensus opinion between the experts. If an expert did not agree with the majority of the participants, they have to provide reasoning why.

For the experts that are involved with modelling of the systems, the extended round of questions asked for them to identify what modelling parameter values are most likely to be used when modelling the systems that the consensus confirmed are likely installed.

\section{Round three}

Round three questions were only completed by the experts that are involved with the modelling of HVAC systems. The objective of the questions in this round was to form a consensus opinion of what the modelling parameter values should be for the HVAC systems. To form the consensus between the experts, the responses of the most selected parameter values were presented and the experts were asked if they agree with the collected values. Any expert that disagreed with the values presented was asked to justify why. 


\section{Survey Responses}

This chapter analyses the Delphi survey responses. It reports the consensus that was formed between the experts who have been surveyed. The consensus is on the types of heating, ventilation, and air conditioning (HVAC) systems that are most commonly installed for different building classifications; and the equipment and associated performance values used when modelling the systems. The number of experts that participated in each round of questions and their level of experience are also reported as critical features of the Delphi process.

\section{The experts that participated in this survey}

To ensure that the experts that participated were knowledgeable in the field of HVAC design in commercial buildings, the survey was addressed to members of two relevant professional associations in New Zealand: IRHACE (Institute of Refrigeration, Heating \& Air Conditioning Engineers) and EMANZ (Energy Management Association of New Zealand).

As outlined in the chapter; Design of the study - Method of data collection, the Delphi consensus process requires multiple rounds of questions, ideally of 10 to 18 experts (Okoli and Pawlowski, 2004). The total number of experts that participated in this survey was 22.

\section{Number of experts in the survey}

The experts participated on a voluntary basis after being made aware of the survey. At the end of the first round of questions, there were 22 experts that participated in the survey. The number of experts reduced to 19 by the end of the second round of questions.

Table 5 shows a breakdown of the number of experts in each round of questions. The experts were divided into groups of simulators and non-simulators. For the second round of questions, those who are involved in simulation were asked additional questions regarding modelling parameter values. In round two and three, the number of experts in the simulators group was reduced to eight in total. Although this is slightly below the ideal number of experts to have as suggested by Okoli and Pawlowski, it is still able to form a reliable consensus using the Delphi method. This is because the "average group error drops radically as the number of Delphi group increases to about eight to twelve" (Paliwoda, 1983. pg36); therefore the absolute lowest number of experts to consult and receive responses from is eight as the likely errors of the responses are minimised. 


\begin{tabular}{|r|c|c|c|}
\hline Question Round & $\mathbf{1}$ & $\mathbf{2}$ & $\mathbf{3}$ \\
\hline Simulators & 10 & 8 & 8 \\
\hline Non-Simulators & 12 & $11^{*}$ & - \\
\hline
\end{tabular}

*This value includes one of the experts that was in the simulator group who became a part of the non-simulators group.

Table 5. Breakdown of the number of experts in each round of questions.

As Table 5 shows, the number of experts decreases by two from each group after the first round of questions. Although initially reduced by two, the non-simulators group gained an additional expert that was originally in the simulators group. This expert changed because they believed that "with their experience and knowledge, they did not know the modelling parameters that would be used". Although the expert did not know the input parameters that are used to model the systems, they were still able to answer the questions on the most commonly installed systems for the different building types. Therefore their responses were able to be recorded with the non-simulators group. This issue has been assumed to have occurred due to a misunderstanding or misinterpretation of the question in round one when asked if they are "involved with dynamic thermal/energy computer simulation".

Contact was made with the experts who did not continue to answer the round two and three questions to identify why they did not continue. Their reasoning for not continuing included; "because they did not have the time to continue participating" and because they "believe that they do not have enough experience to answer the questions about the modelling parameters, and did not want to skew the overall survey results". In respect to the experience of the experts participating, the years of experience was collected to confirm the reliability of the responses.

\section{Years of experience the experts have}

The years of experience the experts have is an important aspect to know as it confirms the reliability of the collected responses. Because the questions involved in this survey are on a specialised topic, only experts with adequate experience are able to answer the questions. To assess the reliability of the responses that the experts provided, a general assumption was used: having more years of experience corresponds to the response being more trustworthy.

In round one, the experts were asked how many years of experience they have with installing, deigning, or simulating HVAC systems in New Zealand commercial buildings. The question provided six divisions of time frames for the experts to select from. The time frames are of five 
year intervals, except for the first division which is a single year to identify if anyone has less than one year's experience.

Figure 7 shows the years of experience that the experts have. The graph is broken down to display the years of experience in relation to the number of simulators and non-simulators. Overall there are no experts that have less than two years of experience. With all experts having a minimum of two years of experience, it is expected that they are familiar with the commonly used HVAC systems within commercial buildings.

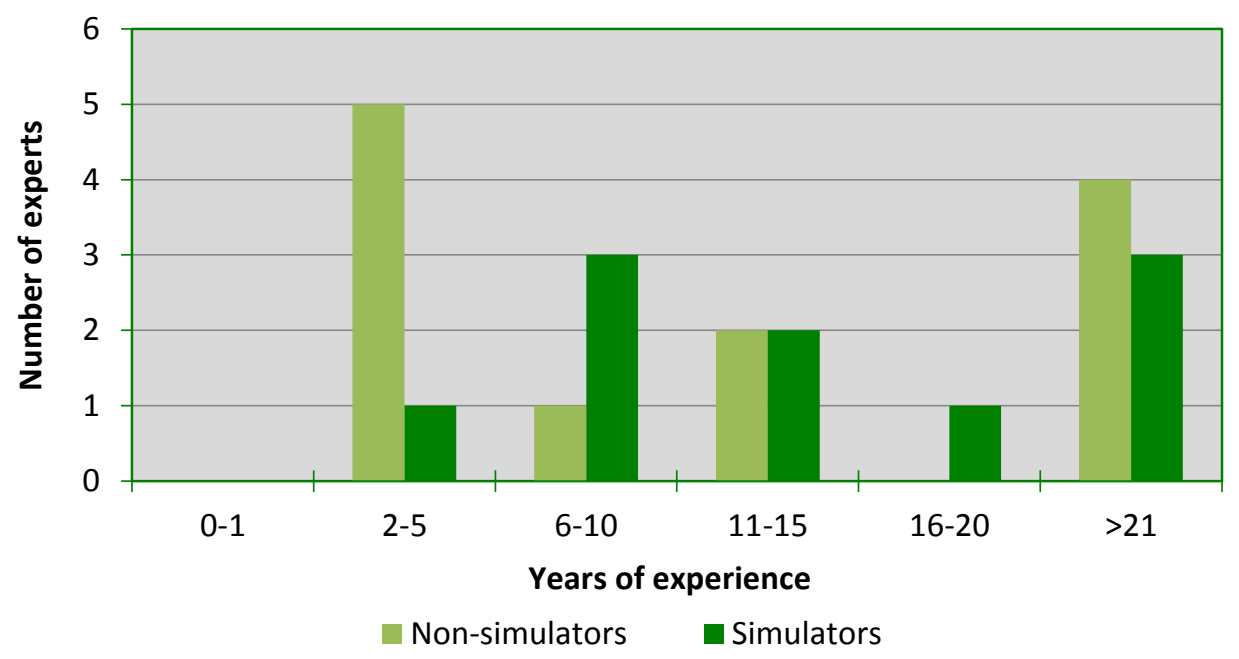

Figure 7. Number of experts and their years of experience.

The results shown in Figure 7 highlight that the majority of the experts that are not involved with simulation have either 2-5 years of experience or greater than 21 years of experience. In contrast to this, the experts that are involved with simulation have a more even distribution across the divisions of years. Although there is a difference between the groups in terms of the distribution of the number of experts and their years of experience, the summed total minimum years of experience is within one year's difference; the summed total for the non-simulators is 122 years while the simulators is 121 years.

With the level of experience that the experts have, and using the assumption that having more years of experience corresponds to more trustworthy responses, it can be stated that the collected information from the survey provides a reliable set of data. The data that is collected forms a consensus that determines the most commonly installed HVAC systems in commercial buildings as well as providing the equipment and associated performance values that are used when modelling the systems. 


\section{The process of forming a consensus}

For this survey, the consensus was formed in four steps as illustrated in Figure 8. The first step was to identify the possible HVAC systems that could be installed in each of the building types. Using the responses of this, a consensus was formed in the following round of questions. The consensus confirmed which types of systems were likely to be installed (step 2). The third step uses the most commonly installed HVAC systems and identifies the values for the modelling input parameters. The values which were selected the most are confirmed with a review of manufacturers' data and are presented in the final round of questions. The consensus of the modelling values is formed when the experts agree that the values are likely to represent the system and building type.
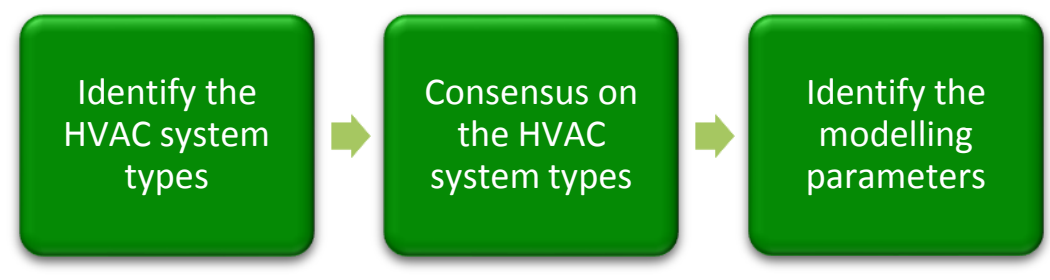

Consensus on

the modelling

parameters

Figure 8. Process of forming consensus.

To illustrate the process of how the consensus was formed between the experts, the good energy efficiency building classification is used as an example. The same process is done for the common practice and poor energy efficiency building classifications. The good energy efficiency building classification describes a building that uses relatively little energy and can be expected to be a GreenStar rated building (New Zealand Green Building Council, 2011).

\section{The likely installed HVAC systems}

To identify the types of systems that are likely to be installed in good energy efficiency buildings, a list of generic systems that are commonly used was presented to the experts. Space was also provided to include additional systems if the experts needed to. For the good energy efficiency building type, one 'other' system type was identified; natural ventilation with no mechanical systems. As this study is only focusing on mechanical systems, natural ventilation does not fit within the scope.

Using the provided types of systems the experts were asked to rank them in order of the most likely installed to the least likely installed. The list of systems that were provided is shown in Table 6. 


\begin{tabular}{|l|}
\hline Chilled Beams \\
\hline Fan Coil Units \\
\hline Packaged AHU \\
\hline Packaged AHU Heat Pump \\
\hline Split System (cooling only) \\
\hline Split System Heat Pump \\
\hline Variable Air Volume (VAV) \\
\hline Variable Refrigerant Volume (VRV) \\
\hline Other (Specify) \\
\hline
\end{tabular}

Table 6. List of HVAC systems provided in the survey.

At the end of the first round of questions, the likely installed HVAC systems were identified. Figure 9 shows the number of times each system was ranked as being the most likely installed. From the responses, it is clear that Variable Air Volume (VAV) and chilled beams are selected the most. Although it is clear that these systems have been selected more than the other types of systems, a consensus has not been formed until the majority of the experts agree on the systems.

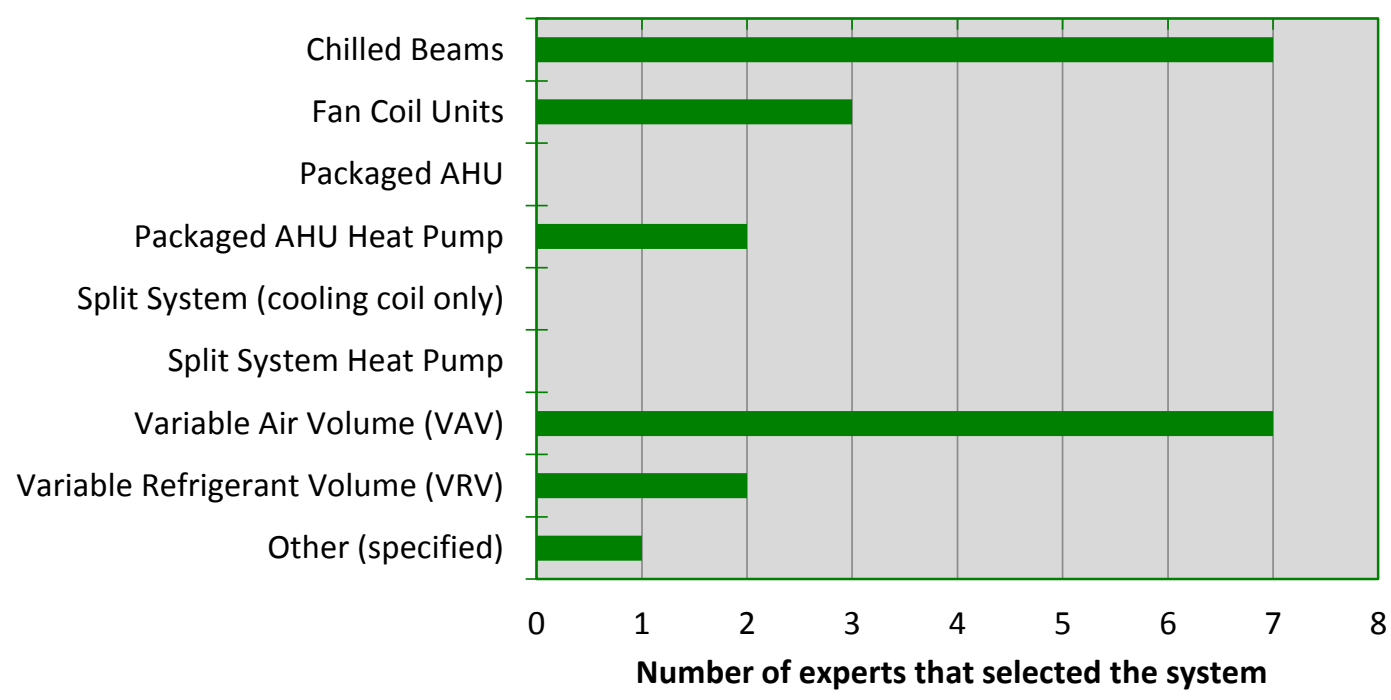

Figure 9. HVAC system types identified for a good energy efficiency building.

To provide the experts that did not select VAV or chilled beams an opportunity to change their selection and form a clear consensus with the majority of the group, the round two questions presented the VAV and chilled beams to all of the experts and asked if they agreed that these systems are likely to be installed. The outcome of asking the experts if they agree with these systems is illustrated in Figure 10. It is clear that a consensus has been formed because all but two of the experts agreed that these systems are likely to be installed. 


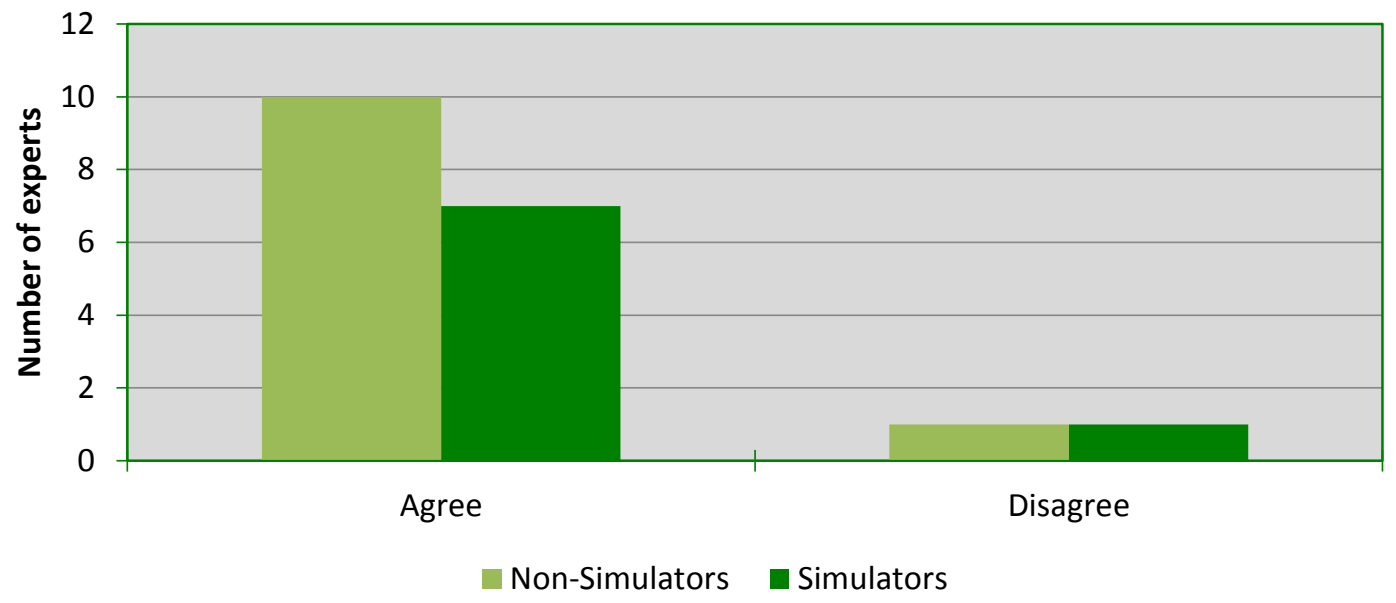

Figure 10. Consensus response on the types of HVAC systems for a good energy efficiency building.

The experts that disagreed had to explain their reasoning why they disagreed. Both experts stated that Variable Refrigerant Flow (VRF) systems can be highly efficient too, and have seen them installed in high energy efficient buildings. One of the experts also said that modern fan coil units are also very low in energy consumption in relation to performance.

\section{The modelling parameter values for the identified HVAC systems}

The round two and three questions are completed by the experts that are involved with simulations. These questions identify and form a consensus on the modelling parameter values for the HVAC systems that have be identified as being most likely installed in the building type.

The questions are based on the modelling input parameters that are required by EnergyPlus to model a system. To minimise the amount of input parameters that are need to model the systems, the EnergyPlus HVAC template objects in the idf editor were used. A summary of the HVAC template objects that were used for each system type is listed in Appendix G.

An attempt was made to simplify these questions by basing them on the EnergyPlus input parameters. The questions provided the suggested default value or any of the possible options. The experts were asked to select the value or equipment type that is likely to be used. If needed, the expert could also provide alternative values. Examples of the questions asked to identify the modelling parameters include: the percentage of the building conditioned by the system, the controls used to operate the system, the types of equipment within the systems, and the performance and efficiency values of the equipment. What the survey does not collect values for is the building specific aspects such as the capacity sizing and loads of the systems. These aspects are auto-sized by EnergyPlus to determine the required sizes and loads. 
The consensus for the modelling parameter values was formed in a similar way as the type of systems was identified. The round two questions identified the equipment types and performance values for each of the HVAC systems. To do this, the parameters that were selected the most by the experts were considered to be the most likely to represent the system. An independent review of manufacturers' data confirmed if the values are reasonable to use.

To form a consensus on the modelling parameters, round three questions presented the experts with all of the values identified to be reasonable from round two. The experts were asked to agree or disagree with the presented values that were suggested by the majority of the group. The experts that disagreed had to provide reasoning for why they disagreed to justify and support their response.

For the chilled beam system, it was identified that this was a cooling only system; heating was identified to be provided by using electric baseboard heaters. All of the modelling parameters that the consensus confirmed are associated with the chilled beam system are displayed in Table 7.

The only parameter that was changed between the initial identified values and the consensus of the values was the cooling coil design set point. Initially this was identified as being $12^{\circ} \mathrm{C}$, however many of the experts disagreed with this values during the consensus process stating that the temperature is too low; $14^{\circ} \mathrm{C}$ was provided by the experts as a more reasonable value. As well as providing an alternative value of $14^{\circ} \mathrm{C}$, each of the experts stated a reason for suggesting the alternative value; this is because "at $12^{\circ} \mathrm{C}$ the temperature is too low, below the dew point. To avoid any issues with condensation, the temperature needs to be increased to at least $14^{\circ} \mathrm{C}^{\prime \prime}$. 


\section{Equipment Types and Modelling Values}

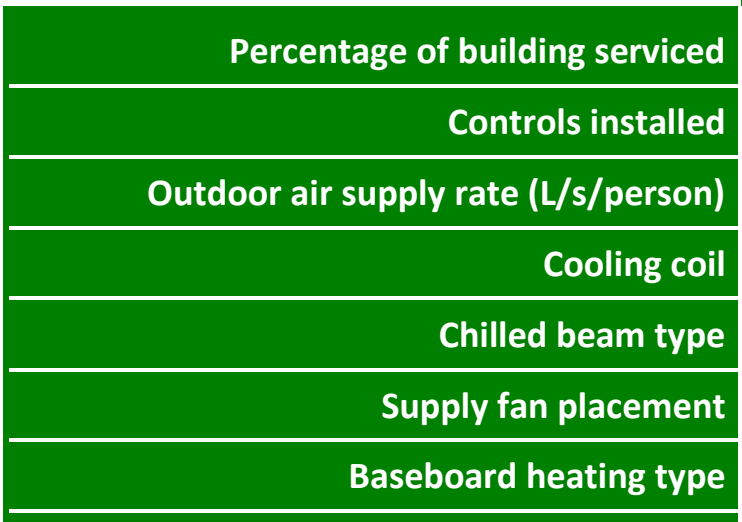

Chiller type

Chiller to coils loop pump type

Condenser type

Condenser water temperature control

Chiller to condenser water loop pump type

Cooling tower type

Supply fan efficiency

Supply fan motor efficiency

Cooling coil design set point $\left({ }^{\circ} \mathrm{C}\right)$

Chiller COP

Chilled water set point $\left({ }^{\circ} \mathrm{C}\right)$
$76-100 \%$

Thermostat, $\mathrm{CO}_{2}$ Sensor, BMS

15

Water

Cooling only, fan assisted

Blow through

Electric

Centrifugal

Constant primary, variable secondary

Water cooled

Variable,

based on outside temperature

Variable

Two speed

0.7

0.9

14

4.2

6.0

Table 7. Modelling input parameter values: Chilled beams, good energy efficiency building.

The other type of system that was identified to be likely installed in a good energy efficiency building was a Variable Air Volume (VAV). This system was identified to use water for both the cooling and heating aspects. A full list of the equipment and the values that the consensus formed are displayed in Table 8. 


$\begin{array}{r}\text { Percentage of building serviced } \\ \text { Controls installed } \\ \hline \text { Outdoor air supply rate (L/s/person) } \\ \hline \text { Cooling coil } \\ \hline \text { Heating coil } \\ \hline \text { Supply fan placement } \\ \hline \text { Fan layout } \\ \hline \text { Baseboard heating type } \\ \hline \text { Reheat coil } \\ \hline \text { Heat recovery } \\ \hline \text { Night cycle ventilation } \\ \hline \text { Chiller type }\end{array}$

Chiller to coils loop pump type

Condenser type

Condenser water temperature control Chiller to condenser water loop pump type $\begin{array}{r}\text { Cooling tower type } \\ \hline \text { Boiler fuel }\end{array}$ Boiler to coils loop pump type Supply fan efficiency Supply fan motor efficiency Cooling coil design set point $\left({ }^{\circ} \mathrm{C}\right)$ Heating coil design set point $\left({ }^{\circ} \mathrm{C}\right)$ Heat recovery effectiveness - Sensible Heat recovery effectiveness - Latent Chiller COP Chilled water set point $\left({ }^{\circ} \mathrm{C}\right)$ Condenser water design set point $\left({ }^{\circ} \mathrm{C}\right)$ Boiler efficiency Hot water set point $\left({ }^{\circ} \mathrm{C}\right)$
$76-100 \%$

Thermostat, $\mathrm{CO}_{2}$ Sensor, BMS 15

Water

Water

Draw through

Parallel

Water

Water

Enthalpy

Central air handler

Centrifugal

Constant primary,

variable secondary

Water cooled

Variable, based on outside temperature

Variable

Two speed

Natural gas

Variable

0.7

0.9

15

10

0.75

0.7

4.2

6

30

0.9

80

Tahle 8 Mndelling innıt narameter valıpc: VAV onnd enerov officiency hıilding 
Aspects of both of these systems that are unique for a highly energy efficiency building are the $\mathrm{CO}_{2}$ sensor control, high outdoor air flow rate, water cooled condenser, and high chiller coefficient of performance (COP).

The consensus confirmed that the $\mathrm{CO}_{2}$ sensor is only common in the good energy efficiency building. It is expected that this is because this type of building is more likely to use natural ventilation and the $\mathrm{CO}_{2}$ sensor would control this aspect. In relation to the outdoor air, both HVAC systems have been identified to use a significantly high flow rate; $15 \mathrm{~L} / \mathrm{s} /$ person (Litres per second per person). To put this into context, the New Zealand Standard for ventilation NZS:4303 - acceptable indoor air quality (Standards New Zealand, 1990) recommends a minimum of $10 \mathrm{~L} / \mathrm{s} /$ person.

Other aspects of the HVAC systems that are unique to the good energy efficiency building are the parameters relating to the chiller. Both HVAC systems use a water cooled condenser and therefore have additional parameters that are needed to be modelled. This consists of the cooling tower and the associated pumps. The COP of the chiller is also significantly greater, making it more efficient in comparison to the EnergyPlus default value provided.

\section{Summary of the consensus for the HVAC systems in the poor energy efficiency and common practice building types}

The process of forming the consensus for the good energy efficiency building was the same process used for the poor energy efficiency and common practice building types. The identified likely installed systems were presented to the experts to form a consensus during the second round of questions. As well as forming a consensus on the likely installed HVAC systems, the experts that are involved with simulations were also asked to identify the values for the modelling input parameters. The identified parameters were confirmed with a review of manufacturers' data, and then presented to the experts to form a consensus opinion on the values in the round three questions.

\section{The likely installed HVAC systems}

For the common practice building type, the identified HVAC systems at the end of the first round were clear as two systems had been selected and ranked the highest more than any other type of system. These systems were Variable Air Volume (VAV) and fan coil units. The response rates for each of the systems are displayed in Appendix $\mathrm{H} 1$.

When forming a consensus on these types of systems in the round two questions, a clear conclusive consensus was formed. 16 experts agreed and 2 disagreed with the two types of 50 | P a g e 
systems being likely installed as common practice. The responses when forming the consensus can be seen in Appendix H2. Both of the experts that disagreed with the types of systems did not provide a reasoning of why they disagreed. One of the experts did however suggest that they believe other systems such as chilled beams and VRF (Variable Refrigerant Flow) systems are becoming more common in new buildings.

For the poor energy efficiency building type, the responses from the round one questions did not clearly identify a likely installed HVAC system. From the provided list of common HVAC systems, the responses from the experts formed a fairly even distribution of systems selected; the responses can be seen in Figure 11. Because of the distribution of the initial responses, a clear type of HVAC system for a poor energy efficiency building was not identified. To form a consensus between the experts on the type of HVAC system that is likely to be installed, the three systems that were selected and ranked the highest were presented in the round two questions. These systems were the packaged air handling unit, fan coil units, and split system heat pump.

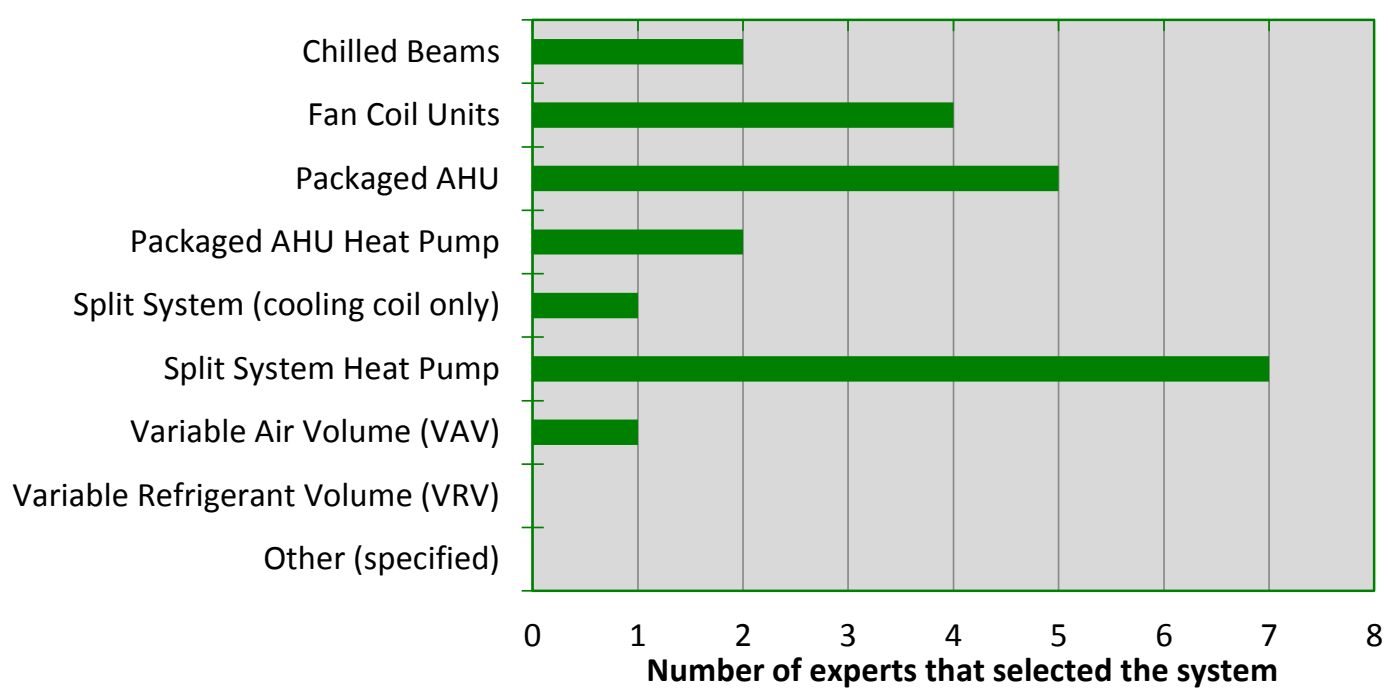

Figure 11. HVAC system types identified for a poor energy efficiency building

The number of experts that agreed upon these three systems in the second round of questions when forming a consensus was low. In total 11 experts agreed on these systems and 7 disagreed. Because the experts that disagreed with the systems were asked to provide reasons for disagreeing, the responses could be analysed to identify why the consensus was not clearly agreeable. With regards to the experts' opinions on the systems that were identified to be likely installed, the responses were primarily in relation to the split system heat pumps and the fan coil units. 
Two of the experts that disagreed with the three systems stated that they agree with the split system heat pumps being installed in a poor energy efficiency building, however they are not intended to be installed in the size of building that this study is focusing on $\left[3,500 \mathrm{~m}^{2}\right]$, they are suited for smaller applications; "although the split system is cost effective, it can offer additional efficiency that is typically not understood by the end user or the installer. If designed correctly, the system can offer a significant efficiency compared to systems with direct electric heating or gas fired boilers". Another of the experts disagreed with the split system heat pumps being in this type of building because the system is "essentially the same as VRF (Variable Refrigerant Flow) systems, which are installed in good energy efficiency buildings".

In respect to the fan coil units, the experts disagreed with this system being likely installed in a poor energy efficiency building type, although only one of the experts provided a reason of why they disagreed. The expert stated that in their professional experience of the system, it is not a system that has poor energy efficiency. Personally, they had recently "completed [designed the system for] at least three, five star GreenStar buildings that have fan coil units; two of which have water cooling and electric heating elements".

The third system that the consensus was confirming was the packaged air handling unit. None of the experts provided any reasoning to disagree with this system. One of the experts commented on how they "expected it to be in the commonly installed building type".

One final comment that was made by an expert was that "nobody purposely makes a less efficient building, it is driven by capital cost and how the system is designed, installed, and commissioned. Different systems are more suitable than others for different building designs". The point that this comment makes, as well as the experience that each expert has, identifies that it is hard to make a conclusive consensus on a poor energy efficiency system as there are many aspects that can affect the efficiency. Because no one purposely designs or installs a HVAC system to have poor energy efficiency, identifying and generalising this type of system is hard to do.

\section{Summary of the installed HVAC systems}

The Delphi method survey has formed a consensus opinion on the most commonly installed HVAC systems for all three building types used in this study. Table 9 summarises the results of the consensus that identified the most commonly installed HVAC systems; the systems are presented in relation to the building type. To clarify how the same systems in different building types vary, the methods used for cooling and heating in the systems are also displayed. The cooling and heating coils types were identified by the experts that are involved with modelling 
of the systems during the round two questions, and a consensus was formed on this aspect in the round three questions.

\begin{tabular}{|c|c|c|c|}
\hline $\begin{array}{c}\text { Building Type } \\
\begin{array}{c}\text { Good Energy } \\
\text { Efficiency }\end{array}\end{array}$ & HVAC System & Cooling coil & Heating Coil \\
\hline Common Practice & VAV & Water & - \\
& VAV & Water & Water \\
\hline $\begin{array}{c}\text { Poor Energy } \\
\text { Efficiency }\end{array}$ & Fan Coil Units & Water & Electric \\
& Packaged AHU & Water & Water \\
\hline
\end{tabular}

Table 9. Summary of the HVAC systems types the consensus formed.

\section{The values of the modelling input parameters}

In round two, after forming a consensus on the likely installed HVAC systems, the experts involved with simulations were asked to identify the values for the modelling input parameters. The process of collecting and assessing this data has been explained using the example of the good energy efficiency building type; this section sums up the responses and consensus that was formed for the poor energy efficiency building and common practice building types.

All of the values for the modelling input parameters that the consensus determined are displayed in Appendix I.

The responses from the round two questions identified that many of the modelling input parameters for the HVAC systems differ from the values that are suggested by default in EnergyPlus. The parameters that differ depend on the type of system and the building that it is associated to. For many of the HVAC systems, the parameters that differ are the outdoor air flow rates, efficiency values of the cooling and heating equipment, and the cooling and heating coil design temperature setpoints.

For all of the HVAC systems in the poor energy efficiency and common practice building types, it was determined that the outdoor air flow rates would be the same; $10 \mathrm{~L} / \mathrm{s} /$ person. This value is slightly greater than the default value provided in EnergyPlus (9.4 L/s/person) and is the minimum allowable by the New Zealand Standard NZS:4304 - acceptable indoor air quality.

Efficiency values for the chillers associated with the fan coil units in both building types were identified to have a lower COP in comparison to the EnergyPlus default values. In contrast to 
this, the boiler efficiencies were greater. The greatest increase in equipment efficiency was with the split system heat pump. The COP for the cooling cycle increased from the default of 3.0 to 4.2 ; and the heating cycle increased from 2.75 to 4.0 .

The design temperature setpoint parameters of the cooling and heating coils were also identified to change from the default values. These values changed by a maximum of four degrees Celsius. When forming a consensus on the HVAC systems, the coil temperature design setpoints were the only parameters that the experts disagreed with and suggested changing. The reasons provided when disagreeing with the values was to avoid performance issues and was suggested based on experiences that the experts had. The experts that disagreed all provided similar reasons and suggested the same alternative values. Because of the similarities of the experts' suggestions, the values were able to be updated without the need for further consultation to form consensus.

A clear consensus was formed with the round three questions for all of the modelling parameter values of the HVAC systems after addressing the design temperature setpoints of the cooling and heating coils. The outcome of the consensus was a set of equipment and performance values that were able to be used to produce a set of HVAC system template models. By using these values to produce a set of HVAC system template models, the models are representative of the designed and installed systems within New Zealand commercial buildings.

After completing the questions in each round of the survey, the experts were provided an opportunity to note any issues or limitations that they had. The assessment of this feedback allowed for questions to be improved and clarified.

\section{Feedback from the experts}

Feedback from the experts at the end of each round of questions was an important aspect of the survey as it identified any limitations and issues that were encountered while completing the questions. This feedback acted as a means of quality control because it determined if the questions could be answered and understood by all of the experts.

\section{Addressing limitations and issues}

At the end of each round of questions, the experts were provided an opportunity to provide feedback regarding any limitations or issues that they had while completing the survey. To assess this aspect, the feedback was reviewed to determine what the limitations or issues were and how it has affected the responses that were provided. 


\section{Round one feedback}

The majority of the feedback that was received at the end of round one was in relation to the HVAC systems and how the efficiency is perceived; the concern was highlighted by six of the experts. The issue is summed up by one of the experts that commented saying that "certain systems can be seen installed in buildings where they're not actually suitable, resulting in poor performance". Another expert commented stating that "the efficiency of a VAV system (or any other system) depends greatly on the design layout and the amount of re-heat needed". This interpretation of what an efficient (or less efficient) HVAC system is could have had a significant influence on the type of system that the experts ranked the most likely installed.

To assess how the interpretation of efficient and less efficient building types has influenced the selection of the HVAC systems, the responses were reviewed after all experts had completed the questions. By tallying the number of responses for each HVAC system, it was assumed that the majority of the experts interpreted the question for the high and poor energy efficiency building type in a similar way due to certain systems being clearly selected the most. Because of the similar responses provided, there was no need to re-assess or change the questions to address the interpretation of the questions in round one.

Another comment stated that they have "no commercial buildings over 3,500 $\mathrm{m}^{2}$ in their location". Although this could have been a potential issue with their knowledge of the type of systems that are likely installed in these sized buildings, a review of their responses identified that they selected the same systems for two of the three building types. For the one building type that they did select a different HVAC system for, their response did not skew the overall responses due to being insignificant in relation to the most selected HVAC system. No action was taken to further address this limitation as it was assumed that this has not affected their knowledge in knowing the most likely installed HVAC systems for large commercial buildings.

\section{Round two feedback}

Four experts provided feedback at the conclusion of the second round of questions. Two of the experts are not involved with simulations while the other two are so therefore had additional questions to identify the modelling input parameters.

For the non-simulators, one of the experts commented that different types of systems could be identified for the same building type depending on it being a low rise - large floor area building, or a high rise with a smaller floor area per storey; both buildings having a total floor area of 3,500 $\mathrm{m}^{2}$ or greater. As there is insufficient data available from the outcomes of the Building Energy End-use Study at this stage, it is unknown if the buildings of this size are more 
likely to be low rise or high rise buildings. The issue raised was therefore unable to be directly answered.

Although this aspect of the building size has not been defined within the survey, the similarities of the responses and being able to form a consensus on the types of HVAC systems have illustrated that this has not been an issue to answer the questions. The survey responses have addressed the aim of the study by determining the types of HVAC systems that are commonly installed in large commercial buildings.

The other non-simulator expert, as well as the two simulator experts, had issues with clarity of the questions. The non-simulator stated that "questions had to be read a couple of time to understand them". A review of their responses did not identify that this affected how they answered the questions as they provided the same responses as others. Both of the simulators stated that the issue was with the interpretation of the temperature set points and whether they are the water temperatures or the off coil air temperatures. To address this issue and ensure that all of the experts interpreted the questions the same way, an email was sent to all experts to clarify this issue. The experts were also provided an opportunity to change their responses if they had already completed the questions.

\section{Round three feedback}

There was no feedback provided at the end of the third round of questions. It was assumed that all limitations and issues previously identified had been adequately addressed.

\section{Responses from experts internationally}

The modelling parameter values were presented to an international audience to receive their input. The purpose of this was to put the HVAC systems and values into context by identifying how they compare to the systems and values that are typically expected to be used in other countries and climates. The responses of the international experts were used to identify if the consensus survey results of this study could be used internationally. Responses were received from Denmark and the United States.

A response from the expert consulted in Denmark commented that "this kind of information is not readily available". Due to the information not being available it could not be determined if the equipment and values used in New Zealand are representative of Denmark too. The expert consulted also stated that in order to know and comment on the equipment types and values collected, engineers and companies would need to be consulted in a similar process as this study has done. 
The expert consulted in the United States (US) was able to provide more detail of how the HVAC systems and the values that are representative of New Zealand relate to the United States. The comments that they provided relate to the difficult task of generalising HVAC systems for building types, the use of chilled beams, how the fan operation differs, and potential issues about the chiller types.

With regards to the types of HVAC systems, "the types of common systems in the US vary by building type"; for this reason it is difficult to define a generalised system and classify it for a building type in the way that this study has done. In addition to the types of buildings and their end-use varying, the climate across the country also significantly changes. Therefore classifications of typical systems would have to be for each state and not generic for the whole country. To emphasise the difference in climate conditions, the temperature design set points of the coils were identified by the experts to be too high and too low for some of the system types. The result of having the lower temperature set points would require "dehumidification, especially in the south-eastern states". It was identified that none of the systems in New Zealand would require additional dehumidification or humidification unless the building was specialised and required it.

The chilled beams that have been identified to be used in good energy efficiency building in New Zealand are not typically used in the US; but a common system that can be found is ground source water-to-water heat pumps. Because this system type was not stated by any of the New Zealand experts, it can be assumed that it is rarely used.

Cycling fan operation of the DX equipment was identified to be the same in the US; however this would not meet the ventilation requirements of ASHRAE Standard 62.1 during occupied hours. To meet this requirement, the fan operation would have to be set to a constant speed with maximum outdoor air flow and then revert back to cycling when unoccupied. The expert also identified that the fan efficiencies, although possible, are too high and would expect them to "be lower for the small supply air fans that are common in fan coil units in comparison to the larger supply air fan in VAV central air handlers and the packaged air handling units".

A potential issue that was raised by the US expert was the types of chillers identified in this study. The consensus determined that centrifugal chillers would be used for all HVAC systems and building types in New Zealand; the majority of the systems have air cooled condensers, while the systems in the good energy efficiency building type have water cooled condensers. The comment received about this was that only the larger buildings in the US use centrifugal chillers and always have water cooled condensers with cooling towers. 


\section{Producing and testing the HVAC template models}

This chapter explains how the consensus responses from the survey were used to produce the HVAC system template models. Concluding the chapter are the results of using the templates in simulations to calculate the monthly energy consumption. The template model results are compared against models which use the default EnergyPlus values in order to illustrate the influence that the updated input parameters have.

All template models are available on the $\mathrm{CD}$ accompanying this thesis.

\section{Producing the HVAC template models}

The template models were produced using EnergyPlus, version 6.0. This section provides a brief description of the values used within the template models and an explanation of how the models are intended to be used.

Using the survey responses to produce EnergyPlus HVAC template models

Each of the HVAC systems that were identified as being commonly installed in New Zealand commercial buildings were modelled in EnergyPlus. The modelling of the HVAC systems was done in two stages; the first stage used the default values within EnergyPlus for each of the HVAC systems modelled, and the second stage updated the default values to the values that were collected in the survey of this study.

The first stage used the existing geometry template models that have previously been produced as an outcome of the Building Energy End-use Study (BEES) (Cory et al., 2009). Within the geometry templates, the types of HVAC systems that have been identified from the responses of the survey in this study were modelled. The HVAC systems in this initial modelling stage used the default values that are within EnergyPlus. The purpose of this modelling stage was to minimise any modelling errors and test that the models were able to be calculated using EnergyPlus.

There are five existing geometry templates, each consisting of a different built form shape. Details of the built forms are explained in Appendix A. Each of the built form geometry template models had the identified HVAC systems assigned to them. Seven different HVAC 
systems were identified as being commonly installed within New Zealand commercial buildings. In total this resulted in 35 template models being produced.

Because of the large number of models needed to represent all of the possible variations, future work may lead to further development of the models to modularise the templates. In this situation, a module is defined as being a standardised independent model that can be used in combination with other modules to construct a complex model (Oxford Dictionary, 2012). By making the models into modules, the number of models available to select from is minimised. An advantage of the systems becoming modules is that they become independent of the built form geometry templates; this allows for additional modules to be developed that can be applied to the geometry templates. For example, solar energy generation systems.

For the second stage of modelling the HVAC systems, the default EnergyPlus values were replaced with the values that have been collected from the survey. Because the updated HVAC system values are based on the responses which formed a consensus by the experts professionally involved with the design and modelling of HVAC systems throughout New Zealand, the values are more reasonable than the default values. This makes the calculated results more representative of the performance that is likely to be found in New Zealand in comparison to what the EnergyPlus default values provide.

\section{The HVAC modelling values collected in the survey}

The modelling parameters and values that were collected in the survey identify the equipment types, efficiency, and other performance aspects of the systems. These were used to update and replace the EnergyPlus default values. A summary of all of the input parameters and the associated modelling values used to construct the HVAC templates are tabulated in Appendix I. For clarity, the parameters and values have been broken down into a table for each system type.

\section{Other modelling input parameters}

The other input parameters for the EnergyPlus templates consist of the geometry, materials and constructions, loads (equipment, lighting, and occupancy), and operational schedules. Respectively, the input parameters used in these aspects of the models can be seen in Appendix B, C, and D.

For a complete understanding of the template models, a summary of the other input are reviewed. 
Geometry: All of the models use the built form geometries that represent common shapes of New Zealand commercial buildings. The built forms are based on Steadman's classification of built forms work (Steadman et al., 2000). In total there are five common built forms that represent New Zealand commercial buildings. All five built forms are summarised in Appendix $A$.

Construction: Concrete is the default construction material for all of the template model surfaces, except for the glazing. A summary of the default constructions in the template models are; floor - concrete slab on ground; walls - Concrete; roof flat trafficable concrete; and windows - clear single glazing with aluminium frames. More detail about the material layers that produce these construction sets can be seen in Appendix B.

Loads: The assigned loads within the template models are currently based on the densities recommended for a modelled reference building using New Zealand building standard NZS4243:Part one and part two (Standards New Zealand, 2007a, Standards New Zealand, 2007b). The loads that are assigned for all zones modelled are; equipment $-8.5 \mathrm{~W} / \mathrm{m}^{2}$; lighting $-12 \mathrm{~W} / \mathrm{m}^{2}$; and occupancy- 0.1 people $/ \mathrm{m}^{2}$.

Schedules: The operational schedules used within the models are based on common office hours. Therefore the majority of loads are on between the hours of 0800 and 1800, Monday to Friday. The HVAC systems are modelled to turn on an hour earlier. A detailed hourly breakdown of the schedules can be seen in Appendix D. These operational and occupancy times are based on the recommended schedules for a reference building in the New Zealand Standard NZS4243:Part one (Standards New Zealand, 2007a).

These input parameters have been assigned as default to the template models. The values do not need to be changed unless the building that is being modelled is significantly different in comparison.

\section{How the HVAC template files are intended to be used}

Copies of the HVAC template models are available on the CD that accompanies this thesis. The models are all in an idf (input data file) format which is readable by EnergyPlus. The idf files contain all of the information that is used by EnergyPlus to do the calculations. The other template models without the HVAC systems assigned are also available on the CD; however 
this explanation of using the models will only focus on how to use the ones with the HVAC systems assigned. The general process is applicable for all of the template models.

The templates can be used for modelling existing or new buildings. The purpose of the template models is to make the modelling of buildings and the associated loads as easy as possible (Cory et al., 2009). This is achieved by minimising the amount of user inputs required to model a building.

Modelling existing buildings is commonly done to match a building's performance in order to test energy conservation measures. When doing this, it is recommended to compare the calculated energy consumption results to the building's actual energy consumption before making any changes to the model. The comparison is done to understand the reliability of the results.

Modelling new buildings is done for a similar reason, to predict the building's energy consumption and performance before being constructed. By modelling the building prior to its construction, various aspects such as equipment and types of HVAC systems can be tested to find the one that provides optimal performance for the building's design. Bojic et al., 2010, and many other studies have shown examples of why testing various equipment and systems is recommended.

\section{Using a template model}

The template files are used in the same way for modelling both existing and new buildings. The process of using the templates is simplified into the following three steps:

1. Select a built form and HVAC system template model and import the idf file into SketchUp using the OpenStudio plug-in.

2. Scale the model to the required building floor plan area and add/subtract any additional storeys if required.

3. Save the idf file and run the calculations using EnergyPlus.

The first step of using the templates uses two additional software packages; Google SketchUp (Google, 2010b) and OpenStudio (National Renewable Energy Laboratory). The geometry built form and HVAC system that best suits the building is selected out of the available model variations. Once selected, the file is imported into Google SketchUp using the OpenStudio plug-in. 
With the idf file imported into SketchUp, the geometry is scaled to the required building floor plan area. If there are additional storeys that need to be added/subtracted, these can be modelled in two ways: either duplicating an intermediate (middle) floor in SketchUp, or by using a zone multiplier using the idf editor (GARD Analytics, 2010). If the modelling option is used, then the newly modelled zones and surfaces need to have their surfaces matched in order for calculations to run successfully. If the zone multiplier method is used, there are no further steps required.

After the model has been scaled to size and any additional storeys added/subtracted, the idf file can be saved and the model can be calculated using EnergyPlus.

The publications by Cory et al., 2009, 2011a, and 2011b explain the development and testing of the original geometry template files. The publications also explain, in more detail, the process of using the template files.

\section{Advanced steps of the template models}

Additional steps can be performed to increase the precision of the template models, however these steps are not essential to make the models reliable. The additional steps are only required if the building being modelled is not constructed like typical New Zealand commercial buildings or is operated in a significantly different way than what is considered typical. These steps are only intended for people experienced with EnergyPlus modelling.

If the building being modelled is not like other typical New Zealand commercial buildings, the input parameters can be updated to better match the building being modelled. To update these parameters, it is recommended to use the idf editor or a text editor. Specific steps or values to use cannot be provided for changing the template model parameters because the changes are specific to the building being modelled. However, examples and reasons of why the parameters would be updated include:

- The materials and construction sets for the building being modelled vary from the default of concrete;

- Loads for equipment, lighting, or occupancy are significantly different than the template values;

- The building is not operated during common office hours because of the occupied use of it;

- And the supply air temperature setpoints in the building are outside of the values provided in the templates. 


\section{The influence of updating the modelling parameters}

From the survey, consensus was formed for two primary outcomes; the identification of the most commonly used HVAC systems within New Zealand commercial buildings and the input parameter values that are used when modelling the systems. Using the consensus results, a set of HVAC template models have been created which replaces the default EnergyPlus values. The input parameter values used to model the seven commonly used HVAC systems are tabulated in Appendix I. The modelling parameters that have changed in the models vary between the different systems and the building types.

This section explains how the updated values used in the template models have influenced the performance of the HVAC systems when calculating energy consumption. The difference in calculated energy consumption between using the default EnergyPlus values and the produced template model values (using the survey results) illustrate the significance of this study. All of the energy consumption values in this chapter relate only to the HVAC energy unless stated otherwise.

\section{Comparing the results of software default values and the HVAC} template values

To compare the influence of changing the default modelling input parameters to the values collected in the survey, two assessments were used;

1. Comparing the difference in performance for annual and monthly energy consumption;

2. Identifying the influence the climate conditions have on the change in energy performance.

Assessment one is a comparison of energy consumption results calculated in EnergyPlus when changing the HVAC default values to the values collected in the surveys. This assessment used the Wellington weather file in the simulation. The second assessment also compares the difference in performance between the default values and the collected values but uses two additional climate weather files; one that is typically cooler (Christchurch) and one that is typically warmer (Auckland). The results using these additional climates, in comparison to the Wellington results. The climate assessment was used to identify if the climate has an influence on the over change in the performance of the systems.

The two assessments use the seven HVAC system types; the five built form geometry models (explained in Appendix A); all using the same total floor area of 3,500 $\mathrm{m}^{2}$. 


\section{Annual and Monthly Energy Performance Difference}

The large open plan built form geometry model is used as an example to illustrate the influence that the new modelling parameter values have on the calculated energy consumption. The three storey built form geometry has core zones which are cooling loads dominated and perimeter zones that are affected more from the external environment so require cooling loads (during summer months) and heating loads (during winter months). The results that are illustrated in Table 10 show the building's total annual HVAC energy consumption (in $\mathrm{kWh} / \mathrm{m}^{2} / \mathrm{yr}$ ) when calculated using a Wellington weather file. Comparing the results of using the default EnergyPlus modelling parameters and the collected template values, it is clear that the template values result in a performance difference; Variable Air Volume (VAV) systems have the most significant difference.

\begin{tabular}{|c|c|c|c|c|c|c|c|}
\hline & \multicolumn{2}{|c|}{$\begin{array}{l}\text { Good Energy } \\
\text { Efficiency }\end{array}$} & \multicolumn{2}{|c|}{ Common Practice } & \multicolumn{3}{|c|}{ Poor Energy Efficiency } \\
\hline & $\begin{array}{l}\text { Chilled } \\
\text { Beams }\end{array}$ & VAV & $\begin{array}{l}\text { VAV - } \\
\text { Electric }\end{array}$ & $\begin{array}{c}\text { Fan Coil } \\
\text { Unit }\end{array}$ & $\begin{array}{c}\text { Fan Coil } \\
\text { Unit }\end{array}$ & $\begin{array}{c}\text { Package } \\
\text { AHU }\end{array}$ & $\begin{array}{l}\text { Split } \\
\text { System }\end{array}$ \\
\hline Default & 19.70 & 152.65 & 134.35 & 36.67 & 36.67 & 19.42 & 12.71 \\
\hline Template & 18.77 & 106.79 & 76.10 & 36.31 & 37.90 & 19.55 & 10.33 \\
\hline Difference & $-4.7 \%$ & $-30.0 \%$ & $-43.4 \%$ & $-1.0 \%$ & $3.4 \%$ & $0.6 \%$ & $-18.7 \%$ \\
\hline
\end{tabular}

Energy consumption results are in $\mathrm{kWh} / \mathrm{m}^{2} / \mathrm{yr}$

Table 10. Annual energy consumption difference for OP5 built form in Wellington.

Negative values in Table 10 mean that the template modelling parameters are resulting in the HVAC system to be more efficient (using less energy) than the default modelling parameters. The system with the greatest energy consumption difference was the VAV systems for both the high efficiency and common practice building types. For these HVAC systems, the template modelling parameter values result in the model using between $45-60 \mathrm{kWh} / \mathrm{m}^{2} /$ year less annual energy than the default EnergyPlus values, a difference of up to $43 \%$. In comparison to the default value systems, five of the seven systems consumed less energy when using the template modelling values; for the two systems that consumed more energy as a result of using the updated modelling parameters, this was no more than $3.4 \%$ more.

With less energy calculated for the majority of systems, it is known that the template values which represent common New Zealand HVAC systems are more efficient than the default EnergyPlus values. To further understand the difference in the systems, a monthly comparison of the energy is illustrated to show how the seasonal changes influence the performance. 


\begin{tabular}{|c|c|c|c|c|c|c|c|}
\hline & \multicolumn{2}{|c|}{ Good Energy Efficiency } & \multicolumn{2}{|c|}{ Common Practice } & \multicolumn{3}{|c|}{ Poor Energy Efficiency } \\
\hline & Chilled Beams & VAV & VAV - Electric & Fan Coil Unit & Fan Coil Unit & Package AHU & Split System \\
\hline Jan & $-15 \%$ & $34 \%$ & $-4 \%$ & $8 \%$ & $8 \%$ & $0 \%$ & $-23 \%$ \\
\hline$\overline{F e b}$ & $-13 \%$ & $28 \%$ & $-8 \%$ & $7 \%$ & $8 \%$ & $0 \%$ & $-23 \%$ \\
\hline$\overline{\text { Mar }}$ & $-9 \%$ & $3 \%$ & $-2 \phi \%$ & $4 \%$ & $5 \%$ & $0 \%$ & $-21 \%$ \\
\hline Apr & $-6 \%$ & $-2 \phi \%$ & $-40 \%$ & $1 \%$ & $4 \%$ & $0 \%$ & $-19 \%$ \\
\hline May & $-3 \%$ & $-38 \%$ & $-49 \%$ & $-2 \%$ & $2 \%$ & $1 \%$ & $-16 \%$ \\
\hline Jun & $0 \%$ & $-51 \%$ & $-55 \%$ & $-3 \%$ & $3 \%$ & $1 \%$ & $-18 \%$ \\
\hline Jul & $0 \%$ & $-54 \%$ & $-5 \not \% \%$ & $-4 \%$ & $2 \%$ & $1 \%$ & $-18 \%$ \\
\hline Aug & $-1 \%$ & $-50 \%$ & $-54 \%$ & $-3 \%$ & $2 \%$ & $1 \%$ & $-17 \%$ \\
\hline Sep & $-2 \%$ & $-41 \%$ & $-51 \%$ & $-3 \%$ & $2 \%$ & $1 \%$ & $-16 \%$ \\
\hline Oct & $-7 \%$ & $-26 \%$ & $-44 \%$ & $-1 \%$ & $3 \%$ & $1 \%$ & $-18 \%$ \\
\hline Nov & $-12 \%$ & $-4 \%$ & $-32 \%$ & $3 \%$ & $5 \%$ & $0 \%$ & $-20 \%$ \\
\hline Dec & $-14 \%$ & $3 \%$ & $-15 \%$ & $8 \%$ & $7 \%$ & $0 \%$ & $-23 \%$ \\
\hline
\end{tabular}

Table 11. Monthly HVAC energy difference for OP5 Built form in Wellington.

The results that are illustrated in Table 11 show the percentage of monthly HVAC energy consumption difference between the default values and the template values; negative percentage values indicate less energy being consumed by the template models. For the OP5 built form, it is clear that there is a connection between the external climate temperatures and the performance of the HVAC systems, in particular the VAV and chilled beam systems. For the VAV systems, during the winter months when there is a high heating energy demand, the energy consumption is $50-60 \%$ more efficient in comparison to using the default EnergyPlus modelling parameter values. However for the VAV system in a high efficiency building, the cooling loads are resulting in more energy consumed with using the template modelling parameters. One change in the modelling parameters that would result in the higher cooling loads is the outside air ventilation rate being changed from the default $9.4 \mathrm{~L} / \mathrm{s} /$ person to $15 \mathrm{~L} / \mathrm{s} /$ person.

In contrast to this, the chilled beams system uses equal energy during the winter months but uses less energy during summer months when there are high cooling loads required. This suggests the chiller performance has a significant influence on the overall system. The default EnergyPlus parameters for the Coefficient Of Performance (COP) for the chiller is 3.2; the collected template value is 4.2 .

The other climates tested show the same trends for all HVAC systems; however the built form has an influence on monthly performance. Refer to Appendix $J$ for the results of all built form models in the three tested climates. 


\section{How different NZ climates influence the change in performance}

To illustrate the influence that the climate has on the difference in energy consumption, the two VAV systems are used as an example. This is because these systems have been identified to result in the greatest annual and monthly energy consumption differences.

Table 12 shows the annual energy consumption difference of how more or less energy the template models consume in comparison to the models using default values. The comparison in Table 12 illustrates how the built form and climate influences the performance of the two VAV systems; all built forms used the same total floor area. These results show that the climate conditions and built form can have a significant influence on the performance for the HVAC systems. With the results in Auckland not having the greatest change in energy consumption, this indicates that the updated modelling parameters relating to the cooling aspects do not result in large annual energy changes. Complementing this outcome are the results in the cooler climates which are using significantly less energy in comparison.

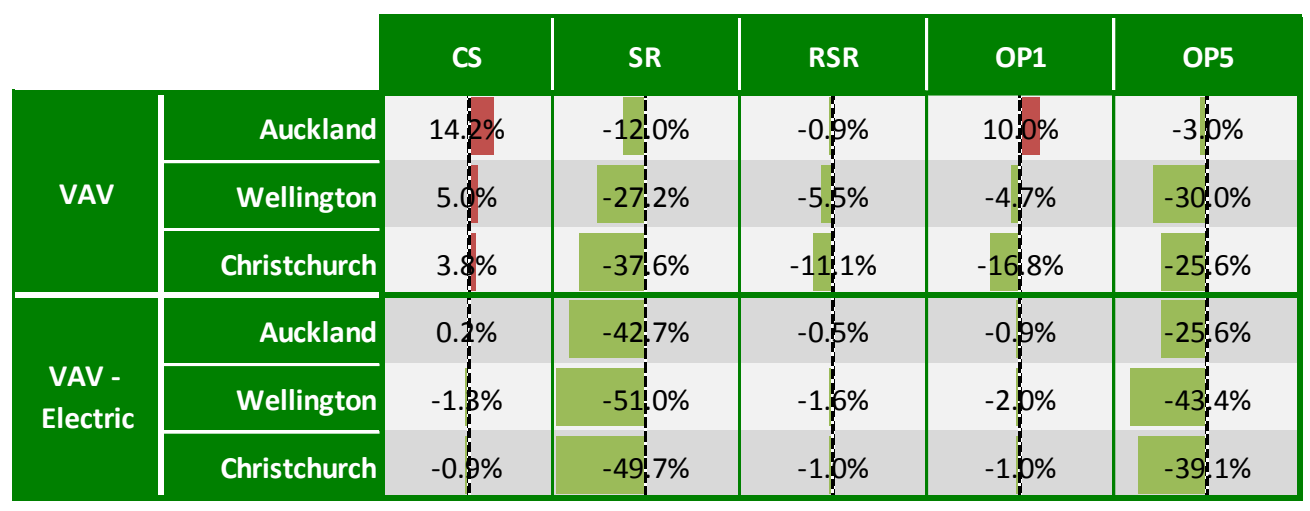

Table 12. How climate and built form influences the performance of the template models.

Appendix J illustrates the other HVAC systems that have been tested and compares them in relation to the three climates and the five built forms. Each comparison is grouped in terms of the built form. The example of the VAV systems in Table 12 show the greatest variation where comparing the energy difference in relation to either to climate or built form.

When taking into account the influence that the built form has on the results, it is clear that not all built forms result in the same performance differences. This is due to the distribution of floor area and the number of zones within the built forms as well as the amount of wall area that is directly connected to outside. Overall, the built forms with smaller thermal zones have less of a difference in HVAC energy consumption; this suggests that the difference in performance that will be experienced when using the template parameters is dependent on the heating and cooling capacity size of the system. This was initially advised by one of the 
survey participants who commented that "the efficiency of a VAV system (or any other system) depends greatly on the building design layout".

To summarise and put the difference in monthly and annual energy consumption values into context, when calibrating an energy calculation model against real building performance data, an acceptable tolerance for accuracy is $\pm 5 \%$ for monthly data or $\pm 10 \%$ for hourly data (ASHRAE Standard, 2002); no tolerance is provided for annual results. Due to the influence of using the updated modelling parameter values, the new parameters could be the cause of the model being calibrated within an acceptable tolerance or not for New Zealand conditions. 


\section{Conclusions}

The primary aim of this study was to collect information on Heating, Ventilation, and Air Conditioning (HVAC) systems that are representative of New Zealand commercial buildings. This aim was achieved and the outcomes are documented for the likely installed HVAC systems in New Zealand commercial buildings; this includes the associated modelling parameters and performance values. To accompany the collected data, a set of HVAC system template models were produced using EnergyPlus.

To conclude this study, three aspects are discussed; the success of the survey, the significance of the collected data, and the availability of the HVAC template models.

\section{Success of the survey - What information was able to be collected?}

The information that was able to be collected and the produced outcomes were used as a measure to determine the success of the survey; this is put into context of the aim of the study. The aim of the study was to collect information of HVAC systems that would be representative of the commonly used systems within New Zealand commercial buildings. To collect the information that was able to determine the most commonly installed HVAC systems and the values used for the modelling input parameters, a Delphi survey was used. A review of surveying methods determined that a Delphi survey would be an appropriate method of data collection as it would be able to achieve the aims of this study. By using the Delphi survey, the panel of experts that were consulted were able to easily form a consensus opinion on the given topic while providing reliable responses. The responses were known to be reliable because the experts that participated are involved with the design and/or installation of HVAC systems as well as being members of a relevant professional association.

To ensure that the collected information was representative of the commonly used systems, the experts consulted are located throughout the country. The survey allowed for the location of the experts to not be an issue as it was administered online. The advantages of using an online survey included the ability to administer it faster and it provided a high level of anonymity between the experts that participated. To address issues commonly associated with online surveys, such as misrepresentation of reality; this study did not allow non-experts to participate.

At the conclusion of the survey, the outcome was a set of data that determined what the most commonly installed HVAC systems are for three building types: good energy efficiency, 
common practice, and poor energy efficiency buildings. As well as identifying the system types, the modelling input parameter values that best represented the systems were also determined. The intention of collecting the modelling input parameter values was to be able to produce a set of HVAC system template models within EnergyPlus. To ensure that the template models could be produced, the survey questions were designed based on the modelling input parameters that are used by EnergyPlus. This allowed for the collected data to be directly useable in EnergyPlus.

The outcomes of the survey prove that it has been a successful method of data collection as the aim of this study was able to be met. After producing the HVAC system template models, the influence that the new values have on energy calculations in comparison to the default values was assessed to determine the significance of the collected data.

\section{Significance of the collected data}

The significance of the collected data was measured through comparing the influence that the new modelling parameters have on the calculated energy consumption on a building model. As well as this, experts were consulted internationally to identify and determine the likelihood of the collected information being representative of other climate locations.

Comparing the calculated energy consumption of a building energy model using the EnergyPlus default values and the values collected in this study identified that the Variable Air Volume (VAV) systems had the greatest difference. A difference of up to $45 \%$ in monthly energy consumption was calculated. It was identified that the difference in energy consumption is a result of the collected values having a significantly greater outdoor air flow rate and more efficient modelling values.

All of the other HVAC systems were tested the same way to identify the influence that the updated modelling parameter values have in comparison to the EnergyPlus default values. The calculated results identified that differences are approximately $\pm 5 \%$ of the monthly energy consumption. The significance of how much difference in energy consumption the updated modelling parameters have is measured by using the acceptable tolerance of accuracy for a calibrated energy model and determined by ASHRAE Guideline 14:2002; an acceptable tolerance of accuracy is $\pm 5 \%$ for monthly energy data. Because the influence that the updated parameters is approximately $\pm 5 \%$, this difference could result in the model being considered calibrated to an acceptable tolerance or not. 
In addition to the comparison of the energy consumption difference, the feedback that was received from consulting with experts internationally was also used to illustrate the significance of the collected data. Through doing this, it was determined if the HVAC systems and modelling parameters are representative of other climates and locations. Feedback was received from an expert in Denmark and one in the United States (US). The outcomes of their feedback identified that, for Denmark, the type of information is not available to make any valid comparisons; however more detail was provided from the US. In the US, because of the size of the country the climate varies which results in generic HVAC systems not being able to be identified as being typical.

\section{Availability of the HVAC system template models}

One of the methods used to make the values for the modelling input parameters available was by producing a set of HVAC system template models. By using the values that were collected in this study, the models are representative of the most commonly used systems in New Zealand commercial buildings. EnergyPlus was used to produce the template models. In conclusion of how the HVAC system template models were produced, an overview of how the models are intended to be used was explained.

In summary of the template models, the HVAC systems are assigned to each of the built form geometries that are representative of commercial buildings as outlined in (Cory et al., 2011b). A separate set of template files without any geometry modelled were also produced. Both types of template files are available on the $C D$ that accompanies this thesis. 
72 | P a g e 


\section{Future work}

To complement the work of this study, aspects that were not included within the scope can be further developed; this primarily focuses on the template models.

Through comparing the calculated energy consumption of the template models using the collected modelling input parameter values and the EnergyPlus default parameter values, it was identified that the difference in energy consumption could range up to, at the worst case $45 \%$ monthly; this was for the Variable Air Volume (VAV) systems. All other systems had a monthly difference of less than $5 \%$. Because of the variation in the energy consumption that was calculated between the template values and the EnergyPlus default values, it would be recommended that the parameters of HVAC systems not covered in this study should be collected.

One aspect that is not included within the scope of this study was to test the produced HVAC template models against real building performance data. Testing the HVAC template models against real building performance data will help identify the accuracy and reliability of the models. In turn, this will confirm the reliability of the models by showing how well they can match a real building's performance. An example study of this without the HVAC templates assigned is documented in Cory et al. 2011a.

Further development of the HVAC template models will be to modularise the way they are constructed. By standardising the way the zones are named within the geometry template models, the HVAC system templates can be constructed as independent modules that can be assigned to the geometry as the modeller requires. By doing this, the number of available models is reduced due to all possible combinations not needing to be pre-constructed. Additional modules will also be able to be developed in a similar way; for example, solar energy generation systems and lifecycle economic calculations. Creating modules will also allow for an automated process to be developed for assigning the modules to the geometry.

Although not directly related to this study; as the BEES team complete the data collection and analysis stages of their study, the equipment and lighting loads, occupancy numbers, and the operational schedules that are likely for New Zealand commercial buildings will be known. These values will be able to be updated within the existing geometry template models. Updating these values will make the models more representative of the actual performance of commercial buildings throughout New Zealand. The conclusion of the BEES project is expected to be in the year 2013 (Isaacs et al., 2009). 
74 | P a g e 


\section{Bibliography}

\section{Literature}

\section{ASHRAE STANDARD. 2002.}

Guideline 14. Measurement of energy and demand savings. Atlanta, GA, United States: American Society of Heating, Refrigerating, and Air-Conditioning Engineers, Inc.

\section{ASHRAE STANDARD. 2004a.}

Standard 62.1 - Ventilation for acceptable indoor air quality. Heating, Ventilation, and Air Conditioning. Atlanta, GA, United States: American Society of Heating, Refrigerating, and Air-Conditioning Engineers, Inc.

\section{ASHRAE STANDARD. 2004b.}

Standard 90.1 - Energy standard for buildings except low-rise residential buildings. Heating, Ventilation, and Air Conditioning. Atlanta, GA, United States: American Society of Heating, Refrigerating, and Air-Conditioning Engineers, Inc.

BARBOSA, R. M. \& MENDES, N. 2008.

Combined simulation of central HVAC systems with a whole-building hygrothermal model. Energy and Buildings, 40. pg 276-288.

BASARKAR, M., PANG, X., WANG, L., HAVES, P. \& HONG, T. 2011.

Modeling and simulation of HVAC faults in EnergyPlus. 12th Conference of International Building Performance Simulation Association, 2011. Sydney, Australia. pg 2897-2903.

BETHLEHEM, J. 2008.

Can We Make Official Statistics with Self-Selection Web Surveys? Component of Statistics Canada's International Symposium Series, 2008. 8.

BETHLEHEM, J. 2010.

Selection Bias in Web Surveys. International Statistical Review, 78. pg 161-188.

BOJIC, M., NIKOLIC, N., NIKOLIC, D., SKERLIC, J. \& MILETIC, I. 2010.

A simulation appraisal of performance of different HVAC systems in an office building. Energy and Buildings, In Press, Corrected Proof.

BRANZ. 2011.

Building Energy End-use Study (BEES) [Online].

Available: http://www.branz.co.nz/cms display.php?sn=126\&st=1

[Accessed 28/November/2011].

\section{BRECSU 2000.}

Energy use in offices. Energy consumption guide 19.

\section{COOMBER, R. 1997.}

Using the internet for survey research [Online]. Sociological Research Online.

Available: http://socresonline.org.uk/2/2/2.html

[Accessed 27/September/2011]. 
CORY, S., CHI-YAO, H. \& DONN, M. 2009.

Template files for commercial building stock energy simulations in New Zealand, Wellington; New Zealand, Victoria University of Wellington.

CORY, S., GATES, A. \& DONN, M. 2011a.

The creation of generic energy simulation models which represent typical commercial buildings and their calibration against real energy data. 12th Conference of International Building Performance Simulation Association, 2011. Sydney, Australia. pg 1473-1480.

CORY, S., GATES, A. \& DONN, M. 2011b.

BEES for energy modelling [Online]. BRANZ.

Available: http://www.branz.co.nz/cms display.php?sn=169\&st=1\&pg=7067

[Accessed 20/Decemeber/2011].

COUPER, M. P. 2000.

Review: Web Surveys: A Review of Issues and Approaches. The Public Opinion Quarterly, 64. pg 464-494.

CRAWLEY, D. B., HAND, J. W., KUMMERT, M. \& GRIFFITH, B. T. 2008.

Contrasting the capabilities of building energy performance simulation programs. Building and Environment, 43. pg 661-673.

CRAWLEY, D. B., LAWRIE, L. K., WINKELMANN, F. C., BUHL, W. F., HUANG, Y. J., PEDERSEN, C. O., STRAND, R. K., LIESEN, R. J., FISHER, D. E., WITTE, M. J. \& GLAZER, J. 2001.

EnergyPlus: creating a new-generation building energy simulation program. Energy and Buildings, 33. pg 319-331.

CUHLS, K. 2004.

Delphi Method. Foresight Methodologies. Vienna, Austria: United Nations Industrial Development Organisation.

DENSCOMBE, M. 2007.

The good research guide for small-scale social research projects, Maidenhead, Berkshire, England, Open University Press.

DEPARTMENT OF BUILDING AND HOUSING. 2009.

Building regulations 1992. Amended 2009. Wellington, New Zealand: Department of Building and Housing.

EMANZ. 2009.

Energy Management Association of New Zealand. [Online].

Available: http://www.emanz.org.nz/

[Accessed 30/March/2012].

ENERGYPLUS. 2010.

Input output reference. The encyclopedic reference to EnergyPlus.

ENERGYPLUS. 2011.

Engineering reference: The reference to EnergyPlus calculations. 
EVALSED. 2009.

Delphi survey. Evaluating socio economic development, Sourcebook 2: Methods \& techniques

FOX, J., MURRAY, C. \& WARM, A. 2003.

Conducting research using web-based questionnaires: Practical, methodological, and ethical considerations. International Journal of Social Research Methodology, 6. pg 167-180.

GORDON, T. J. 1994.

The Delphi Method. Future Research Methodology, 3.0.

HAVES, P. 2010.

Development of a GUI for EnergyPlus. Lawrence Berkeley National Laboratory.

HENNINGER, R. H., WITTE, M. J. \& CRAWLEY, D. B. 2003.

Experience testing EnergyPlus with the IEA HVAC BESTEST E100-E200 series. Eighth international IBPSA conference - Building simulation, 2003. Eindhoven, Netherlands. pg 467-474.

HENNINGER, R. H., WITTE, M. J. \& CRAWLEY, D. B. 2004.

Analytical and comparative testing of EnergyPlus using IEA HVAC BESTEST E100-E200 test suite. Energy and Buildings, 36. pg 855-863.

INTERNATIONAL ENERGY AGENCY. 2012.

Solar Heating and Cooling Programme Task 40 - ECBCS Annex 52 - Participants [Online]. International Energy Agency.

Available: http://iea-shc.org/task40/

[Accessed 05/March/2012].

IRHACE. 2012.

Institue of Refrigeration, Heating \& Air Conditioning Engineers. [Online]. Available: http://www.irhace.org.nz/membership/membership-application/ [Accessed 30/March/2012].

ISAACS, N. 2009.

BEES investigates commercial building energy and water. Build. pg 40-41.

ISAACS, N., SAVILLE-SMITH, K., BABYLON, M., BISHOP, R., CAMILLERI, M., DONN, M., JOWETT, J., MOORE, D. \& ROBERTI, H. 2010.

Building Energy End-use Study (BEES) year 3.

ISAACS, N., SAVILLE-SMITH, K., BISHOP, R., CAMILLERI, M., JOWETT, J., HILLS, A., MOORE, D., BABYLON, M., DONN, M., HEINRICH, M. \& ROBERTI, H. 2009.

Building Energy End-use Study (BEES) years 1\& 2.

ITRON Inc 2006.

California commercial end-use survey. California Energy Commission.

KEMA \& ECNZ. 2007.

New Zealand electric energy-efficiency potential study; Volume 1. 
LEBRUN, J. 1994.

Simulation of HVAC systems. Renewable Energy, 5, 1151-1158.

MURAKAMI, S., LEVINE, M. D., YOSHINO, H., INOUE, T., IKAGA, T., SHIMODA, Y., MIURA, S., SERA, T., NISHIO, M., SAKAMOTO, Y. \& FUJISAKI, W. 2009.

Overview of energy consumption and GHC mitigation technologies in the building sector of Japan. Energy efficiency, 2. pg 179-194.

NAKAGOMI, C., TANAKA, A., OHASHI, H. \& NAKAGAMI, H. 2001.

Energy consumption measurement survey for commercial buildings in Japan - The existence of stand-by electricity. Jyukankyo Research Institute.

NEW ZEALAND GREEN BUILDING COUNCIL. 2011.

About Green Star [Online].

Available: http://www.nzgbc.org.nz/

[Accessed 11/March/2012].

NEYMARK, J. \& JUDKOFF, R. 2002.

International Energy Agency Building Energy Simulation Test and Diagnostic Method for Heating, Ventilating, and Air-Conditioning Equipment Models (HVAC BESTEST); Volume 1: Cases E100-E200.

NEYMARK, J., JUDKOFF, R., KNABE, G., LE, H. T., DURIG, M., GLASS, A. \& ZWEIFEL, G. 2001. HVAC BESTEST: a procedure for testing the ability of whole building energy simulation programs to model space conditioning equipment, National Renewable Energy Laboratory.

NIELSEN, J. 2006.

Quantitative studies: How many users to test? [Online].

Available: http://www.useit.com/alertbox/quantitative testing.html

[Accessed 6/May/2011].

OKOLI, C. \& PAWLOWSKI, S. D. 2004.

The Delphi method as a research tool: an example, design considerations and applications. Information \& Management, 42. pg 15-29.

OXFORD DICTIONARY. 2011.

Expert [Online]. Oxford University Press.

Available: http://english.oxforddictionaries.com/definition/expert

[Accessed 12/September/2011].

OXFORD DICTIONARY. 2012.

Module [Online]. Oxford University Press.

Available: http://english.oxforddictionaries.com/definition/module

[Accessed 27/March/2012].

PALIWODA, S. J. 1983.

Predicting the future using Delphi. Management Decision, 21. pg 31-38.

PEREZ-LOMBARD, L., ORTIZ, J. \& MAESTRE, I. R. 2011.

The map of energy flow in HVAC systems. Applied Energy, 88. pg 5020-5031. 
STANDARDS NEW ZEALAND. 1990.

NZS 4303 - Ventilation for acceptable indoor air quality. Wellington, New Zealand: Standards Association of New Zealand.

STANDARDS NEW ZEALAND. 2007a.

NZS 4243 Energy efficiency - Large buildings. Part 1: Building thermal envelope. Wellington, New Zealand: Standards Association of New Zealand.

\section{STANDARDS NEW ZEALAND 2007b.}

NZS 4243 Energy efficiency - Large buildings. Part 2: Lighting. Wellington, New Zealand: Standards Association of New Zealand.

STEADMAN, P., BRUHNS, H. R., HOLTIER, S. \& GAKOVIC, B. 2000.

A classification of built forms. Environmental and Planning B: Planning and design, 27. pg 73-91.

THE INSTITUTE IN ENERGY ECONOMICS OF JAPAN 2006.

EDMC handbook of energy \& economic statistics in Japan.

TORCELLINI, P., DERU, M., GRIFFITH, B., BENNE, K., HALVERSON, M., WINIARSKI, D. \& CRAWLEY, D. B. 2008.

DOE comercial building benchmark models. In: U.S DEPARTMENT OF ENERGY (ed.). National Renewable Energy Laboratory.

TRČKA, M. \& HENSEN, J. L. M. 2010.

Overview of HVAC system simulation. Automation in Construction, 19. pg 93-99.

U.S DEPARTMENT OF ENERGY. 2011.

About EnergyPlus [Online].

Available: http://apps1.eere.energy.gov/buildings/energyplus/energyplus about.cfm

[Accessed 30/January/2012].

WANG, H. C. \& DOONG, H. S. 2007.

Validation in Internet Survey Research: Reviews and Future Suggestions. 40th annual Hawaii International Conference on System Sciences, 2007. Hawaii, United States.

WITTE, M. J., HENNINGER, R. H., GLAZER, J. \& CRAWLEY, D. B. 2001.

Testing and validation of a new building energy simulation program. Seventh Internation IBPSA Conference - Building simulation, 2001. Rio de Janiero, Brazil. pg 353-359.

WOUDENBERG, F. 1991.

An evaluation of Delphi. Technological Forecasting and Social Change, 40. pg 131-150. 


\section{Software}

\section{IDF Editor.}

GARD ANALYTICS. 2010. Version 1.38a.

Google Earth.

GOOGLE. 2010a. Version 5.2.1.1588.

Google SketchUp Pro.

GOOGLE 2010b. Version 8.0.4811.

Google Streetview.

GOOGLE. 2011.

[Online]. Available: http://maps.google.com

\section{EnergyPlus.}

LAWRENCE BERKELEY NATIONAL LABORATORY. 2010. Version 6.0.

\section{OpenStudio.}

NATIONAL RENEWABLE ENERGY LABORATORY. Version 0.5.0.

\section{Qualtrics Survey Tool.}

QUALTRICS Inc. 2011.

[Online]. Available: https://vuw.qualtrics.com 


\section{Appendices}

\section{Appendix A - BEES geometry template models}

Images and descriptions of the models are all sourced from (Cory et al., 2011a).

\section{SINGLE ROOM FORM}

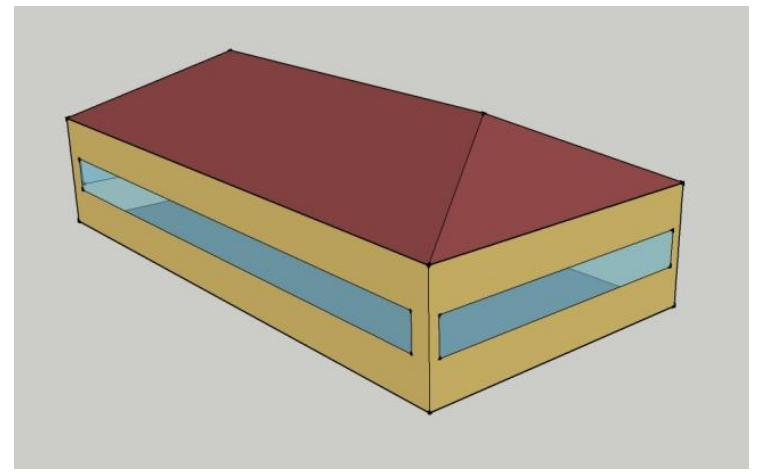

(SR) - This form represents an open planned space that is a stand-alone single storey building. This template would be used when an existing or proposed building has these characteristics.

\section{ROW OF SINGLE ROOM FORMS}

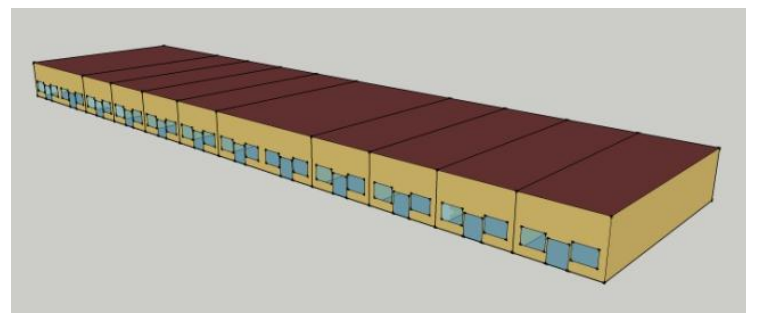

(RSR) - The string of single-room form represents a row of single or multi-storey connected buildings. This template would be used when modelling a building(s) within the row.

\section{$\underline{\text { CELLUAR STRIP }}$}

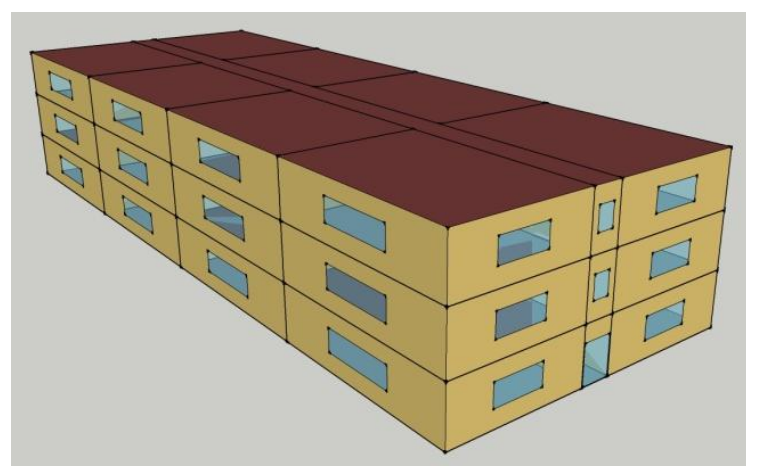

(CS) - The day lit cellular strip template represents a multi-storeyed building with cellular zones. An example of this would be a multi premised office building with internal communal transition space. 


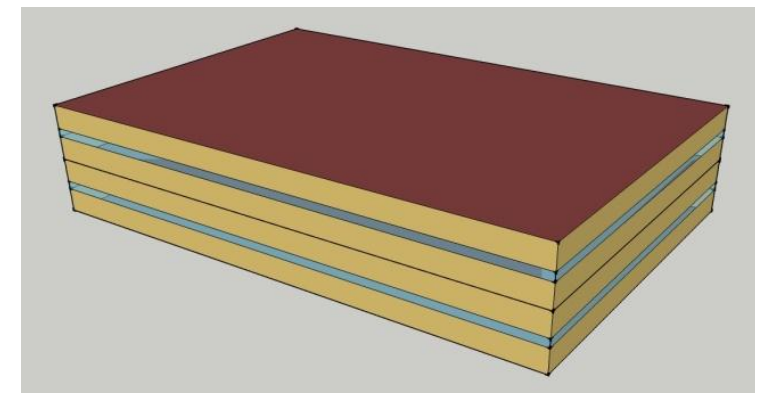

\section{LARGE OPEN PLAN}

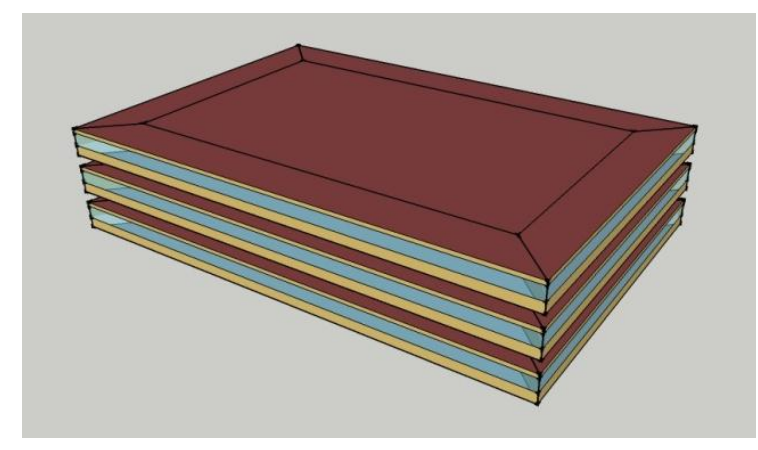

(OP5) - This template represents large multi-storeyed open planned buildings that are daylit and stand-alone. This template would be used if the building has a width and depth that is $14 \mathrm{~m}$ or more. This means, the perimeter zones are no bigger or no smaller than $7 \mathrm{~m}$ in depth. This is typically regarded as the depth where daylight and solar radiation stops having a significant impact on the space. The use of four perimeter zones and a core zone represents a real large open-planned building in more accuracy. This is due to the core being conditioned and having different thermal loads when compared to the perimeter zones. The template would be chosen to model a single building that has these characteristics. 


\section{Appendix B - Template models: assigned materials and construction}

The construction sets that are assigned to all of the template models as default are displayed in Table 13. The primary material for each construction set is concrete.

The material layers that make the construction sets are listed in order from the external surface to the internal surface.

\begin{tabular}{|c|c|c|}
\hline Surface Element & Default Construction & Material layers \\
\hline Exterior Walls & Concrete wall & $\begin{array}{l}\text { Reinforced concrete, } \\
\text { Air gap, } \\
\text { Plasterboard. }\end{array}$ \\
\hline Interior Walls & Internal wall & $\begin{array}{l}\text { Plasterboard, } \\
\text { Air gap, } \\
\text { Plasterboard. }\end{array}$ \\
\hline Roof & Flat trafficable roof - concrete & $\begin{array}{l}\text { Gravel, } \\
\text { Membrane, } \\
\text { Air gap, } \\
\text { Concrete. }\end{array}$ \\
\hline Floor & Ground concrete slab & $\begin{array}{l}\text { Soil, } \\
\text { Reinforced concrete, } \\
\text { Carpet. }\end{array}$ \\
\hline Intermediate floor/ceiling & Intermediate floor/ceil - concrete & $\begin{array}{l}\text { Concrete slab, } \\
\text { Carpet. }\end{array}$ \\
\hline Windows & Single Glaze Aluminium frame & $\begin{array}{l}\text { Clear glazing, } \\
\text { Aluminium framing. }\end{array}$ \\
\hline
\end{tabular}

Table 13. Assigned materials and constructions in the template models. 


\section{Appendix C - Template models: assigned loads}

All of the template files use the energy loads that are recommended by the New Zealand Standard NZS4243: Energy efficiency - Large buildings, parts one and two.

The values provided are energy intensities of Watts of electricity and number of people per square meter of floor area; the values are assigned to every zone within the building model geometry. Appendix D contains the schedules of when these loads are in operation.

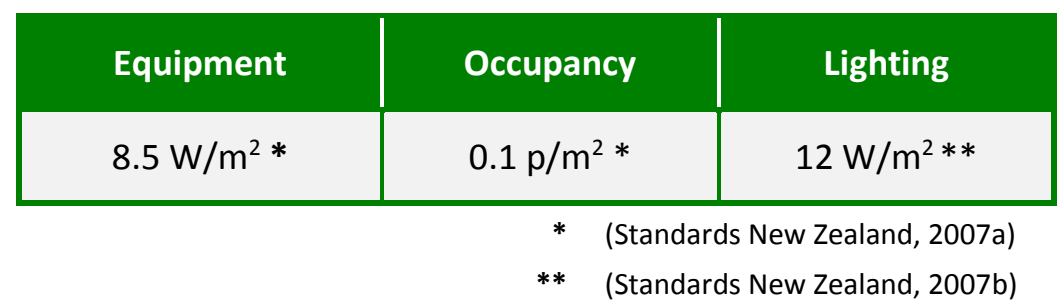

Table 14. Assigned loads in the template models. 


\section{Appendix D - Template models: assigned operational schedules}

The operational schedules for equipment, lighting, occupancy, and HVAC are applied to all of the template models. The values originate from the reference office building modelling schedules stated in the New Zealand Standard NZS4243:Part one, Energy efficiency - Large buildings. The values are a percentage of the assigned loads.

The schedules are written in the format which EnergyPlus uses. It applies to the whole year.

\begin{tabular}{|c|c|c|c|}
\hline Equipment & Lighting & Occupancy & HVAC \\
\hline For: Weekdays & For: Weekdays & For: Weekdays & For: Weekdays \\
\hline Until: 08:00 & Until: 08:00 & Until: 08:00 & Until: 07:00 \\
\hline 0.05 & 0.05 & 0 & 0 \\
\hline Until: 11:00 & Until: $11: 00$ & Until: 11:00 & Until: $18: 00$ \\
\hline 0.9 & 0.9 & 0.95 & 1 \\
\hline Until: 18:00 & Until: 18:00 & Until: 18:00 & Until: 24:00 \\
\hline 0.6 & 0.6 & 0.95 & 0 \\
\hline Until: 22:00 & Until: 22:00 & Until: 22:00 & \\
\hline 0.3 & 0.3 & 0.05 & \\
\hline Until: 24:00 & Until: 24:00 & Until: 24:00 & \\
\hline 0.05 & 0.05 & 0 & \\
\hline For: Saturday & For: Saturday & For: Saturday & For: Saturday \\
\hline Until: 08:00 & Until: 08:00 & Until: 08:00 & Until: 24:00 \\
\hline 0.05 & 0.05 & 0 & 0 \\
\hline Until: 11:00 & Until: 11:00 & Until: 11:00 & \\
\hline 0.3 & 0.3 & 0.1 & \\
\hline Until: $18: 00$ & Until: 18:00 & Until: 18:00 & \\
\hline 0.15 & 0.15 & 0.05 & \\
\hline Until: 22:00 & Until: 22:00 & Until: 22:00 & \\
\hline 0.05 & 0.05 & 0 & \\
\hline Until: $24: 00$ & Until: $24: 00$ & Until: $24: 00$ & \\
\hline 0.05 & 0.05 & 0 & \\
\hline $\begin{array}{c}\text { For: Sunday / } \\
\text { Holidays }\end{array}$ & $\begin{array}{c}\text { For: Sunday / } \\
\text { Holidays }\end{array}$ & $\begin{array}{c}\text { For: Sunday / } \\
\text { Holidays }\end{array}$ & $\begin{array}{c}\text { For: Sunday / } \\
\text { Holidays }\end{array}$ \\
\hline Until: 08:00 & Until: 08:00 & Until: 08:00 & Until: 24:00 \\
\hline 0.05 & 0.05 & 0 & 0 \\
\hline Until: 18:00 & Until: 18:00 & Until: 18:00 & \\
\hline 0.05 & 0.05 & 0.05 & \\
\hline Until: 22:00 & Until: 22:00 & Until: 22:00 & \\
\hline 0.05 & 0.05 & 0 & \\
\hline Until: 24:00 & Until: 24:00 & Until: $24: 00$ & \\
\hline 0.05 & 0.05 & 0 & \\
\hline
\end{tabular}

Table 15. Assigned operational schedules in the template models. 


\section{Appendix E - How the margin of error relates to the sample size}

In a quantitative study, Jakob Nielson summarises that 20 experts are typically the ideal number of experts needed to participate as this provides a reasonably high reliability in the data collected (Nielsen, 2006). Figure 12 illustrates how the number of experts influences the reliability and chances of having error in the collected data.

The graph contains a $90 \%$ reliability and $50 \%$ reliability line which represent the expected consistency of responses from the survey participants. For example, at a 90\% reliability level, this means that $90 \%$ of the experts can be expected to agree on a value and form a consensus opinion; at a 50\% confidence level, the experts are likely to not form a consensus as only half will agree on a value. The reliability lines show that to have more reliable responses with less chance of error, more experts are needed to participate.

In this study, 19 experts formed a consensus on the commonly installed HVAC system types and 8 formed a consensus on the modelling input parameters. Although these are both below the recommended number of 20 , they are still able to form a reliable consensus as the margin of error for the group does not radically increase until fewer than eight experts are used. Eight experts is the minimum recommended by (Paliwoda, 1983).

\section{How the margin of error relates to the number of experts}

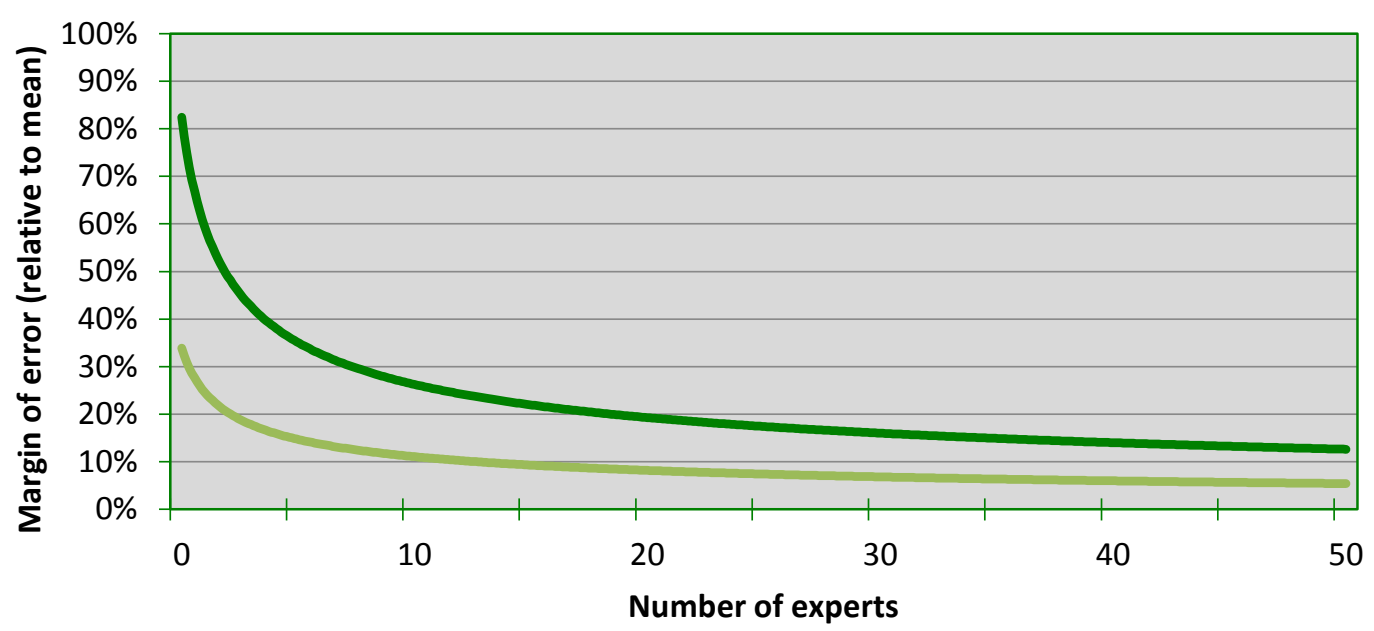

Figure 12. Margin of error in relation to number of experts.

Recreated from (Nielsen, 2006) 


\section{Appendix F - Survey Questions}

The survey was constructed using the online tool Qualtrics. Because the survey was constructed and distributed in an online format, the layout presented here differs slightly in order for it to be presentable in a printed format.

Each surrounding box represents what is shown per web page of the survey.

\section{F1: Round one survey questions}

\section{General Information}

The purpose of this survey is to collect data from which standard descriptions of commonly used New Zealand Heating, Ventilation, and Air Conditioning (HVAC) systems will be created. The descriptions will then be transformed into HVAC templates within the energy simulation program EnergyPlus. This information will be contributing towards the Building Energy End-use Study (BEES).

Scope

This survey is limited to gather information on HVAC systems that have been designed specified, and built in New Zealand commercial buildings.

There is a focus on buildings with a total floor area greater than $3,500 \mathrm{~m}^{2}$ and built or designed over the last 10 years.

\section{The Survey}

This survey is based on the Delphi method of collection which means there are two parts of questions in order to form a consensus opinion. The first part identifies HVAC systems, and for those involved in dynamic thermal/energy simulation, also identifies the related modelling values. The second part forms a consensus opinion.

After the first parts of the questions are completed, it will be analysed and summarised into the questions for the second part. It is expected to be two weeks between the completion of the first part and the release of the second.

\section{You Involvement}

The survey is online and can be completed anywhere and at any time by the participant. It is estimated that it will take 15 minutes to complete each part.

\section{Dissemination of the Research}

At completion of the research project, the thesis will be publicly available within the University library and the outcomes will be presented in the form of a conference or workshop demonstration. 


\section{Confidentiality}

Sufficient personal information is collected to ensure that the survey is only answered once and to contact the participant at the conclusion of the project if they have indicated to do so. The information and data that is collected within this survey will be kept anonymous and confidential, only accessible to the investigator and their supervisor. To ensure this; completed surveys will be securely stored and no individuals, companies, or affiliations will be identified within the reporting of the results.

By completing this survey you are authorising consent, through voluntary participation, to the investigator to use the information gathered in the survey and use it within the research project.

Further Information

For further information or clarification, please contact me or my supervisor.

Student: Anthony Gates

Email: gatesanth@myvuw.ac.nz

Mobile: +64 210652434
Michael Donn :Supervisor michael.donn@vuw.ac.nz :Email +6421611 280: :Mobile +6444636221 :Office

Victoria University of Wellington

School of Architecture

Click on the $\gg$ button to progress

\section{Q1.0 - Email Address}

This is collected to ensure that the survey is only answered once.

Please Type.

Q1.1 - Years of Experience

How many years of experience do you have in designing, simulating, or installing HVAC systems in commercial buildings?

Select one.
$0-1$
2-5
6-10
$11-15$
$16-20$
$>21$ 


\section{Q1.2 - Involved with Simulation}

Are you involved with dynamic energy computer modelling/simulation?

(People involved in computer simulation using programs such as DOE-2, EnergyPlus, and IES will be asked technical questions about input values used. This will be released as a separate round of questions).

Select one.

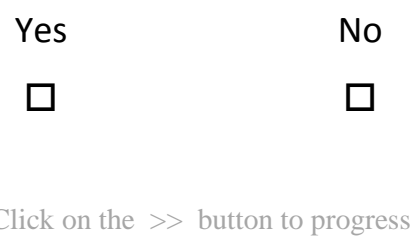

This section will ask you to rank the HVAC systems in order of the most likely installed to the least likely installed in three commercial building types.

The three building types are:

1. Good energy efficiency

2. Common practice

3. Poor energy efficiency

Reminder: this is for commercial buildings with a total floor area greater than $3,500 \mathrm{~m}^{2}$ and designed within the last 10 years.

\section{Q2.0 - Good Energy Efficiency Building}

Rank the HVAC systems in order of the most likely installed to the least likely installed.

Drag and drop the HVAC systems into order.

Where 1 = most likely installed, 9=least likely installed

If is common to have two systems installed, please select the primary HVAC system as the higher priority.

Variable Air Volume (VAV)

Variable Refrigerant Volume (VRV)

Chilled Beams

Split system - cooling only
Split system heat pump - heating and cooling

Packaged Air Handling Unit (AHU)

Fan Coil Units (FCU)

Other, please specify: 
Q2.1 - Common Practice Building

Rank the HVAC systems in order of the most likely installed to the least likely installed.

Drag and drop the HVAC systems into order.

Where 1 = most likely installed, 9=least likely installed

If is common to have two systems installed, please select the primary HVAC system as the higher priority.

Variable Air Volume (VAV)

Variable Refrigerant Volume (VRV)

Chilled Beams

Split system - cooling only

\author{
Split system heat pump - heating and cooling \\ Packaged Air Handling Unit (AHU) \\ Fan Coil Units (FCU) \\ Other, please specify:
}

\section{Q2.2 - Poor Energy Efficiency Building}

Rank the HVAC systems in order of the most likely installed to the least likely installed.

Drag and drop the HVAC systems into order.

Where 1 = most likely installed, 9=least likely installed

If is common to have two systems installed, please select the primary HVAC system as the higher priority.

Variable Air Volume (VAV)

Variable Refrigerant Volume (VRV)

Chilled Beams

Split system - cooling only
Split system heat pump - heating and cooling

Packaged Air Handling Unit (AHU)

Fan Coil Units (FCU)

Other, please specify:

\section{Q3.0 - Copy of the report}

At the completion of this project, would you like to receive a copy of the final report?

The report will be sent to the email address registered at the start of this survey. If you would like it send to a different address, please state it.

$$
\text { Yes No }
$$

Different email address: 
Q4.0 - Any Issues

Were there any issues regarding completion of this survey?

If yes, please note what the issues were.

$$
\text { Yes No }
$$

Issue(s):

Thank you for your time in completing this survey.

The results will be analyses and complied into the second round of questions, you will be contacted with this soon.

If you have any further questions or would like to get in contact, please contact me at: gatesanth@myvuw.ac.nz

Thank you.

\section{Anthony Gates}

Master of Building Science student

Victoria University of Wellington 


\section{F2: Round two survey questions - Simulators}

\section{Introduction}

Thank you for recently completing a survey to identify which HVAC systems are the most commonly installed within New Zealand commercial buildings.

This follow up survey version has been sent to you because you stated that you are involved with dynamic thermal/energy computer simulations of buildings. If this is incorrect, please contact Anthony Gates at gatesanth@myvuw.ac.nz to receive an alternative survey which does not include the computer modelling input parameter questions.

This survey has two objectives:

1. Form a consensus opinion of the most commonly installed systems - based on the results of the previous survey.

2. Collect information on how the HVAC systems are modelled for simulation purposes.

\section{Reminder of the project}

\section{General Information}

This project is using a survey to collect data on the most commonly installed Heating, Ventilation, and Air Conditioning (HVAC) systems in New Zealand commercial buildings.

From this, standard descriptions will be created and transformed into HVAC templates which will be used within computer based building energy simulations. This information is contributing towards the Building Energy End-use Study (BEES) currently being performed by BRANZ (Building Research Association of New Zealand).

\section{Scope}

This survey is limited to gather information on HVAC systems that have been designed, specified, and built in New Zealand commercial buildings.

There is a focus on buildings with a total floor area greater than $3,500 \mathrm{~m}^{2}$ and built or designed over the last 10 years.

\section{Confidentiality}

The information and data that is collected within this survey will be kept anonymous and confidential.

No individuals, companies, or affiliations will be identified within the reporting of the results. 
Q1.0 - Email Address

This is collected to ensure that the survey is only answered once.

Please Type.

Click on the $\gg$ button to progress

The following questions are used to form a consensus opinion on the most commonly installed HVAC systems in New Zealand commercial buildings. This is derived from the responses obtained in the previous survey questions.

For each of the three building types, please select whether you agree or disagree with the responses provided by the majority of the participants.

Reminder: this is for commercial buildings with a total floor area greater than $3,500 \mathrm{~m}^{2}$ and designed within the last 10 years.

\section{Q2.0-Good Energy Efficiency Building}

From the previous round of questions, the majority of the participants identified that the most commonly installed HVAC systems for a building that has good energy efficiency were;

\section{- Variable Air Volume}

\section{$\checkmark$ Chilled Beams}

Do you agree that these systems are most likely installed in a good energy efficiency building (low energy consumption)?

\section{Select one}

If you disagree, please explain your reasoning.
Agree
$\square$ Disagree 
Q2.1 - Common Practice Building

From the previous round of questions, the majority of the participants identified that the most likely HVAC systems installed as common practice were;

- Variable Air Volume

$\checkmark$ Fan coil units

Do you agree that these systems are most likely installed as common practice?

Select one

If you disagree, please explain your reasoning.

$\square$ Agree $\quad \square$ Disagree

Q2.2 - Poor Energy Efficiency Building

From the previous round of questions, the majority of the participants identified that the most commonly installed HVAC systems for a building that has poor energy efficiency were;

- Packaged AHU

$\checkmark$ Fan coil units

Split system heat pumps

Do you agree that these systems are most likely installed in a poor energy efficiency building (high energy consumption)?

\section{Select one}

If you disagree, please explain your reasoning.

$\square$ Agree $\quad \square$ Disagree 
The following questions are to identify what the design and performance values are for the HVAC systems identified to be commonly installed in New Zealand commercial buildings.

It is understandable that all HVAC systems are designed individually for the building they service. Therefore this survey is only asking for approximate values that are still realistically representative of what would be expected with the system and building type.

The questions in this section have been simplified as much as possible to reduce the amount of time to complete it. This is achieved by providing values from an energy simulation program as examples and asking you to either select the appropriate values or type in a value if required.

Reminder: this is for commercial buildings with a total floor area greater than $3,500 \mathrm{~m}^{2}$ and designed within the last 10 years.

\section{Q3.0 - Chilled Beams - good energy efficiency building}

Chilled beams have been identified as being a commonly installed HVAC system in a good energy efficiency building; a building with low energy consumption.

Using the inputs required to model this system in an energy simulation program, what are the appropriate values to use?

\section{Q3.1 - Controls}

Select the control types that are most likely used for the chilled beam system.

\section{Q3.1.1 - Percentage of building typically conditioned}

$$
0 \%-25 \% \quad 26 \%-50 \% \quad 51 \%-75 \% \quad 76 \%-100 \%
$$

\section{Q3.1.2 - Automated control systems}

Select all that apply.
$\square \quad$ Thermostat
$\square$ Humidistat
$\square \quad \mathrm{CO}_{2}$ Sensor
$\square \quad \mathrm{BMS}$
$\square$ Other, Please state:
$\square \quad$ No automated controls 


\section{Q3.1.3 - Outside Air Supply Rate}

How much outside air would be supplied when using this type of system?

Default value of $9 \mathrm{~L} / \mathrm{s}$ per person Other, Please type (L/s per person)

L/s Per person

\section{Q3.2 - Equipment Types}

Select the equipment type that is most likely used for the chilled beam system.

Q3.2.1 - Cooling coil type
Water
DX
None

Q3.2.2 - Heating coil type

Water

DX

Electric

None

Q3.2.3 - Chilled Beam type

$$
\text { Active / fan assisted Passive / Radiant only }
$$

\section{Q3.2.4-Heating system}

$\begin{array}{cccc}\text { None } & \text { Baseboard } & \text { Baseboard heaters } & \text { Other, } \\ & \text { heaters - electric } & - \text { hot water } & \text { Please state } \\ \square & \square & \square & \square\end{array}$

Q3.2.5 - Chiller type

Electric Centrifugal Electric Reciprocating

Q3.2.6 - Chiller to coils loop - water pump configuration

Variable Primary

No Secondary

\begin{abstract}
Constant Primary
\end{abstract}
No Secondary
Variable Primary

Constant Secondary
Constant Primary

Variable Secondary 
Q3.2.7-Condenser type

Water cooled Air cooled Evaporative

Q3.2.8 - Chilled water condenser loop - pump control type

Intermittent
(variable)
$\square$

Continuous

Q3.2.9-Condenser water temperature - control type

Variable

Based on outdoor temperature

$\square$

\section{Q3.2.10 - Cooling tower speed}

Single speed

$\square$

\section{Q3.3 - Plant equipment values}

\section{Q3.3.1 - General system and Chiller}

Select the plant equipment values that are most likely used for the chilled beam system.

\begin{tabular}{|c|c|c|c|}
\hline & Default value OK & $\begin{array}{l}\text { Default value not OK } \\
\text { Unsure of better value }\end{array}$ & $\begin{array}{l}\text { Default value not OK. } \\
\text { Better value suggested }\end{array}$ \\
\hline $\begin{array}{l}\text { Cooling coil inlet design } \\
\text { set point. } \\
\text { Default: } 15^{\circ} \mathrm{C}\end{array}$ & $\square$ & $\square$ & $\square$ \\
\hline $\begin{array}{l}\text { Chiller full load COP } \\
\text { Default: } \mathbf{2 . 5}\end{array}$ & $\square$ & $\square$ & $\square$ \\
\hline $\begin{array}{l}\text { Chiller design set point. } \\
\text { Default: } \mathbf{7 . 2 ^ { \circ } \mathrm { C }}\end{array}$ & $\square$ & $\square$ & $\square$ \\
\hline $\begin{array}{l}\text { Condenser water design } \\
\text { setpoint. } \\
\text { Default: } 29^{\circ} \mathrm{C}\end{array}$ & $\square$ & $\square$ & $\square$ \\
\hline
\end{tabular}

Fixed

Specific set point

Two speed

$\square$ 
The following questions are to identify what the design and performance values are for the HVAC systems identified to be commonly installed in New Zealand commercial buildings.

It is understandable that all HVAC systems are designed individually for the building they service. Therefore this survey is only asking for approximate values that are still realistically representative of what would be expected with the system and building type.

The questions in this section have been simplified as much as possible to reduce the amount of time to complete it. This is achieved by providing values from an energy simulation program as examples and asking you to either select the appropriate values or type in a value if required.

Reminder: this is for commercial buildings with a total floor area greater than 3,500 $\mathrm{m}^{2}$ and designed within the last 10 years.

\section{Q4.0 - Variable Air Volume - good energy efficiency building}

A variable air volume HVAC system has been identified as being a commonly installed in a good energy efficiency building; a building with low energy consumption.

Using the inputs required to model this system in an energy simulation program, what are the appropriate values to use?

\section{Q4.1 - Controls}

Select the control types that are most likely used for the chilled beam system.

\section{Q4.1.1 - Percentage of building typically conditioned}

$$
0 \%-25 \% \quad 26 \%-50 \% \quad 51 \%-75 \% \quad 76 \%-100 \%
$$

\section{Q4.1.2 - Automated control systems}

Select all that apply.

$\begin{array}{ll}\square & \text { Thermostat } \\ \square & \text { Humidistat } \\ \square & \mathrm{CO}_{2} \text { Sensor } \\ \square & \text { BMS } \\ \square & \text { Other, Please state: } \\ \square & \text { No automated controls }\end{array}$




\section{Q4.1.3 - Outside Air Supply Rate}

How much outside air would be supplied when using this type of system?

Default value of $9 \mathrm{~L} / \mathrm{s}$ per person Other, Please type (L/s per person)

L/s Per person

\section{Q4.2 - Equipment Types}

Select the equipment type that is most likely used for a VAV system.

Q4.2.1 - Cooling coil type

Water None

Q4.2.2 - Heating coil type

Water

Electric

None

\section{Q4.2.3 - Supply fan type}

Draw through Blow through Unknown

Q4.2.4 - Fan layout

Series Parallel Unknown

\section{Q4.2.5 - Baseboard heating}

None

Hot Water

Electric

\section{Q4.2.6 - Reheat}

None

Hot Water

Electric

Q4.2.7 - Heat Recovery

None

Sensible

Enthalpy 
Q4.2.8 - Night cycle ventilation

None

Central air handler

Zone/room fan

Natural ventilation

\section{Q4.2.9 - Dehumidifier}

None Yes

Q4.2.10 - Humidifier

None Yes

\section{Q4.3 - Plant Equipment Types}

Select the plant equipment that is most likely used for a VAV system.

\section{Q4.3.1 - Chiller type}

Electric Centrifugal Electric Reciprocating

Q4.3.2 - Chiller to coils loop - water pump configuration

Variable Primary

No Secondary
Variable Primary Constant Secondary
Constant Primary Variable Secondary

\section{Q4.3.3 - Condenser type}

Water cooled Air cooled Evaporative

Q4.3.4 - Chilled water condenser loop - pump control type

$$
\begin{aligned}
& \text { Intermittent Continuous } \\
& \text { (variable) }
\end{aligned}
$$

口 
Q4.3.5 - Condenser water temperature - control type

Variable

Based on outdoor temperature

Q4.3.6 - Cooling tower speed

Single speed

Two speed

Q4.3.7 - Boiler fuel type

Electric Natural Gas Bottled Gas Oil Diesel Coal

Q4.3.8 - Boiler to coils loop - pump control type

Intermittent

(variable)

Continuous
Fixed

Specific set point 
Q4.4 - Plant Equipment Values

Q4.4.1 - General system

Select the plant equipment values that are most likely used for the VAV system.

\begin{tabular}{|c|c|c|c|}
\hline & Default value OK & $\begin{array}{l}\text { Default value not OK } \\
\text { Unsure of better value }\end{array}$ & $\begin{array}{l}\text { Default value not OK. } \\
\text { value suggested }\end{array}$ \\
\hline $\begin{array}{l}\text { Supply fan efficiency } \\
\text { Default: } \mathbf{0 . 7}\end{array}$ & $\square$ & $\square$ & $\square$ \\
\hline $\begin{array}{l}\text { Supply fan motor } \\
\text { efficiency } \\
\text { Default: } \mathbf{0 . 9}\end{array}$ & $\square$ & $\square$ & $\square$ \\
\hline $\begin{array}{l}\text { Cooling coil inlet design } \\
\text { setpoint } \\
\text { Default: } \mathbf{1 3}^{\text {oC }}\end{array}$ & $\square$ & $\square$ & $\square$ \\
\hline $\begin{array}{l}\text { Heating coil inlet design } \\
\text { setpoint } \\
\text { Default: } \mathbf{1 0}^{\circ \mathrm{C}}\end{array}$ & $\square$ & $\square$ & $\square$ \\
\hline $\begin{array}{l}\text { Reheat coil inlet setpoint } \\
\text { Default: } 7^{\circ \mathrm{C}}\end{array}$ & $\square$ & $\square$ & $\square$ \\
\hline $\begin{array}{l}\text { Heat recovery - Sensible } \\
\text { effectiveness } \\
\text { Default: } 0.7\end{array}$ & $\square$ & $\square$ & $\square$ \\
\hline $\begin{array}{l}\text { Heat recovery - Latent } \\
\text { effectiveness } \\
\text { Default: } \mathbf{0 . 6 5}\end{array}$ & $\square$ & $\square$ & $\square$ \\
\hline $\begin{array}{l}\text { Dehumidifier setpoint } \\
\text { Default: } 60 \%\end{array}$ & $\square$ & $\square$ & $\square$ \\
\hline $\begin{array}{l}\text { Humidifier setpoint } \\
\text { Default: } \mathbf{3 0 \%}\end{array}$ & $\square$ & $\square$ & $\square$ \\
\hline $\begin{array}{l}\text { Humidifier rated capacity } \\
\text { Default: } \mathbf{0 . 0 0 1} \text { L/s }\end{array}$ & $\square$ & $\square$ & $\square$ \\
\hline $\begin{array}{l}\text { Humidifier rated electric } \\
\text { power } \\
\text { Default: } \mathbf{2 . 7} \text { kW }\end{array}$ & $\square$ & $\square$ & $\square$ \\
\hline
\end{tabular}




\section{Q4.4.2 - Chiller}

\begin{tabular}{|c|c|c|c|}
\hline & Default value OK & $\begin{array}{l}\text { Default value not OK } \\
\text { Unsure of better value }\end{array}$ & $\begin{array}{l}\text { Default value not OK. } \\
\text { Better value suggested }\end{array}$ \\
\hline $\begin{array}{l}\text { Full load COP } \\
\text { Default: } 2.5\end{array}$ & $\square$ & $\square$ & $\square$ \\
\hline $\begin{array}{l}\text { Chilled water design } \\
\text { setpoint } \\
\text { Default: } \mathbf{7 . 2}{ }^{\circ} \mathrm{C}\end{array}$ & $\square$ & $\square$ & $\square$ \\
\hline $\begin{array}{l}\text { Condenser water design } \\
\text { setpoint } \\
\text { Default: } 29^{\circ} \mathrm{C}\end{array}$ & $\square$ & $\square$ & $\square$ \\
\hline
\end{tabular}

Q4.4.3-Boiler

\begin{tabular}{lc|c|c|} 
& Default value OK & $\begin{array}{c}\text { Default value not OK } \\
\text { Unsure of better value }\end{array}$ & $\begin{array}{c}\text { Default value not OK. } \\
\text { Better value suggested }\end{array}$ \\
\hline Efficiency & $\square$ & $\square$ & $\square$ \\
Default: $\mathbf{0 . 8}$ & $\square$ & $\square$ & $\square$ \\
\hline $\begin{array}{l}\text { Hot water design } \\
\text { setpoint } \\
\text { Default: } \mathbf{8 2 ^ { \circ } \mathrm { C }}\end{array}$ & $\square$ & & $\square$ \\
\hline
\end{tabular}


The following questions are to identify what the design and performance values are for the HVAC systems identified to be commonly installed in New Zealand commercial buildings.

It is understandable that all HVAC systems are designed individually for the building they service. Therefore this survey is only asking for approximate values that are still realistically representative of what would be expected with the system and building type.

The questions in this section have been simplified as much as possible to reduce the amount of time to complete it. This is achieved by providing values from an energy simulation program as examples and asking you to either select the appropriate values or type in a value if required.

Reminder: this is for commercial buildings with a total floor area greater than 3,500 $\mathrm{m}^{2}$ and designed within the last 10 years.

\section{Q5.0-Fan Coil Unit - common practice building}

Fan coil units have been identified as being commonly installed as common practice in New Zealand commercial buildings.

Using the inputs required to model this system in an energy simulation program, what are the appropriate values to use?

\section{Q5.1 - Controls}

Select the control types that are most likely used for the chilled beam system.

\section{Q5.1.1 - Percentage of building typically conditioned}

$$
0 \%-25 \% \quad 26 \%-50 \% \quad 51 \%-75 \% \quad 76 \%-100 \%
$$

\section{Q5.1.2 - Automated control systems}

Select all that apply.

$\begin{array}{ll}\square & \text { Thermostat } \\ \square & \text { Humidistat } \\ \square & \mathrm{CO}_{2} \text { Sensor } \\ \square & \text { BMS } \\ \square & \text { Other, Please state: } \\ \square & \text { No automated controls }\end{array}$




\section{Q5.1.3 - Outside Air Supply Rate}

How much outside air would be supplied when using this type of system?

Default value of $9 \mathrm{~L} / \mathrm{s}$ per person $\quad$ Other, Please type (L/s per person)

L/s Per person

\section{Q5.2-Equipment Types}

Select the equipment type that is most likely used for a fan coil unit system.

Q5.2.1 - Cooling coil type

$$
\text { Water None }
$$

Q5.2.2 - Heating coil type

Water Electric None

$\square \quad \square \quad \square$

\section{Q5.2.3 - Chiller type}

Electric Centrifugal Electric Reciprocating

Q5.2.4 - Chiller to coils loop - water pump configuration

$\begin{array}{cccc}\text { Variable Primary } & \text { Constant Primary } & \text { Variable Primary } & \text { Constant Primary } \\ \text { No Secondary } & \text { No Secondary } & \text { Constant Secondary } & \text { Variable Secondary }\end{array}$

\section{Q5.2.5 - Condenser type}

Water cooled Air cooled Evaporative

Q5.2.6 - Chilled water condenser loop - pump control type

$$
\begin{gathered}
\text { Intermittent } \\
\text { (variable) Continuous }
\end{gathered}
$$

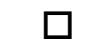


Q5.2.7 - Condenser water temperature - control type

Variable

Based on outdoor temperature
Fixed

Specific set point

Q5.2.8 - Cooling tower speed

Single speed

Two speed

Q5.2.9 - Boiler fuel type

Electric Natural Gas Bottled Gas Oil Diesel Coal

$\square \quad \square \quad \square \quad \square$

Q5.2.10 - Boiler to coils loop - pump control type

Intermittent
(variable)

$\square$

\section{Q5.3 - Plant Equipment Values}

\section{Q5.3.1-General system}

Select the plant equipment values that are most likely used for the fan coil unit system.

\begin{tabular}{|c|c|c|c|}
\hline & Default value OK & $\begin{array}{l}\text { Default value not OK } \\
\text { Unsure of better value }\end{array}$ & $\begin{array}{l}\text { Default value not OK. } \\
\text { Better value suggested }\end{array}$ \\
\hline $\begin{array}{l}\text { Supply fan efficiency } \\
\text { Default: } \mathbf{0 . 7}\end{array}$ & $\square$ & $\square$ & $\square$ \\
\hline $\begin{array}{l}\text { Supply fan motor } \\
\text { efficiency } \\
\text { Default: } \mathbf{0 . 9}\end{array}$ & $\square$ & $\square$ & $\square$ \\
\hline $\begin{array}{l}\text { Cooling coil inlet design } \\
\text { setpoint } \\
\text { Default: } \mathbf{1 4}^{\text {oC }}\end{array}$ & $\square$ & $\square$ & $\square$ \\
\hline $\begin{array}{l}\text { Heating coil inlet design } \\
\text { setpoint } \\
\text { Default: } \mathbf{5 0}^{\circ \mathrm{C}}\end{array}$ & $\square$ & $\square$ & $\square$ \\
\hline
\end{tabular}


Q5.3.2 - Chiller

\begin{tabular}{|c|c|c|c|}
\hline & Default value OK & $\begin{array}{l}\text { Default value not OK } \\
\text { Unsure of better value }\end{array}$ & $\begin{array}{l}\text { Default value not OK. } \\
\text { Better value suggested }\end{array}$ \\
\hline $\begin{array}{l}\text { Full load COP } \\
\text { Default: } \mathbf{2 . 5}\end{array}$ & $\square$ & $\square$ & $\square$ \\
\hline $\begin{array}{l}\text { Chilled water design } \\
\text { setpoint } \\
\text { Default: } \mathbf{7 . 2}{ }^{\circ} \mathrm{C}\end{array}$ & $\square$ & $\square$ & $\square$ \\
\hline $\begin{array}{l}\text { Condenser water design } \\
\text { setpoint } \\
\text { Default: } 29^{\circ} \mathrm{C}\end{array}$ & $\square$ & $\square$ & $\square$ \\
\hline
\end{tabular}

Q5.3.3 - Boiler

\begin{tabular}{|c|c|c|c|}
\hline & Default value OK & $\begin{array}{l}\text { Default value not OK } \\
\text { Unsure of better value }\end{array}$ & $\begin{array}{l}\text { Default value not OK. } \\
\text { Better value suggested }\end{array}$ \\
\hline $\begin{array}{l}\text { Efficiency } \\
\text { Default: } \mathbf{0 . 8}\end{array}$ & $\square$ & $\square$ & $\square$ \\
\hline $\begin{array}{l}\text { Hot water design } \\
\text { setpoint } \\
\text { Default: } \mathbf{8 2 ^ { \circ } \mathrm { C }}\end{array}$ & $\square$ & $\square$ & $\square$ \\
\hline
\end{tabular}

Click on the $>$ button to progress 
The following questions are to identify what the design and performance values are for the HVAC systems identified to be commonly installed in New Zealand commercial buildings.

It is understandable that all HVAC systems are designed individually for the building they service. Therefore this survey is only asking for approximate values that are still realistically representative of what would be expected with the system and building type.

The questions in this section have been simplified as much as possible to reduce the amount of time to complete it. This is achieved by providing values from an energy simulation program as examples and asking you to either select the appropriate values or type in a value if required.

Reminder: this is for commercial buildings with a total floor area greater than 3,500 $\mathrm{m}^{2}$ and designed within the last 10 years.

\section{Q6.0 - Variable Air Volume - common practice building}

A variable air volume HVAC system has been identified as being a commonly installed as common practice in New Zealand commercial buildings.

Using the inputs required to model this system in an energy simulation program, what are the appropriate values to use?

\section{Q6.1 - Controls}

Select the control types that are most likely used for the chilled beam system.

\section{Q6.1.1 - Percentage of building typically conditioned}

$$
0 \%-25 \% \quad 26 \%-50 \% \quad 51 \%-75 \% \quad 76 \%-100 \%
$$

\section{Q6.1.2 - Automated control systems}

Select all that apply.

$\begin{array}{ll}\square & \text { Thermostat } \\ \square & \text { Humidistat } \\ \square & \mathrm{CO}_{2} \text { Sensor } \\ \square & \text { BMS } \\ \square & \text { Other, Please state: } \\ \square & \text { No automated controls }\end{array}$




\section{Q6.1.3 - Outside Air Supply Rate}

How much outside air would be supplied when using this type of system?

Default value of $9 \mathrm{~L} / \mathrm{s}$ per person Other, Please type (L/s per person)

L/s Per person

Q6.2 - Equipment Types

Select the equipment type that is most likely used for a VAV system.

Q6.2.1 - Cooling coil type

Water None

Q6.2.2 - Heating coil type

Water Electric None

Q6.2.3 - Supply fan type

Draw through Blow through Unknown

Q6.2.4 - Fan layout

Series Parallel Unknown

Q6.2.5 - Baseboard heating

None

Hot Water

Electric

Q6.2.6 - Reheat

None

Hot Water

Electric

Q6.2.7 - Heat Recovery

None

Sensible

Enthalpy

$\square$

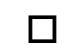


Q6.2.8 - Night cycle ventilation

None Central air handler Zone/room fan Natural ventilation

Q6.2.9 - Dehumidifier

None Yes

Q6.2.10 - Humidifier

None Yes

Q6.3 - Plant Equipment Types

Select the plant equipment that is most likely used for a VAV system.

Q6.3.1 - Chiller type

Electric Centrifugal Electric Reciprocating

Q6.3.2 - Chiller to coils loop - water pump configuration

$\begin{array}{cccc}\text { Variable Primary } & \text { Constant Primary } & \text { Variable Primary } & \text { Constant Primary } \\ \text { No Secondary } & \text { No Secondary } & \text { Constant Secondary } & \text { Variable Secondary }\end{array}$

Q6.3.3 - Condenser type

Water cooled Air cooled Evaporative

Q6.3.4 - Chilled water condenser loop - pump control type

Intermittent
(variable)

Q6.3.5 - Condenser water temperature - control type

Variable

Based on outdoor temperature
Fixed

Specific set point 
Q6.3.6 - Cooling tower speed

Single speed Two speed

Q6.3.7 - Boiler fuel type

Electric Natural Gas Bottled Gas Oil Diesel Coal

$\begin{array}{llllll}\square & \square & \square & \square & \square & \square\end{array}$

Q6.3.8 - Boiler to coils loop - pump control type

Intermittent
(variable) Continuous


Q6.4-Plant Equipment Values

Q6.4.1-General system

Select the plant equipment values that are most likely used for the VAV system.

\begin{tabular}{|c|c|c|c|}
\hline & Default value OK & $\begin{array}{l}\text { Default value not OK } \\
\text { Unsure of better value }\end{array}$ & $\begin{array}{l}\text { Default value not OK. } \\
\text { Better value suggested }\end{array}$ \\
\hline $\begin{array}{l}\text { Supply fan efficiency } \\
\text { Default: } \mathbf{0 . 7}\end{array}$ & $\square$ & $\square$ & $\square$ \\
\hline $\begin{array}{l}\text { Supply fan motor } \\
\text { efficiency } \\
\text { Default: } 0.9\end{array}$ & $\square$ & $\square$ & $\square$ \\
\hline $\begin{array}{l}\text { Cooling coil inlet design } \\
\text { setpoint } \\
\text { Default: } \mathbf{1 3}^{\text {oC }}\end{array}$ & $\square$ & $\square$ & $\square$ \\
\hline $\begin{array}{l}\text { Heating coil inlet design } \\
\text { setpoint } \\
\text { Default: } 10^{\circ \mathrm{C}}\end{array}$ & $\square$ & $\square$ & $\square$ \\
\hline $\begin{array}{l}\text { Reheat coil inlet setpoint } \\
\text { Default: } 7^{\circ \mathrm{C}}\end{array}$ & $\square$ & $\square$ & $\square$ \\
\hline $\begin{array}{l}\text { Heat recovery - Sensible } \\
\text { effectiveness } \\
\text { Default: } 0.7\end{array}$ & $\square$ & $\square$ & $\square$ \\
\hline $\begin{array}{l}\text { Heat recovery - Latent } \\
\text { effectiveness } \\
\text { Default: } 0.65\end{array}$ & $\square$ & $\square$ & $\square$ \\
\hline $\begin{array}{l}\text { Dehumidifier setpoint } \\
\text { Default: } \mathbf{6 0 \%}\end{array}$ & $\square$ & $\square$ & $\square$ \\
\hline $\begin{array}{l}\text { Humidifier setpoint } \\
\text { Default: } \mathbf{3 0 \%}\end{array}$ & $\square$ & $\square$ & $\square$ \\
\hline $\begin{array}{l}\text { Humidifier rated } \\
\text { capacity } \\
\text { Default: } \mathbf{0 . 0 0 1} \mathbf{L / s}\end{array}$ & $\square$ & $\square$ & $\square$ \\
\hline $\begin{array}{l}\text { Humidifier rated electric } \\
\text { power } \\
\text { Default: } \mathbf{2 . 7} \text { kW }\end{array}$ & $\square$ & $\square$ & $\square$ \\
\hline
\end{tabular}


Q6.4.1 - Chiller

\begin{tabular}{|c|c|c|c|}
\hline & Default value OK & $\begin{array}{l}\text { Default value not OK } \\
\text { Unsure of better value }\end{array}$ & $\begin{array}{l}\text { Default value not OK. } \\
\text { Better value suggested }\end{array}$ \\
\hline $\begin{array}{l}\text { Full load COP } \\
\text { Default: } \mathbf{2 . 5}\end{array}$ & $\square$ & $\square$ & $\square$ \\
\hline 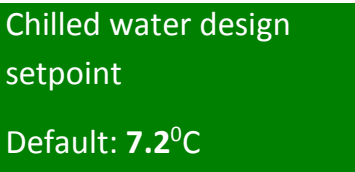 & $\square$ & $\square$ & $\square$ \\
\hline 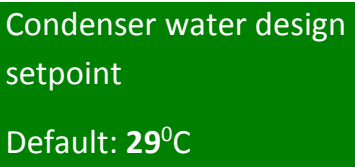 & $\square$ & $\square$ & $\square$ \\
\hline
\end{tabular}

Q6.4.2 - Boiler

\begin{tabular}{lc|c|c|} 
& Default value OK & $\begin{array}{c}\text { Default value not OK } \\
\text { Unsure of better value }\end{array}$ & $\begin{array}{c}\text { Default value not OK. } \\
\text { Better value suggested }\end{array}$ \\
\hline Efficiency & $\square$ & $\square$ & $\square$ \\
Default: $\mathbf{0 . 8}$ & $\square$ & $\square$ & $\square$ \\
\hline $\begin{array}{l}\text { Hot water design } \\
\text { setpoint } \\
\text { Default: } \mathbf{8 2 ^ { \circ } \mathrm { C }}\end{array}$ & $\square$ & & $\square$ \\
\hline
\end{tabular}


The following questions are to identify what the design and performance values are for the HVAC systems identified to be commonly installed in New Zealand commercial buildings.

It is understandable that all HVAC systems are designed individually for the building they service. Therefore this survey is only asking for approximate values that are still realistically representative of what would be expected with the system and building type.

The questions in this section have been simplified as much as possible to reduce the amount of time to complete it. This is achieved by providing values from an energy simulation program as examples and asking you to either select the appropriate values or type in a value if required.

Reminder: this is for commercial buildings with a total floor area greater than 3,500 $\mathrm{m}^{2}$ and designed within the last 10 years.

\section{Q7.0 - Split System Heat Pump - poor energy efficiency building}

A split system heat pump HVAC system has been identified as being a commonly installed in a poor energy efficiency building; a building with high energy consumption.

Using the inputs required to model this system in an energy simulation program, what are the appropriate values to use?

\section{Q7.1 - Controls}

Select the control types that are most likely used for the chilled beam system.

\section{Q7.1.1 - Percentage of building typically conditioned}

$$
0 \%-25 \% \quad 26 \%-50 \% \quad 51 \%-75 \% \quad 76 \%-100 \%
$$

\section{Q7.1.2 - Automated control systems}

Select all that apply.

$\begin{array}{ll}\square & \text { Thermostat } \\ \square & \text { Humidistat } \\ \square & \mathrm{CO}_{2} \text { Sensor } \\ \square & \text { BMS } \\ \square & \text { Other, Please state: } \\ \square & \text { No automated controls }\end{array}$




\section{Q7.1.3 - Outside Air Supply Rate}

How much outside air would be supplied when using this type of system?

Default value of $9 \mathrm{~L} / \mathrm{s}$ per person Other, Please type (L/s per person)

L/s Per person

\section{Q7.2 - Equipment Types}

Select the equipment type that is most likely used for a split system heat pump system.

Q7.2.1 - Cooling coil type

DX

None

Q7.2.2 - Heating coil type

DX None

Q7.2.3 - Supply fan type

Draw through Blow through Unknown

$\begin{array}{lll}\square & \square\end{array}$

Q7.2.4 - Supply fan operation

Variable / Cycling Continuous Unknown

Q7.2.5 - Heat recovery

None Sensible Enthalpy

Q7.2.6 - Night cycle ventilation

None Zone/Room fan Natural Ventilation

Q7.2.7 - Humidifier

None Yes 


\section{Q7.3 - Plant Equipment Values}

Select the plant equipment values that are most likely used for the split system heat pumps.

\begin{tabular}{l|c|c|c|} 
& Default value OK & $\begin{array}{c}\text { Default value not OK } \\
\text { Unsure of better value }\end{array}$ & $\begin{array}{c}\text { Default value not OK. } \\
\text { Better value suggested }\end{array}$ \\
\hline $\begin{array}{l}\text { Supply fan efficiency } \\
\text { Default: } \mathbf{0 . 7}\end{array}$ & $\square$ & $\square$ & $\square$ \\
\hline $\begin{array}{l}\text { Supply fan motor } \\
\text { efficiency } \\
\text { Default: } 0.9\end{array}$ & $\square$ & $\square$ & $\square$ \\
\hline $\begin{array}{l}\text { Cooling coil full load COP } \\
\text { Default: } \mathbf{3 . 0}\end{array}$ & $\square$ & $\square$ & $\square$ \\
\hline $\begin{array}{l}\text { Heating coil full load COP } \\
\text { Default: } \mathbf{2 . 7 5}\end{array}$ & $\square$ & $\square$ & $\square$ \\
\hline $\begin{array}{l}\text { Heat recovery - Sensible } \\
\text { effectiveness } \\
\text { Default: } \mathbf{0 . 7 0}\end{array}$ & $\square$ & $\square$ & $\square$ \\
\hline $\begin{array}{l}\text { Heat recovery - Latent } \\
\text { effectiveness } \\
\text { Default: } \mathbf{0 . 6 5}\end{array}$ & $\square$ & $\square$ & $\square$ \\
\hline $\begin{array}{l}\text { Humidifier setpoint } \\
\text { Default: } \mathbf{3 0 \%}\end{array}$ & $\square$ & $\square$ & $\square$ \\
\hline $\begin{array}{l}\text { Humidifier rated } \\
\text { capacity } \\
\text { Default: } \mathbf{0 . 0 0 1} \text { L/s }\end{array}$ & $\square$ & $\square$ & $\square$ \\
\hline
\end{tabular}


The following questions are to identify what the design and performance values are for the HVAC systems identified to be commonly installed in New Zealand commercial buildings.

It is understandable that all HVAC systems are designed individually for the building they service. Therefore this survey is only asking for approximate values that are still realistically representative of what would be expected with the system and building type.

The questions in this section have been simplified as much as possible to reduce the amount of time to complete it. This is achieved by providing values from an energy simulation program as examples and asking you to either select the appropriate values or type in a value if required.

Reminder: this is for commercial buildings with a total floor area greater than $3,500 \mathrm{~m}^{2}$ and designed within the last 10 years.

\section{Q8.0 - Packaged Air Handling Unit - poor energy efficiency building}

A packaged air handling unit HVAC system has been identified as being a commonly installed in a poor energy efficiency building; a building with high energy consumption.

Using the inputs required to model this system in an energy simulation program, what are the appropriate values to use?

\section{Q8.1 - Controls}

Select the control types that are most likely used for the chilled beam system.

\section{Q8.1.1 - Percentage of building typically conditioned}

$$
0 \%-25 \% \quad 26 \%-50 \% \quad 51 \%-75 \% \quad 76 \%-100 \%
$$

\section{Q8.1.2 - Automated control systems}

Select all that apply.
$\square \quad$ Thermostat
$\square$ Humidistat
$\square \quad \mathrm{CO}_{2}$ Sensor
$\square \quad \mathrm{BMS}$
$\square$ Other, Please state:
No automated controls 


\section{Q8.1.3 - Outside Air Supply Rate}

How much outside air would be supplied when using this type of system?

Default value of $9 \mathrm{~L} / \mathrm{s}$ per person Other, Please type (L/s per person) L/s Per person

\section{Q8.2 - Equipment Types}

Select the equipment type that is most likely used for a packaged air handling unit.

Q8.2.1 - Cooling coil type

$$
\text { Water DX None }
$$

Q8.2.2 - Heating coil type

Water DX Electric None

Q8.2.3 - Supply fan type

Draw through

Blow through

Unknown

Q8.2.4 - Supply fan operation

Variable / Cycling Continuous Unknown 
Q8.3 - Plant Equipment Values

Select the plant equipment values that are most likely used for the packaged air handling unit.

\begin{tabular}{lc|c|c|} 
& Default value OK & $\begin{array}{c}\text { Default value not OK } \\
\text { Unsure of better value }\end{array}$ & $\begin{array}{c}\text { Default value not OK. } \\
\text { Better value suggested }\end{array}$ \\
\hline $\begin{array}{l}\text { Supply fan efficiency } \\
\text { Default: } \mathbf{0 . 7}\end{array}$ & $\square$ & $\square$ & $\square$ \\
\hline $\begin{array}{l}\text { Supply fan motor } \\
\text { efficiency } \\
\text { Default: } \mathbf{0 . 9}\end{array}$ & $\square$ & $\square$ & $\square$ \\
\hline $\begin{array}{l}\text { Cooling coil full load COP } \\
\text { Default: } \mathbf{3 . 0}\end{array}$ & $\square$ & $\square$ & $\square$ \\
\hline
\end{tabular}


The following questions are to identify what the design and performance values are for the HVAC systems identified to be commonly installed in New Zealand commercial buildings.

It is understandable that all HVAC systems are designed individually for the building they service. Therefore this survey is only asking for approximate values that are still realistically representative of what would be expected with the system and building type.

The questions in this section have been simplified as much as possible to reduce the amount of time to complete it. This is achieved by providing values from an energy simulation program as examples and asking you to either select the appropriate values or type in a value if required.

Reminder: this is for commercial buildings with a total floor area greater than 3,500 $\mathrm{m}^{2}$ and designed within the last 10 years.

\section{Q9.0 - Fan Coil Unit - poor energy efficiency building}

Fan coil units has been identified as being a commonly installed in a poor energy efficiency building; a building with high energy consumption.

Using the inputs required to model this system in an energy simulation program, what are the appropriate values to use?

\section{Q9.1 - Controls}

Select the control types that are most likely used for the chilled beam system.

\section{Q9.1.1 - Percentage of building typically conditioned}

$$
0 \%-25 \% \quad 26 \%-50 \% \quad 51 \%-75 \% \quad 76 \%-100 \%
$$

\section{Q9.1.2 - Automated control systems}

Select all that apply.

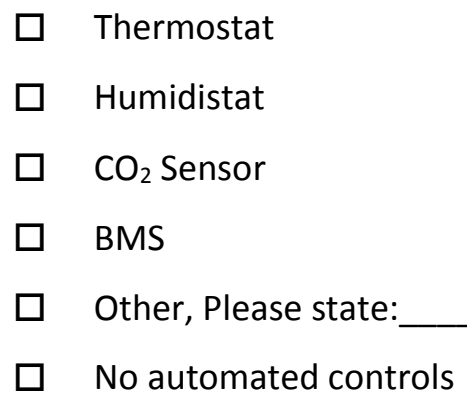




\section{Q9.1.3 - Outside Air Supply Rate}

How much outside air would be supplied when using this type of system?

Default value of $9 \mathrm{~L} / \mathrm{s}$ per person Other, Please type (L/s per person)

L/s Per person

\section{Q9.2 - Equipment Types}

Select the equipment type that is most likely used for a fan coil unit system.

Q9.2.1 - Cooling coil type

Water None

Q9.2.2 - Heating coil type

Water Electric None

Q9.2.3 - Chiller type

Electric Centrifugal Electric Reciprocating

Q9.2.4 - Chiller to coils loop - water pump configuration

$\begin{array}{cccc}\text { Variable Primary } & \text { Constant Primary } & \text { Variable Primary } & \text { Constant Primary } \\ \text { No Secondary } & \text { No Secondary } & \text { Constant Secondary } & \text { Variable Secondary }\end{array}$

Q9.2.5 - Condenser type

Water cooled $\quad$ Air cooled Evaporative

\section{Q9.2.6 - Chilled water condenser loop - pump control type}

Intermittent

(variable)

Continuous

$\square$ 
Q9.2.7 - Condenser water temperature - control type

Variable

Based on outdoor temperature

ㅁ
Fixed

Specific set point

\section{Q9.2.8 - Cooling tower speed}

$$
\text { Single speed Two speed }
$$

Q9.2.9 - Boiler fuel type

Electric Natural Gas Bottled Gas Oil Diesel Coal

$\begin{array}{llllll}\square & \square & \square & \square & \square & \square\end{array}$

Q9.2.10 - Boiler to coils loop - pump control type

$$
\begin{aligned}
& \text { Intermittent Continuous } \\
& \text { (variable) }
\end{aligned}
$$

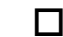

\section{Q9.3 - Plant Equipment Values \\ Q9.3.1 - General system}

Select the plant equipment values that are most likely used for the fan coil unit system.

\begin{tabular}{l|c|c|c} 
& Default value OK & $\begin{array}{c}\text { Default value not OK } \\
\text { Unsure of better value }\end{array}$ & $\begin{array}{c}\text { Default value not OK. } \\
\text { Better value suggested }\end{array}$ \\
$\begin{array}{l}\text { Supply fan efficiency } \\
\text { Default: } \mathbf{0 . 7}\end{array}$ & $\square$ & $\square$ & $\square$ \\
\hline $\begin{array}{l}\text { Supply fan motor } \\
\text { efficiency } \\
\text { Default: } \mathbf{0 . 9}\end{array}$ & $\square$ & $\square$ & $\square$ \\
\hline $\begin{array}{l}\text { Cooling coil inlet design } \\
\text { setpoint }\end{array}$ & $\square$ & $\square$ & $\square$ \\
$\begin{array}{l}\text { Default: } \mathbf{1 4} \mathbf{4}^{\circ \mathrm{C}} \\
\text { Heating coil inlet design } \\
\text { setpoint }\end{array}$ & $\square$ & $\square$ & $\square$ \\
Default: $\mathbf{5 0} 0^{\circ \mathrm{C}}$ & & & $\square$ \\
\hline
\end{tabular}


Q9.3.1 - Chiller

\begin{tabular}{|c|c|c|c|}
\hline & Default value OK & $\begin{array}{l}\text { Default value not OK } \\
\text { Unsure of better value }\end{array}$ & $\begin{array}{l}\text { Default value not OK. } \\
\text { Better value suggested }\end{array}$ \\
\hline $\begin{array}{l}\text { Full load COP } \\
\text { Default: } \mathbf{2 . 5}\end{array}$ & $\square$ & $\square$ & $\square$ \\
\hline $\begin{array}{l}\text { Chilled water design } \\
\text { setpoint } \\
\text { Default: } \mathbf{7 . 2 { } ^ { \circ } \mathrm { C }}\end{array}$ & $\square$ & $\square$ & $\square$ \\
\hline 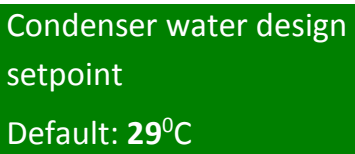 & $\square$ & $\square$ & $\square$ \\
\hline
\end{tabular}

\section{Q9.3.2 - Boiler}

\begin{tabular}{|c|c|c|c|}
\hline & Default value OK & $\begin{array}{l}\text { Default value not OK } \\
\text { Unsure of better value }\end{array}$ & $\begin{array}{l}\text { Default value not OK. } \\
\text { Better value suggested }\end{array}$ \\
\hline $\begin{array}{l}\text { Efficiency } \\
\text { Default: } \mathbf{0 . 8}\end{array}$ & $\square$ & $\square$ & $\square$ \\
\hline $\begin{array}{l}\text { Hot water design } \\
\text { setpoint } \\
\text { Default: } \mathbf{8 2}^{\circ} \mathrm{C}\end{array}$ & $\square$ & $\square$ & $\square$ \\
\hline
\end{tabular}

Click on the $>$ button to progress

\section{Q10.0 - Any Issues}

Were there any issues regarding completion of this survey?

If yes, please note what the issues were.

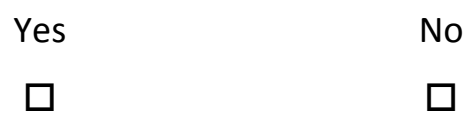

Issue(s): 
Thank you for your time in completing this survey.

The results will be analyses and complied into the thirdround of questions, you will be contacted with this soon.

If you have any further questions or would like to get in contact, please contact me at: gatesanth@myvuw.ac.nz

Thank you.

\section{Anthony Gates}

Master of Building Science student

Victoria University of Wellington 


\section{F3: Round two survey questions - Non-simulators}

\section{Introduction}

Thank you for recently completing a survey to identify which HVAC systems are the most commonly installed within New Zealand commercial buildings.

This follow up survey is used to form a consensus opinion based on the results of the previous survey.

There are three questions in this survey with a simple agree or disagree answer for each. It is expected that this will take only a couple minutes of your time to complete.

This survey version has been sent to you because you stated that you are not involved with dynamic thermal/energy computer simulations of buildings. If this is incorrect, please contact Anthony Gates at gatesanth@myvuw.ac.nz to receive an alternative survey which addresses the computer input parameters that are used to model the systems.

\section{Reminder of the project}

General Information

This project is using a survey to collect data on the most commonly installed Heating, Ventilation, and Air Conditioning (HVAC) systems in New Zealand commercial buildings.

From this, standard descriptions will be created and transformed into HVAC templates which will be used within computer based building energy simulations. This information is contributing towards the Building Energy End-use Study (BEES) currently being performed by BRANZ (Building Research Association of New Zealand).

\section{Scope}

This survey is limited to gather information on HVAC systems that have been designed, specified, and built in New Zealand commercial buildings.

There is a focus on buildings with a total floor area greater than $3,500 \mathrm{~m}^{2}$ and built or designed over the last 10 years.

\section{Confidentiality}

The information and data that is collected within this survey will be kept anonymous and confidential.

No individuals, companies, or affiliations will be identified within the reporting of the results. 
Q1.0 - Email Address

This is collected to ensure that the survey is only answered once.

Please Type.

These questions are used to form a consensus opinion on the most commonly installed HVAC systems in New Zealand commercial buildings. This is derived from the responses obtained in the previous survey questions.

For each of the three building types, please select whether you agree or disagree with the responses provided by the majority of the participants.

Reminder: this is for commercial buildings with a total floor area greater than $3,500 \mathrm{~m}^{2}$ and designed within the last 10 years.

\section{Q2.0 - Good Energy Efficiency Building}

From the previous round of questions, the majority of the participants identified that the most commonly installed HVAC systems for a building that has good energy efficiency were;

$\checkmark$ Chilled Beams

\section{- Variable Air Volume}

Do you agree that these systems are most likely installed in a good energy efficiency building (low energy consumption)?

\section{Select one}

If you disagree, please explain your reasoning.
Agree
Disagree 


\section{Q2.1 - Common Practice Building}

From the previous round of questions, the majority of the participants identified that the most likely HVAC systems installed as common practice were;

- Variable Air Volume

\section{$\checkmark$ Fan coil units}

Do you agree that these systems are most likely installed as common practice?

Reminder: this is for commercial buildings with a total floor area greater than $3,500 \mathrm{~m}^{2}$ and designed within the last 10 years.

\section{Select one}

If you disagree, please explain your reasoning.
Agree
$\square$ Disagree

\section{Q2.2 - Poor Energy Efficiency Building}

From the previous round of questions, the majority of the participants identified that the most commonly installed HVAC systems for a building that has poor energy efficiency were;

\section{- Packaged AHU}

$\checkmark$ Fan coil units

\section{Split system heat pumps}

Do you agree that these systems are most likely installed in a poor energy efficiency building (high energy consumption)?

Reminder: this is for commercial buildings with a total floor area greater than $3,500 \mathrm{~m}^{2}$ and designed within the last 10 years.

\section{Select one}

If you disagree, please explain your reasoning.

Agree

$\square$ Disagree 
Q10.0 - Any Issues

Were there any issues regarding completion of this survey?

If yes, please note what the issues were.

Yes No

Issue(s):

Click on the $>$ button to progress

Thank you for your time in completing this survey.

If you have any further questions or would like to get in contact, please contact me at:

\section{gatesanth@myvuw.ac.nz}

Thank you.

\section{Anthony Gates}

Master of Building Science student

Victoria University of Wellington 


\section{F4: Round three survey questions}

\section{Introduction}

Thank you for recently completing a survey to identify the input parameters and values that are used to model the HVAC systems that are commonly used in New Zealand commercial buildings. This follow up survey is used to form a consensus based on the results of the previous survey.

You are asked to review the values that have been provided by the majority of the participants of this study and say if you agree with the values or not. The values are based on the responses from the participants as well as a review of manufacturers' data sheets to confirm.

\section{Your Involvement}

There are seven questions, each one requires an agree or disagree answer.

It is estimated that it will take 10 minutes to complete all questions in this survey.

\section{Reminder of the project}

\section{General Information}

This project is using a survey to collect data on the most commonly installed Heating, Ventilation, and Air Conditioning (HVAC) systems in New Zealand commercial buildings.

From this, standard descriptions will be created and transformed into HVAC templates which will be used within computer based building energy simulations. This information is contributing towards the Building Energy End-use Study (BEES) currently being performed by BRANZ (Building Research Association of New Zealand).

\section{Scope}

This survey is limited to gather information on HVAC systems that have been designed, specified, and built in New Zealand commercial buildings.

There is a focus on buildings with a total floor area greater than $3,500 \mathrm{~m}^{2}$ and built or designed over the last 10 years.

\section{Confidentiality}

The information and data that is collected within this survey will be kept anonymous and confidential.

No individuals, companies, or affiliations will be identified within the reporting of the results. 
Q1.0-Email Address

This is collected to ensure that the survey is only answered once.

Please Type.

Q2.0 - Chilled Beams, good energy efficiency building

From the previous round of questions, these values were identified as being likely for a chilled beam system in a commercial building that has good energy efficiency.

\section{General Aspects}

Percentage of building serviced: $\mathbf{7 6 \%}-\mathbf{1 0 0 \%}$

Controls: Thermostat, $\mathrm{CO}_{2}$ Sensor, BMS

Outdoor air supply rate: $15 \mathrm{~L} / \mathrm{s}$ per person

\section{Equipment Types}

Cooling coil: Water

Heating coil: None, but with baseboard heating

Chilled beam type: Active / fan assisted

Plant Type

Chiller type: Centrifugal

Chiller to chilled beam water loop pumps: Constant primary, variable secondary

Chiller condenser type: Water cooled

Chilled water condenser water loop pump: Variable (Intermittent)

Chiller condenser water temperature control: Variable (Based on outside temperature) Cooling tower: Two speed

\section{Performance Values}

Chilled beam water inlet temperature: $12^{\circ} \mathrm{C}$

Chiller full load COP: $\mathbf{4 . 2}$

Chiller cold water setpoint temperature: $6^{\circ} \mathrm{C}$ 
Please indicate any fields that you disagree with, suggest a better value, and provide reasoning(s) why you disagree.

Type text in the box below

If nothing is typed in the box above, it will be assumed that you agree with all of the values presented for this system.

\section{Q2.0 - Variable Air Volume, good energy efficiency building}

From the previous round of questions, these values were identified as being likely for a VAV system in a commercial building that has good energy efficiency.

\section{General Aspects}

Percentage of building serviced: $\mathbf{7 6 \%}-\mathbf{1 0 0 \%}$

Controls: Thermostat, $\mathrm{CO}_{2}$ Sensor, BMS

Outdoor air supply rate: $15 \mathrm{~L} / \mathrm{s}$ per person

$$
\text { Equipment Types }
$$

Cooling coil: Water

Heating coil: Water

Baseboard heating type: Water heated

Reheat coil: Water heated

Supply fan type: Draw through

Fan layout: Parallel

Heat recovery: Enthalpy (Recovers both sensible and latent heat)

Night cycle ventilation: Using central air handler fan

Dehumidifier: None

Humidifier: None 
Plant Type

Chiller type: Centrifugal

Chiller to coil water loop pumps: Constant primary, variable secondary

Chiller condenser type: Water cooled

Chilled water condenser water loop pump: Variable (Intermittent)

Chiller condenser water temperature control: Variable (Based on outside temperature)

Cooling tower: Two speed

Boiler fuel type: Natural gas

Boiler to coils water loop pumps: Variable (Intermittent)

\section{Performance Values}

Supply fan efficiency: $\mathbf{0 . 7}$

Supply fan motor efficiency: $\mathbf{0 . 9}$

Cooling coil inlet setpoint temperature: $15^{\circ} \mathrm{C}$

Heating coil inlet setpoint temperature: $10^{\circ} \mathrm{C}$

Preheat coil setpoint temperature: $35^{\circ} \mathrm{C}$

Heat recovery - Sensible effectiveness: $\mathbf{0 . 7 5}$

Heat recovery - Latent effectiveness: $\mathbf{0 . 7 0}$

Chiller full load COP: $\mathbf{4 . 0}$

Chiller cold water setpoint temperature: $6^{\circ} \mathrm{C}$

Condenser water setpoint temperature: $30^{\circ} \mathrm{C}$

Boiler efficiency: $\mathbf{0 . 9 0}$

Boiler hot water setpoint temperature: $80^{\circ} \mathrm{C}$

Please indicate any fields that you disagree with, suggest a better value, and provide reasoning(s) why you disagree.

Type text in the box below

If nothing is typed in the box above, it will be assumed that you agree with all of the values presented for this system. 
Q3.0 - Fan Coil Units, common practice building

From the previous round of questions, these values were identified as being likely for a fan coil unit system installed as common practice in a commercial building.

\section{General Aspects}

Percentage of building serviced: $\mathbf{5 1 \%}-\mathbf{7 5 \%}$

Controls: Thermostat, BMS

Outdoor air supply rate: $10 \mathrm{~L} / \mathrm{s}$ per person

\section{Equipment Types}

Cooling coil: Water

Heating coil: Water

\section{Plant Types}

Chiller type: Centrifugal

Chiller condenser type: Air cooled

Chiller to coils water loop pumps: Constant primary, variable secondary

Boiler fuel type: Natural gas

Boiler to coils water loop pump: Variable (Intermittent)

\section{Performance Values}

Supply fan efficiency: $\mathbf{0 . 7 0}$

Supply fan motor efficiency: $\mathbf{0 . 9 0}$

Cooling coil inlet setpoint temperature: $14^{\circ} \mathrm{C}$

Heating coil inlet setpoint temperature: $50^{\circ} \mathrm{C}$

Chiller full load COP: $\mathbf{2 . 5}$

Chiller cold water setpoint temperature: $6^{\circ} \mathrm{C}$

Boiler efficiency: $\mathbf{0 . 8 5}$

Boiler hot water setpoint temperature: $82^{\circ} \mathrm{C}$ 
Please indicate any fields that you disagree with, suggest a better value, and provide reasoning(s) why you disagree.

Type text in the box below

If nothing is typed in the box above, it will be assumed that you agree with all of the values presented for this system.

Q4.0 - Variable Air Volume, common practice building

From the previous round of questions, these values were identified as being likely for a VAV system installed as common practice in a commercial building.

\section{General Aspects}

Percentage of building serviced: $\mathbf{7 6} \%$ - $\mathbf{1 0 0 \%}$

Controls: Thermostat, BMS

Outdoor air supply rate: $10 \mathrm{~L} / \mathrm{s}$ per person

\section{Equipment Types}

Cooling coil: Water

Heating coil: Electric

Reheat coil: Electric

Baseboard heating type: None

Supply fan type: Draw through

Fan layout: Parallel

Heat recovery: None

Night cycle ventilation: None

Dehumidifier: None

Humidifier: None 


\section{Plant Type}

Chiller type: Centrifugal

Chiller condenser type: Air cooled

Chiller to coils water loop pumps: Constant primary, variable secondary

\section{Performance Values}

Supply fan efficiency: $\mathbf{0 . 7 0}$

Supply fan motor efficiency: $\mathbf{0 . 9 0}$

Cooling coil inlet setpoint temperature: $15^{\circ} \mathrm{C}$

Heating coil inlet setpoint temperature: $12^{\circ} \mathrm{C}$

Chiller full load COP: $\mathbf{3 . 8}$

Chiller cold water setpoint temperature: $7.2^{\circ} \mathrm{C}$

Please indicate any fields that you disagree with, suggest a better value, and provide reasoning(s) why you disagree.

Type text in the box below

If nothing is typed in the box above, it will be assumed that you agree with all of the values presented for this system. 
Q5.0 - Split System Heat Pump, poor energy efficiency building

From the previous round of questions, these values were identified as being likely for a split system heat pump system in a commercial building that has poor energy efficiency.

\section{General Aspects}

Percentage of building serviced: $\mathbf{5 1 \%}-\mathbf{7 5 \%}$

Controls: Thermostat

Outdoor air supply rate: $10 \mathrm{~L} / \mathrm{s}$ per person

\section{Equipment Types}

Cooling coil: DX

Heating coil: DX

Supply fan type: Draw through

Heat recovery type: None

Night cycle ventilation: None

Humidifier: None

\section{Performance Values}

Supply fan efficiency: $\mathbf{0 . 7 0}$

Supply fan motor efficiency: $\mathbf{0 . 9 0}$

Cooling coil full load COP: 4.2

Heating coil fuel load COP: 4.0

Please indicate any fields that you disagree with, suggest a better value, and provide reasoning(s) why you disagree.

Type text in the box below

If nothing is typed in the box above, it will be assumed that you agree with all of the values presented for this system. 
Q6.0 - Packaged Air Handling Unit, poor energy efficiency building

From the previous round of questions, these values were identified as being likely for a packaged air handling unit system in a commercial building that has poor energy efficiency.

\section{General Aspects}

Percentage of building serviced: $\mathbf{7 6} \% \mathbf{- 1 0 0 \%}$

\section{Controls: Thermostat, BMS}

Outdoor air supply rate: $10 \mathrm{~L} / \mathrm{s}$ per person

\section{Equipment Types}

Cooling coil: DX

Heating coil: Electric

Supply fan type: Draw through

Supply fan operation: Variable/Cycling

\section{Performance Values}

Supply fan efficiency: $\mathbf{0 . 7 0}$

Supply fan motor efficiency: $\mathbf{0 . 9 0}$

Cooling coil full load COP: $\mathbf{3 . 0}$

Please indicate any fields that you disagree with, suggest a better value, and provide reasoning(s) why you disagree.

Type text in the box below

If nothing is typed in the box above, it will be assumed that you agree with all of the values presented for this system. 
Q7.0-Fan Coil Units, poor energy efficiency building

From the previous round of questions, these values were identified as being likely for a fan coil units system in a commercial building that has poor energy efficiency.

\section{General Aspects}

Percentage of building serviced: $\mathbf{7 6} \% \mathbf{- 1 0 0 \%}$

Controls: Thermostat, BMS

Outdoor air supply rate: $10 \mathrm{~L} / \mathrm{s}$ per person

\section{Equipment Types}

Cooling coil: Water

Heating coil: Water

\section{Plant Types}

Chiller type: Centrifugal

Chiller condenser type: Air cooled

Chiller to coils water loop pumps: Constant primary, variable secondary

Boiler fuel type: Natural gas

Boiler to coils water loop pump: Variable (Intermittent)

\section{Performance Values}

Supply fan efficiency: $\mathbf{0 . 7 0}$

Supply fan motor efficiency: $\mathbf{0 . 9 0}$

Cooling coil inlet setpoint temperature: $10^{\circ} \mathrm{C}$

Heating coil inlet setpoint temperature: $50^{\circ} \mathrm{C}$

Chiller full load COP: $\mathbf{2 . 5}$

Chiller cold water setpoint temperature: $6^{\circ} \mathrm{C}$

Boiler efficiency: $\mathbf{0 . 8 0}$

Boiler hot water setpoint temperature: $\mathbf{8 0}^{\circ} \mathrm{C}$ 
Please indicate any fields that you disagree with, suggest a better value, and provide reasoning(s) why you disagree.

Type text in the box below

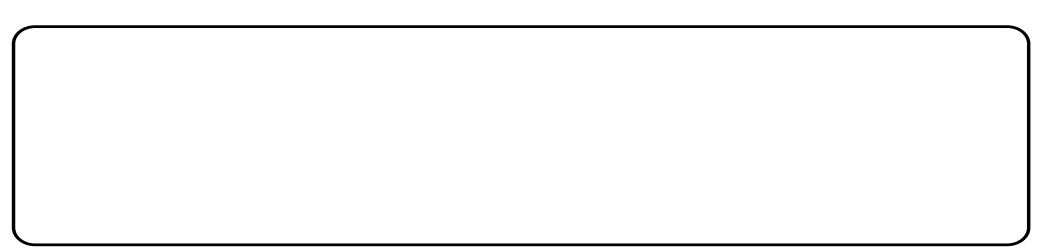

If nothing is typed in the box above, it will be assumed that you agree with all of the values presented for this system.

Click on the $>$ button to progress

Q8.0 - Any Issues

Were there any issues regarding completion of this survey?

If yes, please note what the issues were.

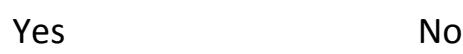

Issue(s):

Click on the >> button to progress

Thank you for your time in completing this survey.

The results will be analyses and complied into the third round of questions which will form a consensus on the equipment types and values, you will be contacted with this soon.

If you have any further questions or would like to get in contact, please contact me at: gatesanth@myvuw.ac.nz

Thank you.

\section{Anthony Gates}

Master of Building Science student

Victoria University of Wellington

Click on the $\gg$ button to submit your responses 


\section{Appendix G - EnergyPlus objects used for modelling HVAC systems}

To model the HVAC systems in EnergyPlus, the HVAC template objects within the idf editor were used. By using these objects to model the HVAC systems, the modelling process is simplified and the chances of receiving modelling errors is reduced. Further explanation of how to use the HVAC template objects is documented in the EnergyPlus Input Output reference document (EnergyPlus, 2010. pg1950).

This appendix provides a list of all objects used in EnergyPlus to model each HVAC system.

Appendix I contains all of the input values that are associated with these modelling objects.

\section{G1: Good energy efficiency building}

\section{Chilled beams}

As there is no HVAC template object for a chilled beams system in the idf editor, the fan coil unit objects were used to collect the data as the inputs are the same. When modelling the chilled beams, the expanded idf (expidf) file was used in order to change the modelling objects to the ones required for a chilled beams system.

- Thermostat

Zone:FanCoil

- Plant:ChilledWaterLoop

- Plant:HotWaterLoop

$\checkmark$ Plant:Chiller

- Plant:Boiler

\section{Variable Air Volume}

$\checkmark$ Thermostat

- Zone:VAV:FanPowered

- System:VAV

$\checkmark$ Plant:ChilledWaterLoop

- Plant:HotWaterLoop

- Plant:Chiller

$\checkmark$ Plant:Boiler

$\checkmark$ Plant:Tower 


\section{G2: Common practice building}

Variable Air Volume

$\checkmark$ Thermostat

Zone:VAV:FanPowered

System:VAV

- Plant:ChilledWaterLoop

Plant:Chiller

\section{Fan coil unit}

$\checkmark$ Thermostat

Zone:FanCoil

- Plant:ChilledWaterLoop

- Plant:HotWaterLoop

- Plant:Chiller

- Plant:Boiler

\section{G3: Poor energy efficiency building}

Split system heat pump

$\checkmark$ Thermostat

Zone:Unitary

- System:UnitaryHeatPump:AirToAir

Packaged air handling unit

$\checkmark$ Thermostat

- Zone:PTAC

Fan coil units

$\checkmark$ Thermostat

- Zone:FanCoil

- Plant:ChilledWaterLoop

- Plant:HotWaterLoop

- Plant:Chiller

- Plant:Boiler 


\section{Appendix H - Identified HVAC system types}

This appendix documents the types of HVAC systems that were identified as being commonly installed in the different building types as well as the responses from the experts when forming a consensus on these systems.

\section{H1: Round one - Identifying likely installed HVAC systems}

The responses from the first round of questions were used to identify which HVAC systems are most commonly installed in the three building types. The systems that were selected the most were used in the round two questions to form a consensus between the experts.

\section{Good energy efficiency building type}

For the good energy efficiency building type, it was clear that the two types of HVAC systems that are likely to be installed are chilled beams and variable air volume. These systems were presented to the experts in the second round to ask if they agree with the majority of the responses.

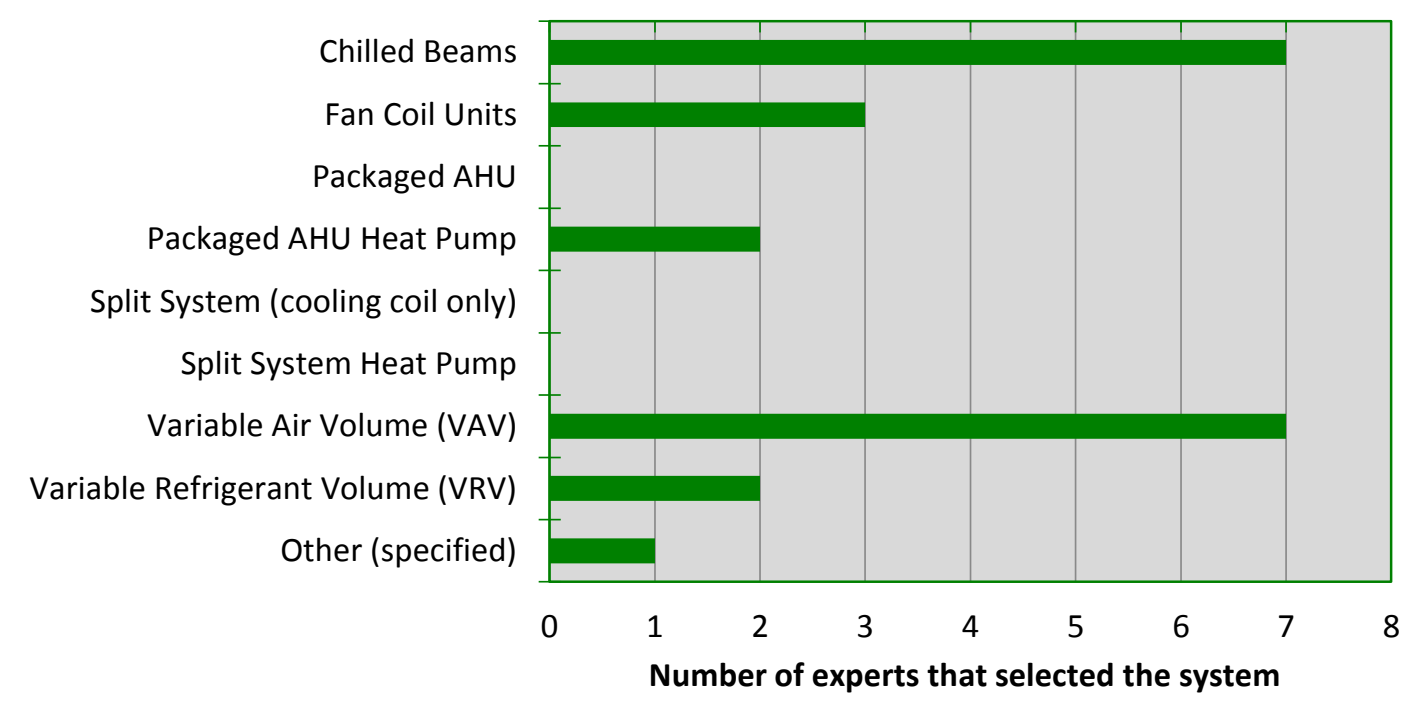

Figure 13. HVAC system types identified for a good energy efficiency building. 


\section{Common practice building type}

Fan coil units and the variable air volume system were the most selected HVAC systems for the common practice building type. These two systems were used in the second round of questions when forming a consensus.

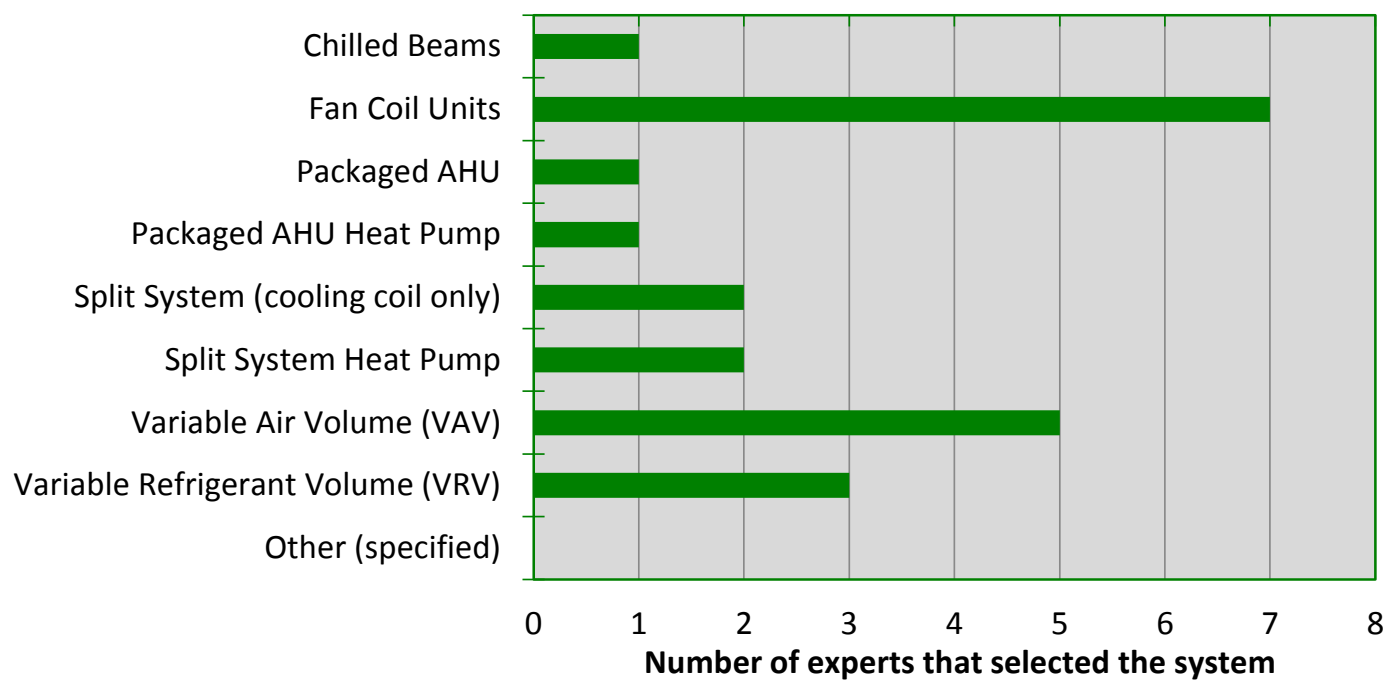

Figure 14. HVAC system types identified for a common practice building.

\section{Poor energy efficiency building type}

For the poor energy efficiency building type, it was less clear which systems are the most commonly installed HVAC systems. Therefore, the three systems that were selected the most were used when forming a consensus in the second round of questions: fan coil units, packaged $\mathrm{AHU}$, and split system heat pump.

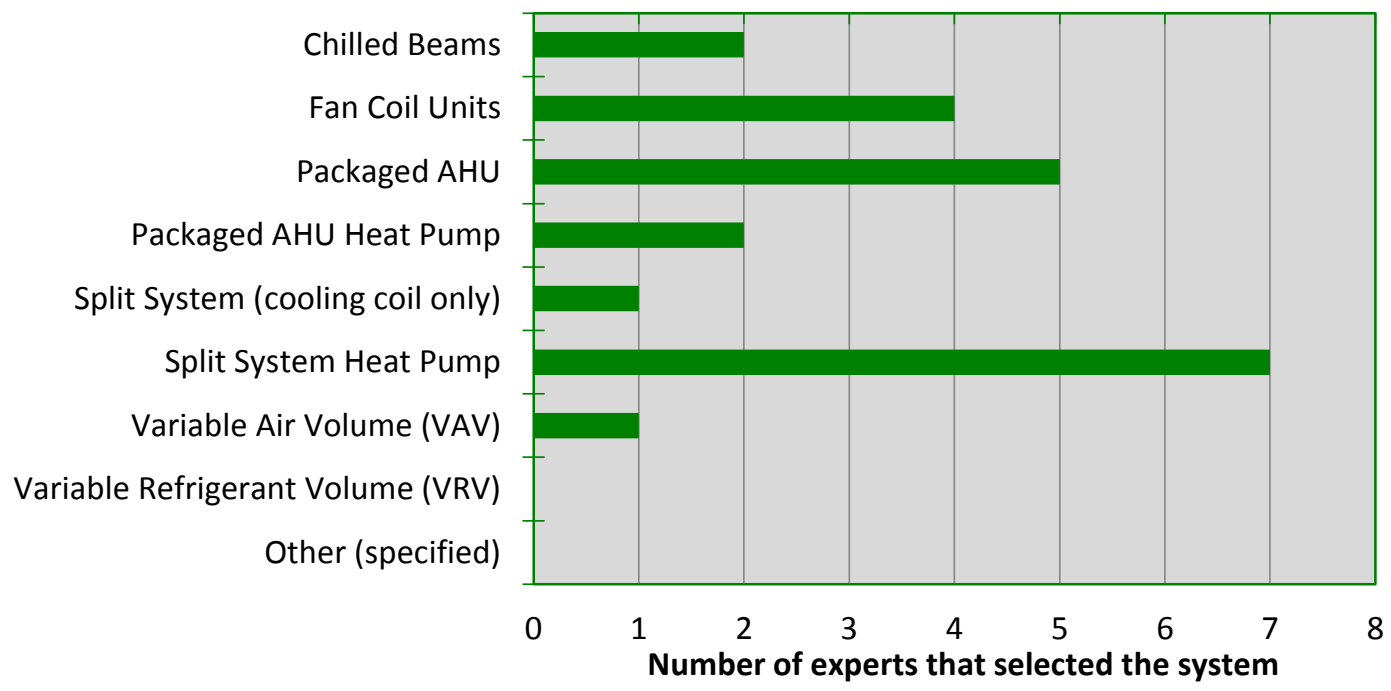

Figure 15. HVAC system types identified for a poor energy efficiency building. 


\section{H2: Round two - Forming a consensus}

The round two questions formed a consensus on the types of HVAC systems that are commonly installed in the three building types. The following graphs show how many experts agreed and disagreed with the types of systems that were presented to them.

It should be noted that the second round of questions had fewer experts participate than the first round of questions. Each graph is broken down to show the responses provided by the non-simulators and simulators.

\section{Good energy efficiency building type}

For the good energy efficiency building type, a clearly agreed consensus is shown by both types of experts. Chilled beams and variable air volume are the HVAC systems identified for this building type.

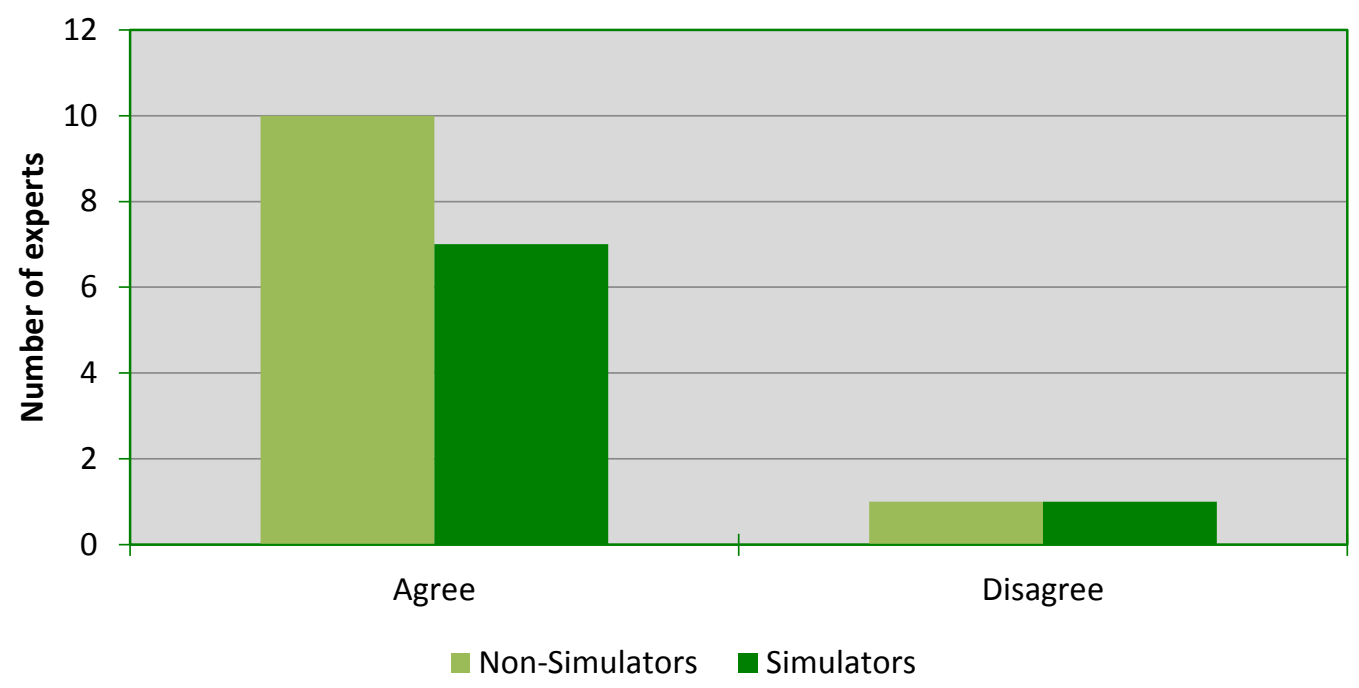

Figure 16. Consensus response on the types of HVAC systems for a good energy efficiency building. 


\section{Common practice building type}

Variable air volume and fan coil units had a clearly agreed consensus formed to confirm that they are installed as common practice.

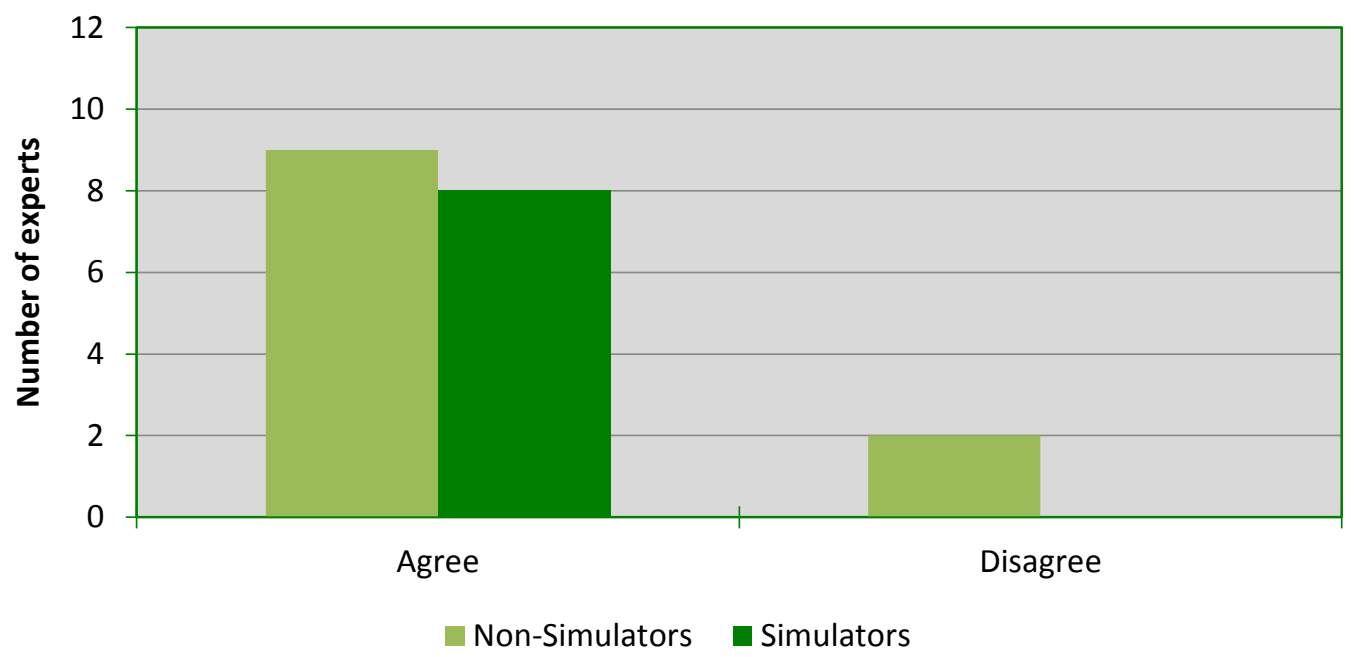

Figure 17. Consensus response on the types of HVAC systems for a common practice building.

\section{Poor energy efficiency building type}

For the poor energy efficiency building type, a consensus was formed as shown by the number of agreeing experts being greater than the experts that disagreed. However the level of agreement is not as clear as the consensus for the other building types.

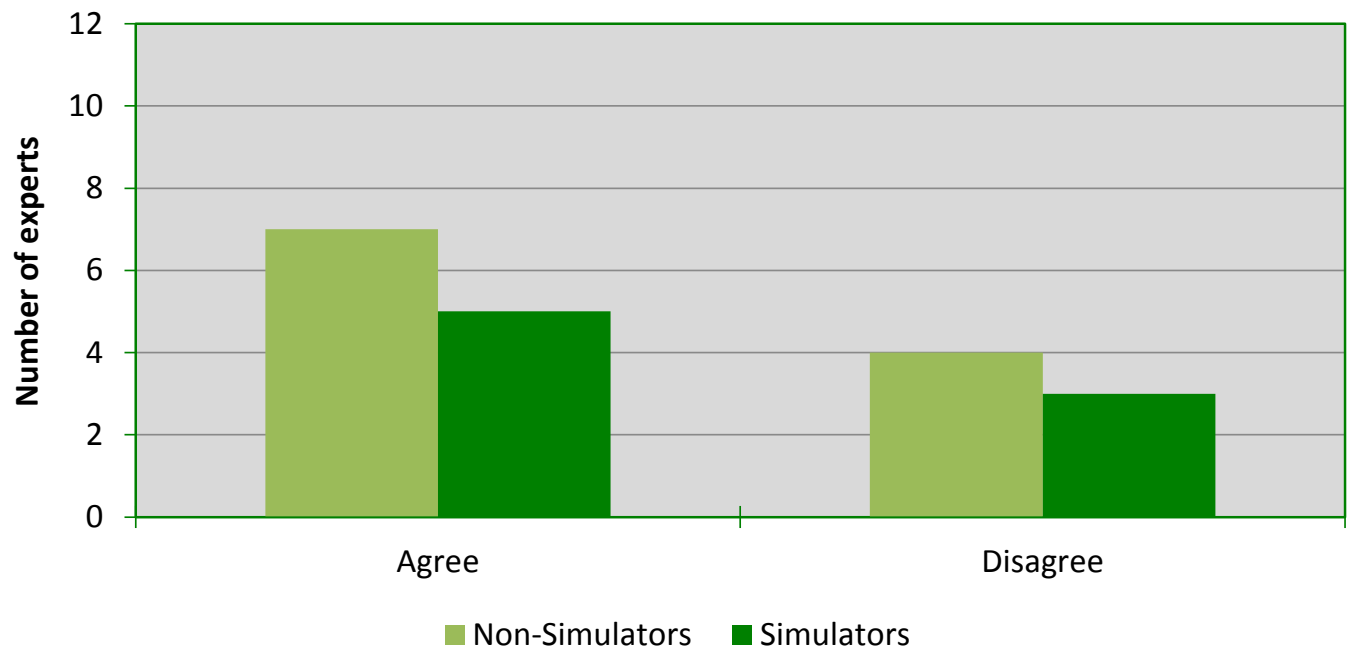

Figure 18. Consensus response on the types of HVAC systems for a poor energy efficiency building. 


\section{Appendix I - Summary of HVAC modelling input values}

This appendix documents the modelling input parameter values that are within the HVAC template models. The consensus of the survey has determined all of the values to be representative of the likely installed systems. The values are tabulated next to the EnergyPlus objects used to model the systems.

\section{I1: Good energy efficiency building type}

Chilled beams

\begin{tabular}{r|c|} 
& Equipment Types and Modelling Values \\
\hline Percentage of building serviced & $76-100 \%$ \\
\hline Controls installed & Thermostat, $\mathrm{CO}_{2}$ Sensor, BMS \\
\hline Outdoor air supply rate (L/s/person) & 15 \\
\hline Cooling coil & Water \\
\hline Chilled beam type & Cooling only, fan assisted \\
\hline Supply fan placement & Blow through \\
\hline Baseboard heating type & Electric \\
\hline Chiller type & Centrifugal \\
\hline Chiller to coils loop pump type & Constant primary, variable secondary \\
\hline Condenser type & Water cooled \\
\hline Condenser water temperature control & Variable, \\
\hline Chiller to condenser water loop pump type & based on outside temperature \\
\hline Cooling tower type & Variable \\
\hline Supply fan efficiency & Two speed \\
\hline Supply fan motor efficiency & 0.7 \\
\hline Chiller COP & 0.9 \\
\hline Coil design set point $\left({ }^{\circ} \mathrm{C}\right)$ & 14 \\
\hline water set point $\left({ }^{\circ} \mathrm{C}\right)$ & 4.2 \\
\hline
\end{tabular}

Table 16. Modelling input parameter values: Chilled beams, good energy efficiency building. 
Variable air volume

Equipment Types and Modelling Values

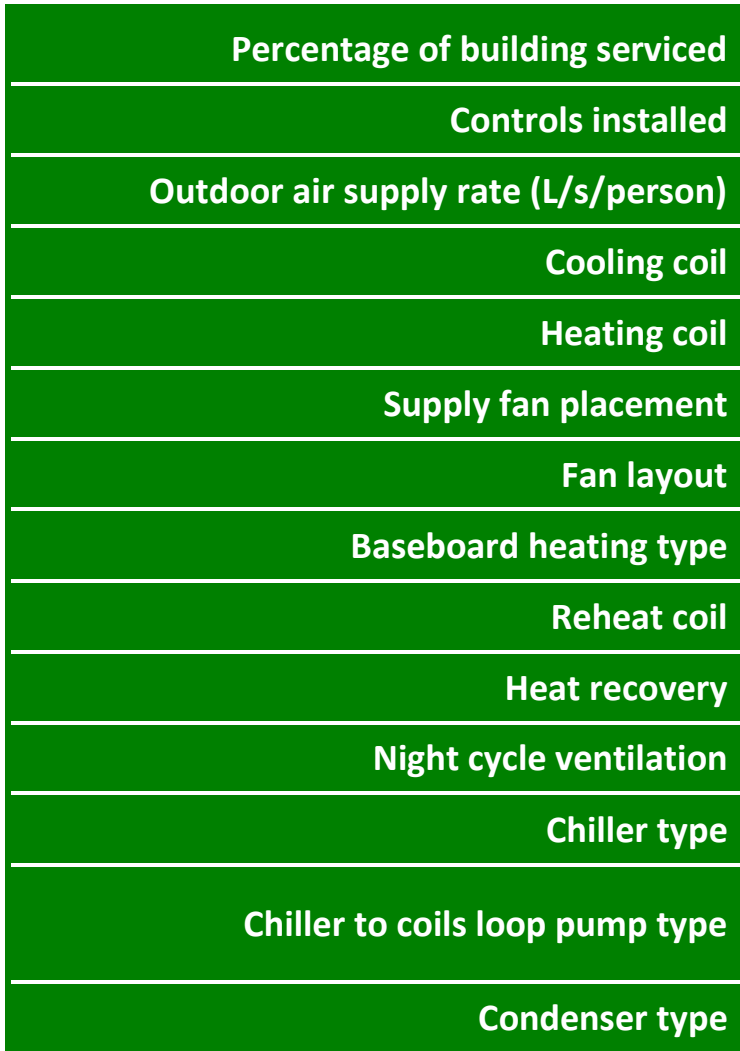

Condenser water temperature control

Chiller to condenser water loop pump type Cooling tower type Boiler fuel

Boiler to coils loop pump type Supply fan efficiency Supply fan motor efficiency Cooling coil design set point $\left({ }^{\circ} \mathrm{C}\right)$ Heating coil design set point $\left({ }^{\circ} \mathrm{C}\right)$ Heat recovery effectiveness - Sensible Heat recovery effectiveness - Latent Chiller COP

$\begin{array}{r}\text { Chiller COP } \\ \hline \text { Chilled water set point }\left({ }^{\circ} \mathrm{C}\right)\end{array}$

Condenser water design set point $\left({ }^{\circ} \mathrm{C}\right)$ Boiler efficiency Hot water set point $\left({ }^{\circ} \mathrm{C}\right)$
$76-100 \%$

Thermostat, $\mathrm{CO}_{2}$ Sensor, BMS 15

Water

Water

Draw through

Parallel

Water

Water

Enthalpy

Central air handler

Centrifugal

Constant primary, variable secondary

Water cooled

Variable, based on outside temperature

Variable

Two speed

Natural gas

Variable

0.7

0.9

15

10

0.75

0.7

4.2

6

30

0.9

80

Table 17. Modelling input parameter values: VAV, good energy efficiency building. 


\section{I2: Common practice building type}

Variable air volume

Equipment Types and Modelling Values

\begin{tabular}{|r|}
\hline Percentage of building serviced \\
\hline Controls installed \\
\hline
\end{tabular}

$76-100 \%$

Thermostat, BMS

Outdoor air supply rate (L/s/person)

10

Cooling coil

Heating coil

Supply fan placement

Fan layout

Preheat coil

Reheat coil

Chiller type

Chiller to coils loop pump type

Condenser type

Supply fan efficiency

Supply fan motor efficiency

Cooling coil design set point $\left({ }^{\circ} \mathrm{C}\right)$

Heating coil design set point $\left({ }^{\circ} \mathrm{C}\right)$

Preheat coil design set point $\left({ }^{\circ} \mathrm{C}\right)$

Chiller COP

Chilled water set point $\left({ }^{\circ} \mathrm{C}\right)$

Water

Electric

Draw through

Parallel

Electric

Electric

Centrifugal

Constant primary, variable secondary

Air cooled

$$
0.7
$$

0.9

15

12

6

3.8

7.2

Table 18. Modelling input parameter values: VAV, common practice building. 
Fan coil units

Equipment Types and Modelling Values

\begin{tabular}{|c|c|}
\hline Percentage of building serviced & $51-75 \%$ \\
\hline Controls installed & Thermostat, BMS \\
\hline Outdoor air supply rate (L/s/person) & 10 \\
\hline Cooling coil & Water \\
\hline Heating coil & Water \\
\hline Chiller type & Centrifugal \\
\hline Chiller to coils loop pump type & Constant primary, variable secondary \\
\hline Condenser type & Air cooled \\
\hline Boiler fuel & Natural gas \\
\hline Boiler to coils loop pump type & Variable \\
\hline Supply fan efficiency & 0.7 \\
\hline Supply fan motor efficiency & 0.9 \\
\hline Cooling coil design set point $\left({ }^{\circ} \mathrm{C}\right)$ & 14 \\
\hline Heating coil design set point $\left({ }^{\circ} \mathrm{C}\right)$ & 50 \\
\hline Chiller COP & 2.5 \\
\hline Chilled water set point $\left({ }^{\circ} \mathrm{C}\right)$ & 6 \\
\hline Boiler efficiency & 0.85 \\
\hline Hot water set point $\left({ }^{\circ} \mathrm{C}\right)$ & 82 \\
\hline
\end{tabular}

Table 19. Modelling input parameter values: Fan coil unit, common practice building. 


\section{I3: Poor energy efficiency building type}

Split system heat pump

\begin{tabular}{|r|c|}
\hline Percentage of building serviced & Equipment Types and Modelling Values \\
\hline Controls installed & $51-75 \%$ \\
\hline Outdoor air supply rate (L/s/person) & Thermostat \\
\hline Cooling/Heating coil type & 10 \\
\hline Supply fan placement & DX \\
\hline Supply fan operation & Draw through \\
\hline Supply fan efficiency & Cycling \\
\hline Supply fan motor efficiency & 0.7 \\
\hline Cooling COP & 0.9 \\
\hline Heating COP & 4.2 \\
\hline
\end{tabular}

Table 20. Modelling input parameter values: Split system heat pump, poor energy efficiency building.

Packaged air handling unit

\begin{tabular}{|r|c|}
\hline Percentage of building serviced & Equipment Types and Modelling Values \\
\hline Controls installed & $76-100 \%$ \\
\hline Outdoor air supply rate (L/s/person) & Thermostat, BMS \\
\hline Cooling coil type & 10 \\
\hline Heating coil & DX \\
\hline Supply fan placement & Electric \\
\hline Supply fan operation & Draw through \\
\hline Supply fan efficiency & Cycling \\
\hline Supply fan motor efficiency & 0.7 \\
\hline Cooling COP & 0.9 \\
\hline
\end{tabular}

Table 21. Modelling input parameter values: Packaged AHU, poor energy efficiency building. 
Fan coil unit

Equipment Types and Modelling Values

\begin{tabular}{|c|c|}
\hline Percentage of building serviced & $76-100 \%$ \\
\hline Controls installed & Thermostat, BMS \\
\hline Outdoor air supply rate (L/s/person) & 10 \\
\hline Cooling coil & Water \\
\hline Heating coil & Water \\
\hline Chiller type & Centrifugal \\
\hline Chiller to coils loop pump type & Constant primary, variable secondary \\
\hline Condenser type & Air cooled \\
\hline Boiler fuel & Natural gas \\
\hline Boiler to coils loop pump type & Variable \\
\hline Supply fan efficiency & 0.7 \\
\hline Supply fan motor efficiency & 0.9 \\
\hline Cooling coil design set point $\left({ }^{\circ} \mathrm{C}\right)$ & 10 \\
\hline Heating coil design set point $\left({ }^{\circ} \mathrm{C}\right)$ & 50 \\
\hline Chiller COP & 2.5 \\
\hline Chilled water set point $\left({ }^{\circ} \mathrm{C}\right)$ & 6 \\
\hline Boiler efficiency & 0.8 \\
\hline Hot water set point $\left({ }^{\circ} \mathrm{C}\right)$ & 80 \\
\hline
\end{tabular}

Table 22. Modelling input parameter values: Fan coil unit, poor energy efficiency building. 
Appendix J - Comparison of energy consumption: default values vs template values

To illustrate how the updated input parameter values have affected the calculated monthly energy performance; this appendix documents the percentage difference for all five built form geometries in the three tested climates. The percentage difference is how much the new HVAC template values have changed the calculated results in comparison to using the EnergyPlus default values.

A summary of the five built form geometries is explained in Appendix A.

J1: Cellular Strip

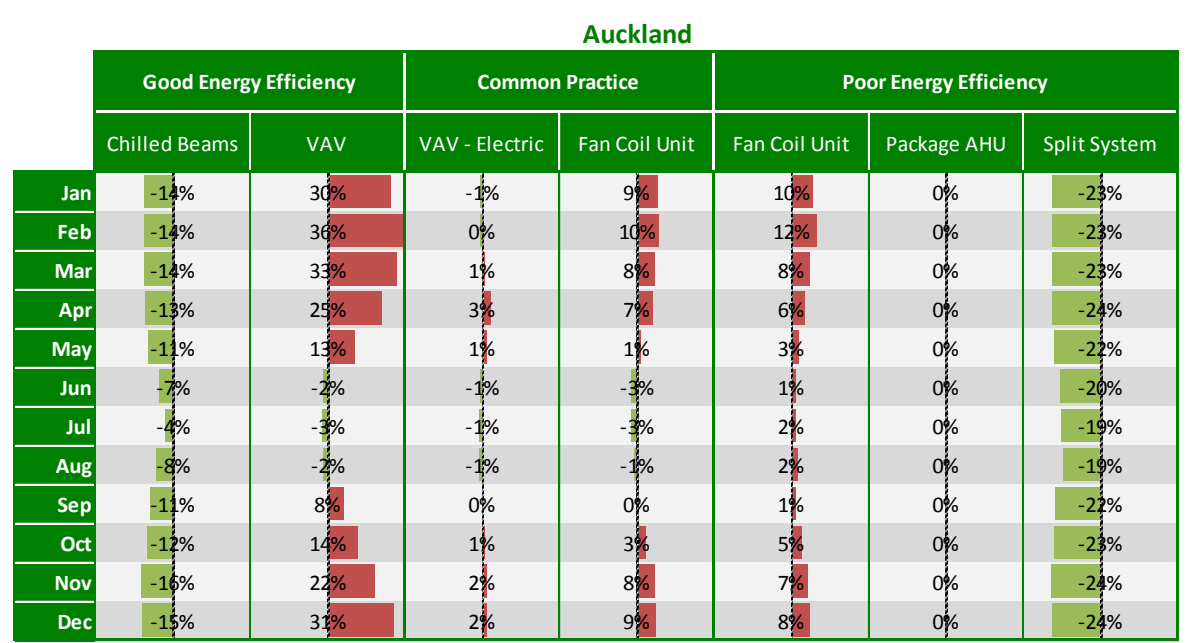

Wellington

\begin{tabular}{|c|c|c|c|c|c|c|}
\hline \multicolumn{2}{|c|}{ Good Energy Efficiency } & \multicolumn{2}{|c|}{ Common Practice } & \multicolumn{3}{|c|}{ Poor Energy Efficiency } \\
\hline & & & & & & \\
\hline Chilled Beams & vav & VAV - Electric & Fan Coil Unit & Fan Coil Unit & Package AHU & Split System \\
\hline$-16 \%$ & $29 \%$ & $0 \%$ & $8 \%$ & $8 \%$ & $0 \%$ & $-24 \%$ \\
\hline$-15 \%$ & $33 \%$ & $1 \%$ & $9 \%$ & $10 \%$ & $0 \%$ & $-24 \%$ \\
\hline$-14 \%$ & $27 \%$ & $1 \%$ & 5\% & 6\% & $0 \%$ & $-23 \%$ \\
\hline$-12 \%$ & $11 \%$ & $1 \%$ & $2 \%$ & 460 & $0 \%$ & $-28 \%$ \\
\hline$-7 \%$ & $-2 \%$ & $-1 \%$ & $-2 \%$ & $2 \%$ & $0 \%$ & $-19 \%$ \\
\hline$-1 \%$ & $-8 \%$ & $-3 \%$ & $-2 \%$ & 3\% & $\%$ & $-18 \%$ \\
\hline$-1 \%$ & $-8 \%$ & $-3 \%$ & $-3 \%$ & 3\% & $0 \%$ & $-18 \%$ \\
\hline$-2 \%$ & $-7 p_{0}$ & $-3 \%$ & $-3 \%$ & 3\% & $0 \%$ & $-18 \%$ \\
\hline$-6 \%$ & $-2 \%$ & $-2 \%$ & $-1 \%$ & $3 \%$ & $0 \%$ & $-17 \%$ \\
\hline$-10 \%$ & 5\% & $-1 \%$ & $1 \%$ & $4 \%$ & $0 \%$ & $-2 \%$ \\
\hline$-15 \%$ & $18 \%$ & $0 \%$ & 5\% & $7 \%$ & $0 \%$ & $-23 \%$ \\
\hline$-16 \%$ & & $1 \%$ & $8 \%$ & $8 \%$ & $\%$ & \\
\hline
\end{tabular}

\begin{tabular}{|c|c|c|c|c|c|c|c|}
\hline & \multicolumn{7}{|c|}{ Christchurch } \\
\hline & \multicolumn{2}{|c|}{ Good Energy Efficiency } & \multicolumn{2}{|c|}{ Common Practice } & \multicolumn{3}{|c|}{ Poor Energy Efficiency } \\
\hline & Chilled Beams & VAV & VAV-Electric & Fan Cool Unit & Fan Coil Unit & Package AHU & Split System \\
\hline & $-16 \%$ & $25 \%$ & $2 \%$ & $8 \%$ & $8 \%$ & $0 \%$ & $-23 \%$ \\
\hline & $-16 \%$ & $30 \%$ & $2 \%$ & $9 \%$ & $9 \%$ & $0 \%$ & $-28 \%$ \\
\hline$M=$ & $-14 \%$ & $30 \%$ & $3 \%$ & 5\% & 6\% & $0 \%$ & $-23 \%$ \\
\hline$A_{\mathrm{p}}$ & $-9 \%$ & $7 \%$ & $0 \%$ & $0 \%$ & 3\% & $0 \%$ & $-1 \% \%$ \\
\hline M & $-3 \%$ & $-4 \%$ & $-2 \%$ & $-2 \%$ & 3\% & $0 \%$ & $-14 \%$ \\
\hline Ju & $0 \%$ & $-8 \%$ & $-3 \%$ & $-3 \%$ & 3\% & $1 \%$ & $-12 \%$ \\
\hline & $0 \%$ & $-9 \%$ & $-3 \%$ & $-3 \%$ & $2 \%$ & $1 \%$ & $-10 \%$ \\
\hline & $-1 \%$ & $-6 \%$ & $-3 \%$ & $-3 \%$ & $2 \%$ & $0 \%$ & $-12 \%$ \\
\hline & $-4 \%$ & $-2 \%$ & $-2 \%$ & $-2 \%$ & $3 \%$ & $0 \%$ & $-14 \%$ \\
\hline 0 & $-11 \%$ & $9 \%$ & $0 \%$ & $\%$ & $4 \%$ & $0 \%$ & $-18 \%$ \\
\hline No & $-12 \%$ & $10 \%$ & $0 \%$ & $2 \%$ & 5\% & $0 \%$ & $-21 \%$ \\
\hline & & & & & & & \\
\hline
\end{tabular}

Table 23. Difference in energy consumption: CS built form - Auckland, Wellington, and Christchurch. 
J2: Row of Single Rooms

\begin{tabular}{|c|c|c|c|c|c|c|c|c|c|c|c|c|c|c|c|c|c|c|c|c|c|c|c|}
\hline & \multicolumn{7}{|c|}{ Auckland } & \multicolumn{8}{|c|}{ Wellington } & \multicolumn{8}{|c|}{ Christchurch } \\
\hline & \multicolumn{2}{|c|}{ Good Energy Efficiency } & \multicolumn{2}{|c|}{ Common Practice } & \multicolumn{3}{|c|}{ Poor Energy Efficiency } & \multicolumn{3}{|c|}{ Good Energy Efficiency } & \multicolumn{2}{|c|}{ Common Practice } & \multicolumn{3}{|c|}{ Poor Energy Efficiency } & \multicolumn{3}{|c|}{ Good Energy Efficiency } & \multicolumn{2}{|c|}{ Common Practice } & \multicolumn{3}{|c|}{ Poor Energy Efficiency } \\
\hline & Chilled Beams & vav & VAV-Electric & Fan Coil Unit & Fan Cool Unit & Package AHU & Split System & & Chilled Beams & vav & VAV-Electric $\mid$ & Fan Coil Unit & Fan Coil Unit & Package AHU & Split System & & Chilled Beams & vav & VAV-Electric $\mid$ & Fan Coil Unit & Fan Coil Unit & Package AHU & Split System \\
\hline $\operatorname{Jan}$ & $-15 \%$ & $13 \%$ & $1 \%$ & $9 \%$ & $9 \%$ & $0 \%$ & $-23 \%$ & $\operatorname{Jan}$ & $-13 \%$ & $10 \%$ & $0 \%$ & $5 \%$ & $5 \%$ & $0 \%$ & $-23 \%$ & Jan & $-13 \%$ & $-5 \%$ & $0 \%$ & $5 \%$ & $6 \%$ & $0 \%$ & $-22 \%$ \\
\hline$\overline{\mathrm{Feb}}$ & $-15 \%$ & $17 \%$ & $1 \%$ & $10 \%$ & $10 \%$ & $0 \%$ & $-23 \%$ & Feb & $-13 \%$ & $8 \%$ & $0 \%$ & $5 \%$ & $7 \%$ & $0 \%$ & $-23 \%$ & Feb & $-13 \%$ & $-1 \%$ & $1 \%$ & 4\% & 5\% & $0 \%$ & $-22 \%$ \\
\hline Mar & $-13 \%$ & $14 \%$ & $2 \%$ & $7 \%$ & $7 \%$ & $0 \%$ & $-23 \%$ & Mar & $-9 \%$ & $2 \%$ & $\%$ & $1 \%$ & 3i & $0 \%$ & $-22 \%$ & Mar & $-9 \%$ & $-6 \%$ & $1 \%$ & $0 \%$ & 24 & $0 \%$ & $-21 \%$ \\
\hline Apr & $-9 \%$ & $6 \%$ & $2 \%$ & $2 \%$ & $1 \%$ & $\%$ & $-2 \%$ & Apr & $-5 \%$ & $-4 \%$ & $\%$ & $-1 \%$ & $2 \sqrt{6}$ & $1 \%$ & $-20 \%$ & Apr & $-4 \%$ & $-12 \%$ & $0 \%$ & $-3 \%$ & $1 \%$ & $1 \%$ & $-15 \%$ \\
\hline May & $-4 \%$ & $-4 \%$ & $\%$ & $-3 \%$ & $-1 \%$ & $1 \%$ & $-20 \%$ & May & $-1 \%$ & $-8 \%$ & $-2 \%$ & $-3 \%$ & $2 \%$ & $1 \%$ & $-18 \%$ & May & $0 \%$ & $-14 \%$ & $-2 \%$ & $-3 \%$ & $2 \%$ & $1 \%$ & $-13 \%$ \\
\hline Jun & $0 \%$ & $-8 \%$ & $-1 \%$ & $-4 \%$ & $1 \%$ & $1 \%$ & $-19 \%$ & Jun & $0 \%$ & $-10 \%$ & $-3 \%$ & $-3 \%$ & $2 \%$ & $1 \%$ & $-19 \%$ & Jun & $0 \%$ & $-14 \%$ & $-2 \%$ & $-3 \%$ & $2 \%$ & $1 \%$ & $-12 \%$ \\
\hline Jul & $0 \%$ & $-8 \%$ & $-1 \%$ & $-4 \%$ & $1 \%$ & $1 \%$ & $-18 \%$ & Jul & $0 \%$ & $-10 \%$ & $-3 \%$ & $-4 \%$ & 2 & $1 \%$ & $-20 \%$ & Jul & $0 \%$ & $-13 \%$ & $-2 \%$ & $-4 \%$ & 2 & $1 \%$ & $-11 \%$ \\
\hline Aug & $-2 \%$ & $-8 \%$ & $-1 \%$ & $-4 \%$ & $\%$ & $1 \%$ & $-18 \%$ & Aug & $\%$ & $-10 \%$ & $-2 \%$ & $-3 \%$ & $2 \%$ & $1 \%$ & $-20 \%$ & Aug & $0 \%$ & $-14 \%$ & $-2 \%$ & $-4 \%$ & $2 \%$ & $1 \%$ & $-12 \%$ \\
\hline Sep & $-3 \%$ & $-5 \%$ & $-1 \%$ & $-4 \%$ & $0 \%$ & $1 \%$ & $-19 \%$ & Sep & $-2 \%$ & $-9 \%$ & $-2 \%$ & $-4 \%$ & $1 \%$ & $1 \%$ & $-19 \%$ & Sep & $-1 \%$ & $-19 \%$ & $-1 \%$ & $-3 \%$ & $1 \%$ & $1 \%$ & $-19 \%$ \\
\hline$\overline{\text { Oct }}$ & $-6 \%$ & $-2 \%$ & $-1 \%$ & $1 \%$ & $2 \%$ & $1 \%$ & $-21 \%$ & Oct & $-5 \%$ & $-6 \%$ & $-2 \%$ & $-3 \%$ & $1 \%$ & $1 \%$ & $-20 \%$ & Oct & $-5 \%$ & $-11 \%$ & $-1 \%$ & $-3 \%$ & $0 \%$ & $1 \%$ & $-17 \%$ \\
\hline Nov & $-10 \%$ & $3 \%$ & $-1 \%$ & 3\% & $3 \%$ & $0 \%$ & $-22 \%$ & Nov & $-8 \%$ & $-2 \%$ & $-1 \%$ & $0 \%$ & 3\% & $0 \%$ & $-20 \%$ & Nov & $-7 \%$ & $-9 \%$ & $-1 \%$ & $.1 \%$ & $2 \%$ & $0 \%$ & $-20 \%$ \\
\hline$\overline{\mathrm{Dec}}$ & $-13 \%$ & $12 \%$ & $0 \%$ & $7 \%$ & $8 \%$ & $0 \%$ & $-28 \%$ & $\overline{\text { Dec }}$ & $-12 \%$ & $5 \%$ & $-1 \%$ & $6 \%$ & $6 \%$ & $0 \%$ & $-23 \%$ & Dec & $-13 \%$ & $-2 \%$ & $1 \%$ & $5 \%$ & $5 \%$ & $0 \%$ & $-22 \%$ \\
\hline
\end{tabular}

Table 24. Difference in energy consumption: RSR built form - Auckland, Wellington, and Christchurch.

J3: Single Room

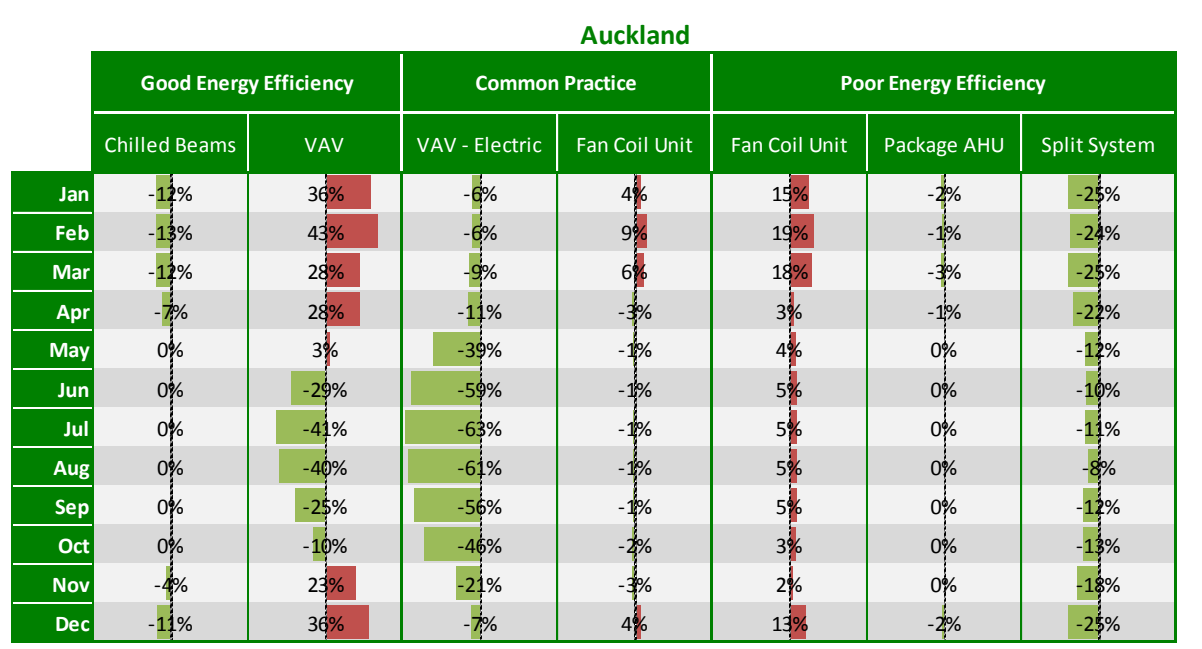

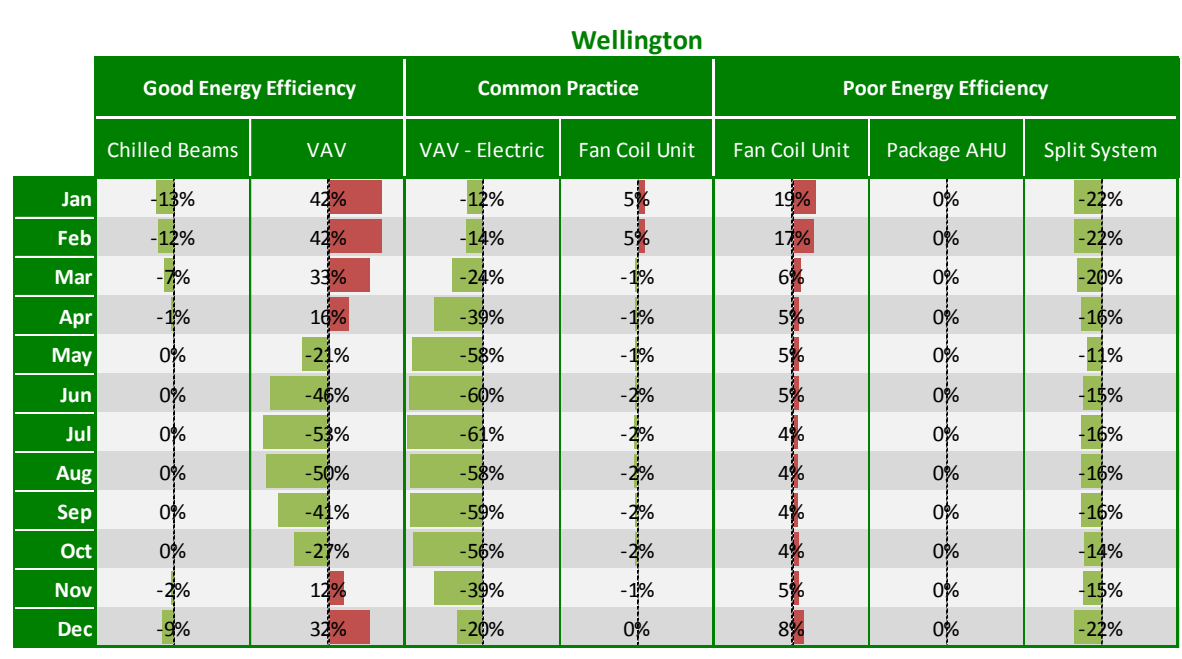

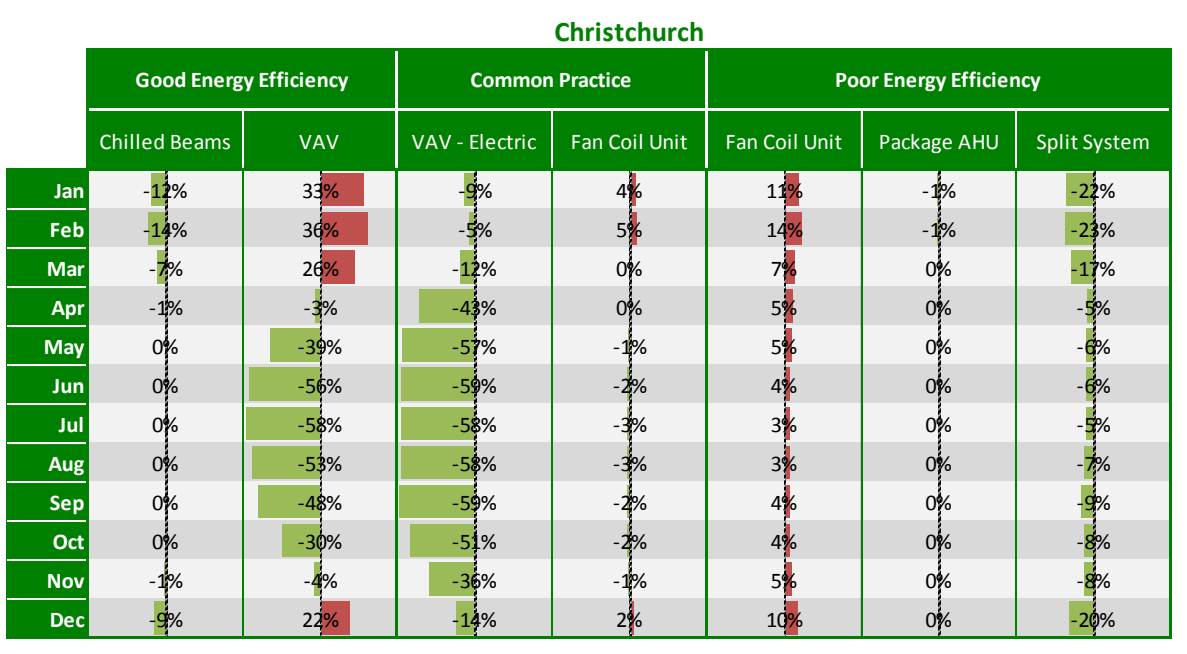

Table 25. Difference in energy consumption: SR built form - Auckland, Wellington, and Christchurch. 
J4: Small Open Plan
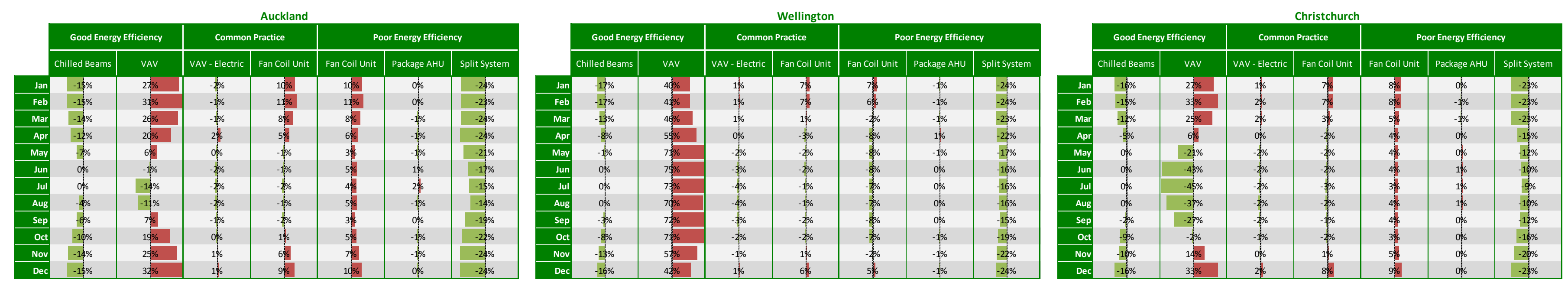

Table 26. Difference in energy consumption: OP1 built form - Auckland, Wellington, and Christchurch.

J5: Large Open Plan

\begin{tabular}{|c|c|c|c|c|c|c|c|c|c|c|c|c|c|c|c|}
\hline & \multicolumn{7}{|c|}{ Auckland } & & \multicolumn{7}{|c|}{ Wellington } \\
\hline & \multicolumn{2}{|c|}{ Good Energy Efficiency } & \multicolumn{2}{|c|}{ Common Practice } & \multicolumn{3}{|c|}{ Poor Energy Efficiency } & & \multicolumn{2}{|c|}{ Good Energy Efficiency } & \multicolumn{2}{|c|}{ Common Practice } & \multicolumn{3}{|c|}{ Poor Energy Efficiency } \\
\hline & hilled Beams & vav & VAV-Electric & Fan Coil Unit & Fan Coil Unit & Package AHU & Split System & & hilled Beams & VAV & VAV- Electric & Fan Coil Unit & Fan Coil Unit & Package AHU & Split System \\
\hline & $-14 \%$ & $26 \%$ & $-2 \%$ & $9 \%$ & 8) & $0 \%$ & $-23 \%$ & Jan & $-15 \%$ & $34 \%$ & $-4 \%$ & 8. & $8 \%$ & $0 \%$ & $-23 \%$ \\
\hline $\mathrm{Feb}$ & $-14 \%$ & $33 \%$ & $-1 \%$ & $10 \%$ & $10 \%$ & $0 \%$ & $-23 \%$ & $\mathrm{Feb}$ & $-13 \%$ & $28 \%$ & $-8 \%$ & 7 & $8 \%$ & $0 \%$ & $-23 \%$ \\
\hline Mar & -19\% & $\begin{array}{l}2010 \\
270\end{array}$ & $1 \%$ & $10 \%$ & 7 & $0 \%$ & $23 \%$ & Mar & $-9 \%$ & $3 \%$ & $\begin{array}{ll}-20 \% \\
-26 \%\end{array}$ & 40 & 5\% & $0 \%$ & $-21 \%$ \\
\hline Apr & $-10 \%$ & $24 \%$ & $-6 \%$ & 70 & $5 \%$ & $0 \%$ & $-23 \%$ & Apr & $-6 \%$ & $-20 \%$ & $-40 \%$ & $1 \%$ & $4 \%$ & $0 \%$ & $-19 \%$ \\
\hline May & $-7 \%$ & $-3 \%$ & $-26 \%$ & $0 \%$ & $2 \%$ & $1 \%$ & $-20 \%$ & May & $-3 \%$ & $-38 \%$ & $-49 \%$ & $-2 \%$ & $2 \%$ & $1 \%$ & $-16 \%$ \\
\hline Jun & $-3 \%$ & $-25 \%$ & $-41 \%$ & $-3 \%$ & $2 \%$ & $0 \%$ & $-19 \%$ & Jun & $0 \%$ & $-51 \%$ & $-55 \%$ & $-3 \%$ & $3 \%$ & $1 \%$ & $-18 \%$ \\
\hline Jul & $-1 \%$ & $-34 \%$ & $-4 \%$ & $-3 \%$ & $2 \%$ & $1 \%$ & $-19 \%$ & Jul & $0 \%$ & $-54 \%$ & $-5 \%$ & $4 \%$ & $2 \%$ & $1 \%$ & $-18 \%$ \\
\hline Aug & $-4 \%$ & $-30 \%$ & $-43 \%$ & $-2 \%$ & 3\% & $1 \%$ & $-19 \%$ & Aug & $-1 \%$ & $-50 \%$ & $-54 \%$ & $-3 \%$ & $2 \%$ & $1 \%$ & $-19 \%$ \\
\hline Sep & $-5 \%$ & $-11 \%$ & $-34 \%$ & $1 \%$ & $3 \%$ & $0 \%$ & $-21 \%$ & Sep & $-2 \%$ & $-41 \%$ & $-51 \%$ & $-3 \%$ & $2 \%$ & $1 \%$ & $-16 \%$ \\
\hline oct & $-8 \%$ & $0 \%$ & $-20 \%$ & $2 \%$ & $2 \%$ & $0 \%$ & $-22 \%$ & $\overrightarrow{\text { oct }}$ & $-7 \%$ & $-26 \%$ & $-44 \%$ & $-1 \%$ & $3 \%$ & $1 \%$ & $-18 \%$ \\
\hline Nov & $-14 \%$ & $33 \%$ & $-9 \%$ & 7 & $5 \%$ & $0 \%$ & $-23 \%$ & Nov & $-12 \%$ & $-4 \%$ & $-32 \%$ & $3 \%$ & $5 \%$ & $\%$ & $-20 \%$ \\
\hline Dec & $-14 \%$ & $45 \%$ & $1 \%$ & $9 \%$ & $8 \%$ & $0 \%$ & $-23 \%$ & Dec & $-14 \%$ & $31 \%$ & $-15 \%$ & 8\% & $7 \%$ & $0 \%$ & $-23 \%$ \\
\hline
\end{tabular}

\begin{tabular}{|c|c|c|c|c|c|c|c|}
\hline & \multicolumn{7}{|c|}{ Christchurch } \\
\hline & \multicolumn{2}{|c|}{ Good Energy Efficiency } & \multicolumn{2}{|c|}{ Common Practice } & \multicolumn{3}{|c|}{ Poor Energy Efficiency } \\
\hline & Chilled Beams & VAV & VAV-Electric & Fan Coil Unit & Fan Coil Unit & Package AHU & Split System \\
\hline & $-14 \%$ & $32 \%$ & $-7 \%$ & 5] & $6 \%$ & $0 \%$ & $-23 \%$ \\
\hline & $-14 \%$ & $38 \%$ & $-5 \%$ & $6 \%$ & $8 \%$ & $0 \%$ & $-22 \%$ \\
\hline Ma & $9 \%$ & $20 \%$ & $-13 \%$ & $2 \%$ & $4 \%$ & $0 \%$ & $-22 \%$ \\
\hline A & $-4 \%$ & $-14 \%$ & $-38 \%$ & $-1 \%$ & $3 \%$ & $1 \%$ & $-15 \%$ \\
\hline & $-1 \%$ & $-37 \%$ & $-45 \%$ & $-3 \%$ & $2 \%$ & $1 \%$ & $-14 \%$ \\
\hline & $\%$ & $-52 \%$ & $-5 \% \%$ & $-4 \%$ & $2 \%$ & $1 \%$ & $-14 \%$ \\
\hline & $0 \%$ & $-53 \%$ & $-55 \%$ & $-4 \%$ & $2 \%$ & $1 \%$ & $-12 \%$ \\
\hline & $-1 \%$ & $-4 \%$ & $-49 \%$ & $-4 \%$ & $2 \%$ & $1 \%$ & $-19 \%$ \\
\hline & $-1 \%$ & $-3 \%$ & $-46 \%$ & $-3 \%$ & $2 \%$ & $1 \%$ & $-15 \%$ \\
\hline & $-7 \%$ & $-15 \%$ & $-3 \%$ & $-2 \%$ & $3 \%$ & $1 \%$ & $-16 \%$ \\
\hline & $-7 \%$ & $4 \%$ & $-27 \%$ & $0 \%$ & $4 \%$ & $1 \%$ & $-19 \%$ \\
\hline & & & & & & 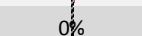 & \\
\hline
\end{tabular}

Table 27. Difference in energy consumption: OP5 built form - Auckland, Wellington, and Christchurch. 


\section{Appendix K - HVAC template models}

The contents of this disc contain:

HVAC template models;

$\checkmark$ BEES geometry template models;

$\checkmark$ and a copy of this thesis.

EnergyPlus is required to use and run calculations with the template models. Note that the program version 6.0 has been used to create the files and will have compatibility issues with the earlier and later versions. In addition to this, when making changes to the geometry of the models, it is recommended to use the OpenStudio Legacy version plug-in for SketchUp.

The software is available from:

- EnergyPlus: http://apps1.eere.energy.gov/buildings/energyplus/

- OpenStudio: http://openstudio.nrel.gov/

- SketchUp: http://sketchup.google.com/ 